\title{
Analyzing the Impact of Residential Building Attributes, Demographic and Behavioral Factors on Natural Gas Usage
}

OV Livingston

KA Cort

March 2011

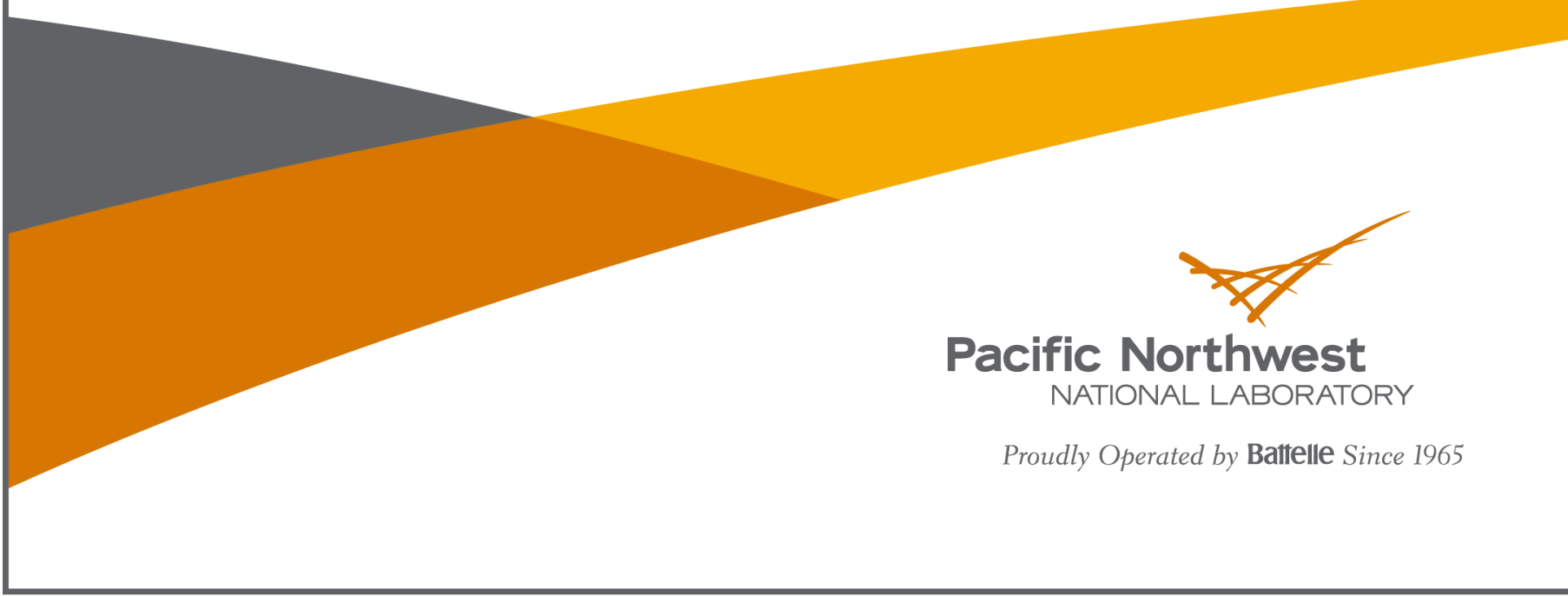




\title{
DISCLAIMER
}

This report was prepared as an account of work sponsored by an agency of the United States Government. Neither the United States Government nor any agency thereof, nor Battelle Memorial Institute, nor any of their employees, makes any warranty, express or implied, or assumes any legal liability or responsibility for the accuracy, completeness, or usefulness of any information, apparatus, product, or process disclosed, or represents that its use would not inf ringe privately owned rights. Reference herein to any specific commercial product, process, or service by trade name, trademark, manufacturer, or otherwise does not necessarily constitute or imply its endorsement, recommendation, or favoring by the United States Government or any agency thereof, or Battelle Memorial Institute. The views and opinions of authors expressed herein do not necessarily state or reflect those of the United States Government or any agency thereof.

\author{
PACIFIC NORTHWEST NATIONAL LABORATORY \\ operated by \\ BATTELLE \\ for the \\ UNITED STATES DEPARTMENT OF ENERGY \\ under Contract DE-AC05-76RL01830
}

Printed in the United States of America
Available to DOE and DOE contractors from the
Office of Scientific and Technical Information
P.O. Box 62, Oak Ridge, TN 37831-0062;
ph: (865) 576-8401
fax: $(865) 576-5728$
email: reports@adonis.osti.gov

Available to the public from the National Technical Information Service

5301 Shawnee Rd., Alexandria, VA 22312

ph: (800) 553-NTIS (6847)

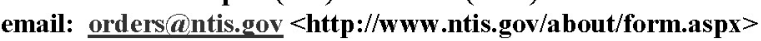

Online ordering: http://www.ntis.gov

This document was printed on recycled paper. 


\section{Analyzing the Impact of Residential Building Attributes, Demographic and Behavioral Factors on Natural Gas Usage}

OV Livingston

KA Cort

March 2011

Prepared for

the U.S. Department of Energy

under Contract DE-AC05-76RL01830

Pacific Northwest National Laboratory

Richland, Washington 99352 



\section{Summary}

This analysis examines the relationship between energy demand and residential building attributes, demographic characteristics, and behavioral variables using the U.S. Department of Energy's Residential Energy Consumption Survey 2005 microdata. This study investigates the applicability of the smooth backfitting estimator to statistical analysis of residential energy consumption via nonparametric regression. The methodology utilized in the study extends nonparametric additive regression via local linear smooth backfitting to categorical variables.

The conventional methods used for analyzing residential energy consumption are econometric modeling and engineering simulations. This study suggests an econometric approach that can be utilized in combination with simulation results. A common weakness of previously used econometric models is a very high likelihood that any suggested parametric relationships will be misspecified. Nonparametric modeling does not have this drawback. Its flexibility allows for uncovering more complex relationships between energy use and the explanatory variables than can possibly be achieved by parametric models.

Traditionally, building simulation models overestimated the effects of energy efficiency measures when compared to actual "as-built" observed savings. While focusing on technical efficiency, they do not account for behavioral or market effects. The magnitude of behavioral or market effects may have a substantial influence on the final energy savings resulting from implementation of various energy conservation measures and programs. Moreover, variability in behavioral aspects and user characteristics appears to have a significant impact on total energy consumption. Inaccurate estimates of energy consumption and potential savings also impact investment decisions. The existing modeling literature, whether it relies on parametric specifications or engineering simulation, does not accommodate inclusion of a behavioral component. This study attempts to bridge that gap by analyzing behavioral data and investigate the applicability of additive nonparametric regression to this task.

This study evaluates the impact of 31 regressors on residential natural gas usage. The regressors include weather, economic variables, demographic and behavioral characteristics, and building attributes related to energy use. In general, most of the regression results were in line with previous engineering and economic studies in this area. There were, however, some counterintuitive results, particularly with regard to thermostat controls and behaviors. There are a number of possible reasons for these counterintuitive results including the inability to control for regional climate variability due to the data sanitization (to prevent identification of respondents), inaccurate data caused by to self-reporting, and the fact that not all relevant behavioral variables were included in the data set, so we were not able to control for them in the study.

The results of this analysis could be used as an in-sample prediction for approximating energy demand of a residential building whose characteristics are described by the regressors in this analysis, but a certain combination of their particular values does not exist in the real world. In addition, this study has potential applications for benefit-cost analysis of residential upgrades and retrofits under a fixed budget, because the results of this study contain information on how natural gas consumption might change once a particular characteristic or attribute is altered. Finally, the results of this study can help establish a relationship between natural gas consumption and changes in behavior of occupants. 



\section{Acronyms and Abbreviations}

$\begin{array}{ll}\text { DOE } & \text { U.S. Department of Energy } \\ \text { HDD } & \text { Heating Degree Days } \\ \text { CDD } & \text { Cooling Degree Days } \\ \text { EIA } & \text { Energy Information Administration } \\ \text { MBtu } & \text { million British thermal units } \\ \text { NG } & \text { natural gas } \\ \text { ORC } & \text { Opinion Research Corporation } \\ \text { R\&D } & \text { research and development } \\ \text { RECS } & \text { residential energy consumption survey } \\ \text { SBE } & \text { smooth backfitting estimation }\end{array}$





\section{Contents}

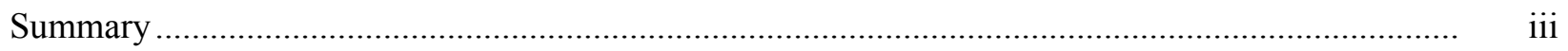

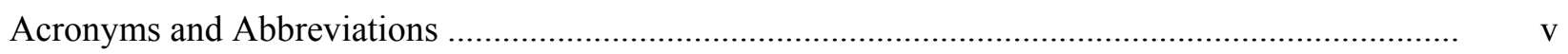

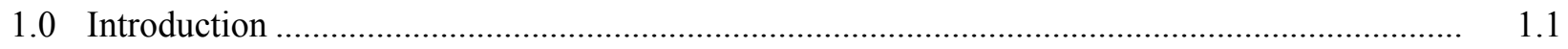

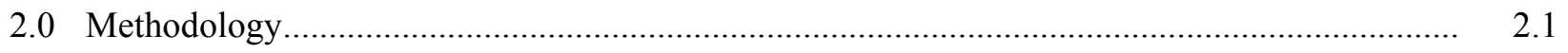

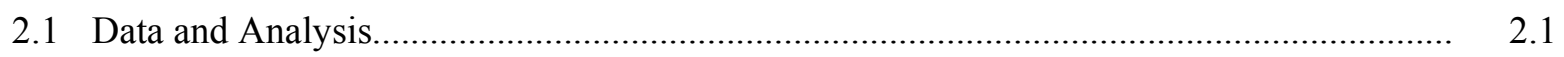

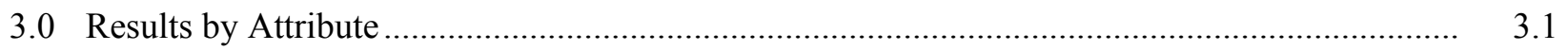

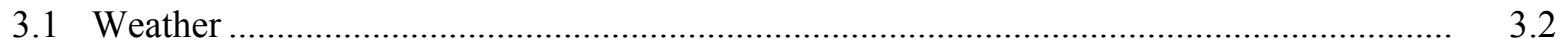

3.2 Fuel and Equipment/Appliance Choice ................................................................. 3.2

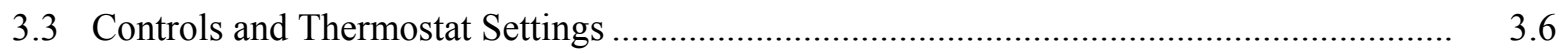

3.4 Prices and Billing Structure...................................................................................... 3.9

3.5 Home Construction Attributes ............................................................................ 3.10

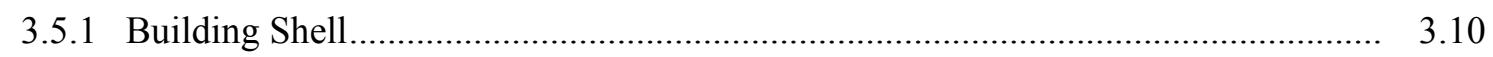

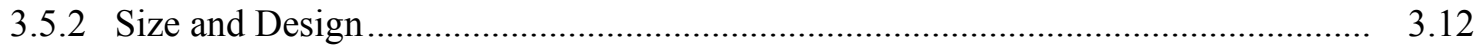

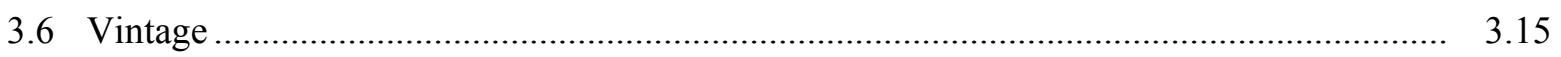

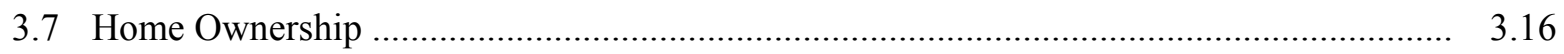

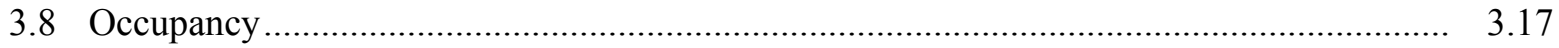

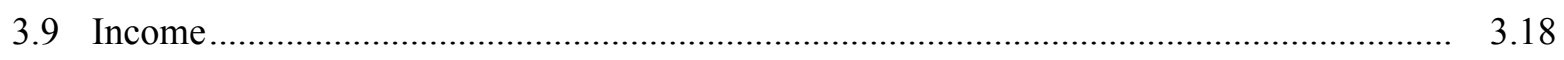

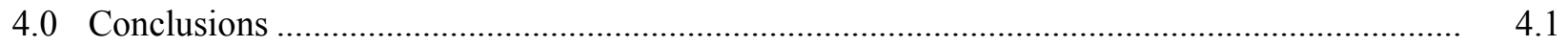

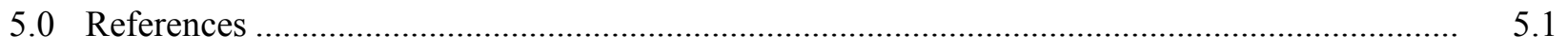

Appendix A - Detailed Methodology ....................................................................................... A.

Appendix B - Complete Set of Graphical Results................................................................. B. 1 


\section{Figures}

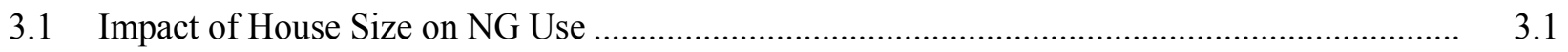

3.2 Impact of Heating Degree Days on NG Use ..................................................................... 3.2

3.3 Impact of Main Heating Fuel Choice on NG Use .............................................................. 3.3

3.4 Impact of Heating Equipment Choice on NG Use .............................................................. 3.4

3.5 Secondary Heating Equipment Impact on NG ................................................................ 3.5

3.6 Setting During the Winter Day When Someone is Home...................................................... 3.6

3.7 Setting During the Winter Day When No One is Home ..................................................... 3.7

3.8 Impact of Thermostat and Programmable Thermostat on NG Use ......................................... 3.8

3.9 Impact of Number of Thermostats on NG Use .................................................................

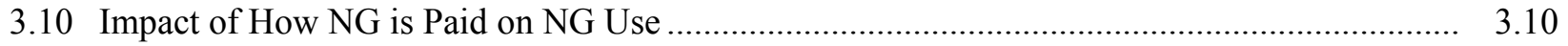

3.11 Secondary Heating Equipment Impact on NG ................................................................ 3.11

3.12 Impact of Type of Window Glass on NG Use ................................................................ 3.12

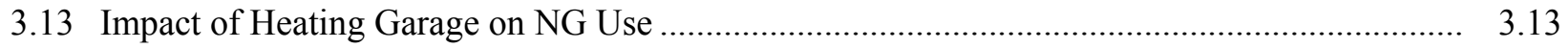

3.14 Impact of Basement/crawl space on NG Use .................................................................. 3.14

3.15 Impact of Number of Rooms Not Heated on NG Use ...................................................... 3.15

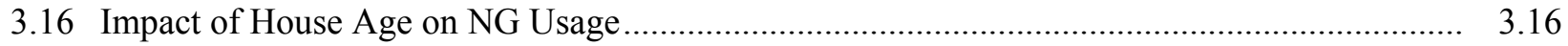

3.17 Impact of Ownership/Rental Status on NG Use.............................................................. 3.17

3.18 Impact of Number of Occupants on NG Use ................................................................... 3.18

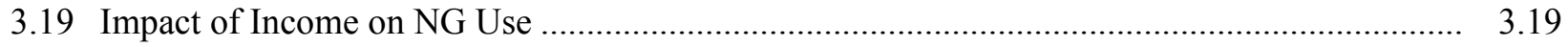

\section{Tables}

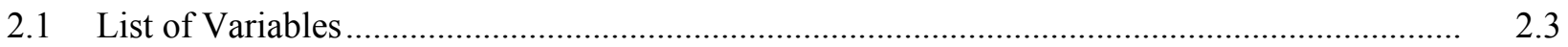




\subsection{Introduction}

There are three main approaches to residential energy demand analysis: engineering, sociopsychological and econometric. The engineering approach relies on simulating different types of building energy use within an engineering modeling framework such as Energy Plus, DOE-2 and the like (Crawley et al. 2004). These building energy simulation tools construct demand projections by performing hourly energy simulations of buildings, air-handling systems, and equipment based on building and weather characteristics and an assumed operation schedule. The second approach evaluates the impact of institutions, beliefs and group influences on the long-term trends in energy use. The econometric approach links energy use to prices of energy products and their substitutes, as well as household income, demographic characteristics and features of the occupied buildings. This study fits into the third category, exploring the behavioral data on energy consumption at the micro level.

Detailed studies of energy use at the household level using microeconomic data were conducted by Baker et al. (1989), Schmalensee and Stoker (1999), Halvorsen and Larsen (2001), Yatchew and No (2001), Nesbakken (2001), Larsen and Nesbakken (2004), Garcia-Cerruti (2000), Holtedahl and Joutz (2004), Kamerschen and Porter (2004) and Narayan and Smyth (2005) to name a few. The reviewed econometric studies all estimate energy demand functions; however, the explanatory variables employed by these studies differ. These studies can generally be categorized into two groups. The first group includes economic variables such as fuel prices and income level, as well as climate information. The second group of studies incorporates additional household and demographic characteristics of the dwelling into the model. An extensive overview of econometric analysis of residential energy demand predating the above-listed research is included in Madlener (1996).

The focus of this analysis is residential natural gas (NG) demand. Space heating is the single largest end use of energy in residential buildings, and furnaces fueled by natural gas are the primary source of residential heating. Natural gas also provides fuel for residential water heating, cooking, clothes drying, and other miscellaneous uses. In terms of on-site energy use measured in British thermal units (Btu), in 2006 the Energy Information Administration (EIA) estimated that natural gas supplied approximately $65 \%$ of 4.4 quadrillion Btu delivered for residential space heating, and approximately $68 \%$ of total residential site energy for water heating (DOE/EIA 2009). The primary substitute for natural gas in residential homes is electricity (i.e., electric furnaces, heat pumps, electric water heaters, etc.).

The majority of econometric research on electricity and natural gas consumption relies on a fully specified parametric functional relationship between energy use and its conditioning variables. As a result, there is the potential for severe misspecification of the proposed econometric models. Also, the categorical variables, which are typically present in residential microdata, are usually treated either by including dummy variables or via sub-sample regression. Nonparametric modeling is robust to functional form misspecification. Its flexibility allows for uncovering more complex relationships between energy use and conditioning variables than can be possibly achieved by parametric models.

In this study we adopt additive nonparametric modeling for energy consumption, which would be estimated using the smooth backfitting procedure of Mammen et al. (1999). This procedure achieves convergence rates equal to this of univariate models thus bypassing the curse of dimensionality. In addition, recognizing that both continuous and categorical variables impact energy demand, this 
application of backfitting procedure incorporates the kernel smoothing methods of Racine and Li (2003) and Racine et al. (2004) for categorical variables.

The data for this research comes from the Residential Energy Consumption Survey (RECS) designed by the U.S. Department of Energy's Energy Information Administration. The microdata obtained from the 2005 survey covers energy consumption for several major fuel types and includes information on household characteristics, standard demographics, dwelling characteristics, as well as information about televisions and other media devices, personal computers and peripherals, Energy Star labeling, energy efficient lighting, window glazing, window replacement, and thermostat usage. The 2005 survey also incorporates questions on behavioral aspects of energy use. This analysis contributes to existing literature by analyzing and quantifying behavioral impacts on residential energy consumption.

The study is organized into three sections. A brief description of the smooth backfitting approach is presented in Section 2. Section 3 describes the results of the empirical analysis. Section 4 provides the conclusions of this analysis. The local linear smooth backfitting estimator (SBE) for continuous and mixed variables is described in more detail in Appendix A. Appendix B contains a complete set of result charts. 


\subsection{Methodology}

This study investigates the applicability of the smooth backfitting estimator to statistical analysis of residential energy consumption via nonparametric regression. The nonparametric modeling does not require an analyst to assume any particular functional relationship between the energy consumption and analyzed variables. This is one of the advantages that nonparametric approach has over traditionally used parametric models. The quality of any parametric results directly depends on how close the assumed functional form is to the true relationship. Household energy usage depends on a complicated set of variables whose impact is not fully understood or separated.

The model used here is a special case of a very broad class of generalized additive models, which are gaining significant attention in the current econometric literature. The utilized methodology extends nonparametric additive regression via local linear SBE to categorical variables, which are, in this case, attributes of the residential building and demographic characteristics of its occupants.

The smooth backfitting estimator is a projection of the data on the space of additive functions. Projection here is taken with respect to the norm defined by the local polynomial kernel estimator. This particular definition of the estimator allows separating effects (i.e., the effect of natural gas prices versus the effect of exterior wall construction, etc.) within complicated multidimensional problems into onedimensional effects. Also the number of controlled variables that can be meaningfully utilized in the parametric modeling is usually limited. SBE method is capable of successfully accommodating a large number of explanatory variables. Nielsen and Spierlich (2005) demonstrated that the SBE method produces better results in "extreme cases of complexity and data sparseness" by comparing performance in finite samples on a model with 100 correlated variables. The SBE methodology of Mammen et al. (1999) and computational algorithm outlined by Nielsen and Spierlich (2005) are described in detail in Appendix A of this report.

\subsection{Data and Analysis}

The data for this research comes from the RECS survey designed by DOE-EIA. The microdata obtained from the 2005 survey covers energy consumption for several major fuel types and includes information on household characteristics, standard demographics, dwelling characteristics, as well as information about televisions and other media devices, personal computers and peripherals, Energy Star labeling, energy efficient lighting, window glazing, window replacement, and thermostat usage. The 2005 survey also incorporates questions on behavioral aspects of energy use. This analysis contributes to existing literature by analyzing and quantifying impacts of demographic and behavioral variables on residential NG consumption.

Upon close examination of the RECS questions and microdata for 2005, it became apparent that it would be an extremely complex task to cover all the end fuel uses for all fuel types included in the survey. The decision was made to investigate the applicability of smooth backfitting by isolating natural gas usage and related variables. RECS data was filtered out to include only households using natural gas, resulting in a subset of 1388 observations. For 1053 of these observations natural gas consumption data came directly from the provider company records. The regressand is natural gas usage in millions of 
British thermal units (MBtu). There are 31 regressors, ${ }^{1}$ which include demographic and behavioral characteristics, as well as building attributes related to energy consumption. The regressors enter the model additively in the following way:

$$
E\left(Y \mid X_{1}=x_{1}, \ldots, X_{d}=x_{d}\right)=m_{0}+\sum_{j=1}^{d} m_{j}\left(x_{j}\right)
$$

where $\mathrm{E}\left(\mathrm{Y} \mid \mathrm{X}_{1}=\mathrm{x}_{1}, \ldots, \mathrm{X}_{\mathrm{d}}=\mathrm{x}_{\mathrm{d}}\right)=$ conditional mean of natural gas energy consumption

$\mathrm{x}_{\mathrm{j}}=$ regional/residential home attributes, behavioral and demographic characteristics,

$\mathrm{m}_{0}=$ unknown scalar parameter, $\mathrm{m}_{\mathrm{j}}\left(\mathrm{x}_{\mathrm{j}}\right)=$ unknown function of $\mathrm{x}_{\mathrm{j}}$ for all $\mathrm{j}=1, \ldots \mathrm{d}$,

Out of the 31 regressors, 8 are continuous variables, 14 are unordered categorical variables, and the remaining 9 are ordered categorical variables. These are described in Table 2.1.

Individual cross-validated bandwidth values were computed for each regressor. Although unordered categorical regressors have the potential to violate the mean-zero assumption for each direction to meet the identification conditions as part of the smooth backfitting algorithm, the results of these regressions are reasonable. The results of the ordered categorical regressions suggest that at least some of them could have been treated as continuous variables. Several directional regressions show rather smooth change, which may be suggestive of the particular type of a parametric relationship. Specific results are discussed in Section 3 of this report.

\footnotetext{
${ }^{1}$ Initially the model was to include 44 categorical variables, but cross-validation produced the bandwidth values equal to the upper bound of $\left(c_{t}-1\right) / c_{t}$ for 13 of the categorical variables. When the bandwidth takes this upper value, it implies that the regressor is irrelevant and, if included, it will effectively be smoothed out.
} 
Table 2.1. List of Variables

\begin{tabular}{|c|c|c|}
\hline Regressor & Description & \multirow{2}{*}{$\begin{array}{l}\text { Regressor Code } \\
\text { (Chart Label) }\end{array}$} \\
\hline Continuous & Unit of Measurement & \\
\hline Heating degree days & Degrees Fahrenheit (sanitized) & Direction 1 \\
\hline Cooling degree days & Degrees Fahrenheit (sanitized) & Direction 2 \\
\hline Total house area & Square feet & Direction 3 \\
\hline Price of electricity & Cents/kWh & Direction 4 \\
\hline Price of natural gas & Cents/kBtu & Direction 5 \\
\hline Thermostat setting: Occupied & Degrees Fahrenheit & Direction 6 \\
\hline Thermostat setting: Unoccupied & Degrees Fahrenheit & Direction 7 \\
\hline Thermostat setting: Sleeping & Degrees Fahrenheit & Direction 8 \\
\hline Exterior wall construction & $\begin{array}{l}\text { Indescribable, brick, wood, siding, stucco, composition, } \\
\text { stone, concrete, glass, other }\end{array}$ & Direction 9 \\
\hline Garage & No garage, garage not heated, yes garage heated & Direction 10 \\
\hline Ownership status & Owned, rented, occupied without payment & Direction 11 \\
\hline Cooking fuel & Natural gas, propane, electricity, some other fuel & Direction 12 \\
\hline Clothes dryer fuel & Natural gas, propane, electricity, no dryer & Direction 13 \\
\hline Secondary heating equipment & $\begin{array}{l}\text { No secondary heating, furnace, radiant (water), built-in } \\
\text { floor, built-in room heater, cooking stove }\end{array}$ & Direction 14 \\
\hline Programmable Thermostat & Not programmable, yes programmable, no thermostat & Direction 15 \\
\hline $\begin{array}{l}\text { Programmable Thermostat set-back: } \\
\text { night }\end{array}$ & $\begin{array}{l}\text { Not set-back at night, yes set-back at night, no thermostat } \\
\text { or not programmable }\end{array}$ & Direction 16 \\
\hline $\begin{array}{l}\text { Programmable Thermostat set-back: } \\
\text { day }\end{array}$ & $\begin{array}{l}\text { Not set-back during day, yes set-back during day, no } \\
\text { thermostat or not programmable }\end{array}$ & Direction 17 \\
\hline Main heating fuel & $\begin{array}{l}\text { Propane, natural gas, fuel oil, kerosene, electricity, wood, } \\
\text { solar }\end{array}$ & Direction 18 \\
\hline Heating equipment & $\begin{array}{l}\text { No heating equipment, radiant (water), heat pump, } \\
\text { central furnace, built-in electric wall, built-in floor, built- } \\
\text { in room heater (gas, oil, kerosene), wood stove, fireplace, } \\
\text { portable electric heaters, portable kerosene heaters, } \\
\text { cooking stove }\end{array}$ & Direction 19 \\
\hline Water heating fuel & Yes natural gas, do not use natural gas & Direction 20 \\
\hline Billing & $\begin{array}{l}\text { Household pays all, included in rent, some paid and } \\
\text { some included in rent, other }\end{array}$ & Direction 21 \\
\hline Occupancy & $\begin{array}{l}\text { Not occupied typically during day/weekday, typically } \\
\text { occupied during day/weekday }\end{array}$ & Direction 22 \\
\hline Ordered Categorical & Categories & $\begin{array}{c}\text { Regressor Code } \\
\text { (Chart Label) }\end{array}$ \\
\hline Number of stories & $\begin{array}{l}\text { One story, two stories, three stories, four or more stories, } \\
\text { split level, other }\end{array}$ & Direction 23 \\
\hline Basement/crawlspace heat & No basement, not heated, part heated, all heated & Direction 24 \\
\hline Attic heat & No attic, not heated, partially heated, all heated & Direction 25 \\
\hline Home vintage & $\begin{array}{l}\text { Before 1940, 1940-49, 1950-59, 1960-69, 1970-79, } \\
1980-89,1990-99,2000-02,2003,2004,2005\end{array}$ & Direction 26 \\
\hline Number of thermostats & Actual number (e.g., $0,1,2 \ldots$ ) & Direction 27 \\
\hline Number of rooms not heated & Actual number (e.g., $0,1,2 \ldots$ ) & Direction 28 \\
\hline Type of window glass & $\begin{array}{l}\text { Single-pane, double-pane, double pane with low-e, } \\
\text { triple-pane glass, triple-pane with low-e }\end{array}$ & Direction 29 \\
\hline Occupants & Actual number (e.g., $0,1,2 \ldots$ ) & Direction 30 \\
\hline Income & $5 \mathrm{k}$ groupings from 0 to $\$ 120,000$ or more & Direction 31 \\
\hline
\end{tabular}





\subsection{Results by Attribute}

The results of this study are presented graphically throughout the Section 3 and also in Appendix B of this report. In all cases, the vertical axes on the graph show changes in natural gas consumption in million British thermal units (MBtu). The horizontal axes represent a characteristic, attribute or a variable of interest specified below the graph. Each graph shows an effect of changes in the variable of interest on natural gas consumption, holding all other variables in the model fixed. Throughout the paper the results are referred to as directional regression results (or Direction 1, 2, 3, etc) because SBE assumes additive separability, thus, we are considering impact of changes only in one direction [dimension] at a time. Note, that vertical axes do not show absolute level of consumption, but represent the magnitude of deviation from the mean. For example, Figure 3.1 illustrates relationship between total square footage of the house and natural gas consumption. Zero on the vertical axes stands for the mean NG consumption of 77.5 MBtu, which corresponds to the house size of approximately 2700 square feet (s.f.). If we consider two identical houses (identical in the sense that all factors that we control for in the model are equal), where one is 2,000 s.f. and the other one is 4,000 s.f., the difference between NG consumption of those is almost 9 MBtu.

It should be noted that nonparametric methods produce estimates of a function at every data point instead of a functional form itself as it is done in parametric estimation. Therefore, the results for continuous variables are presented as vectors of the same size as data, while bar charts are used to depict impact of the categorical variables, where each bar corresponds to a distinct category.

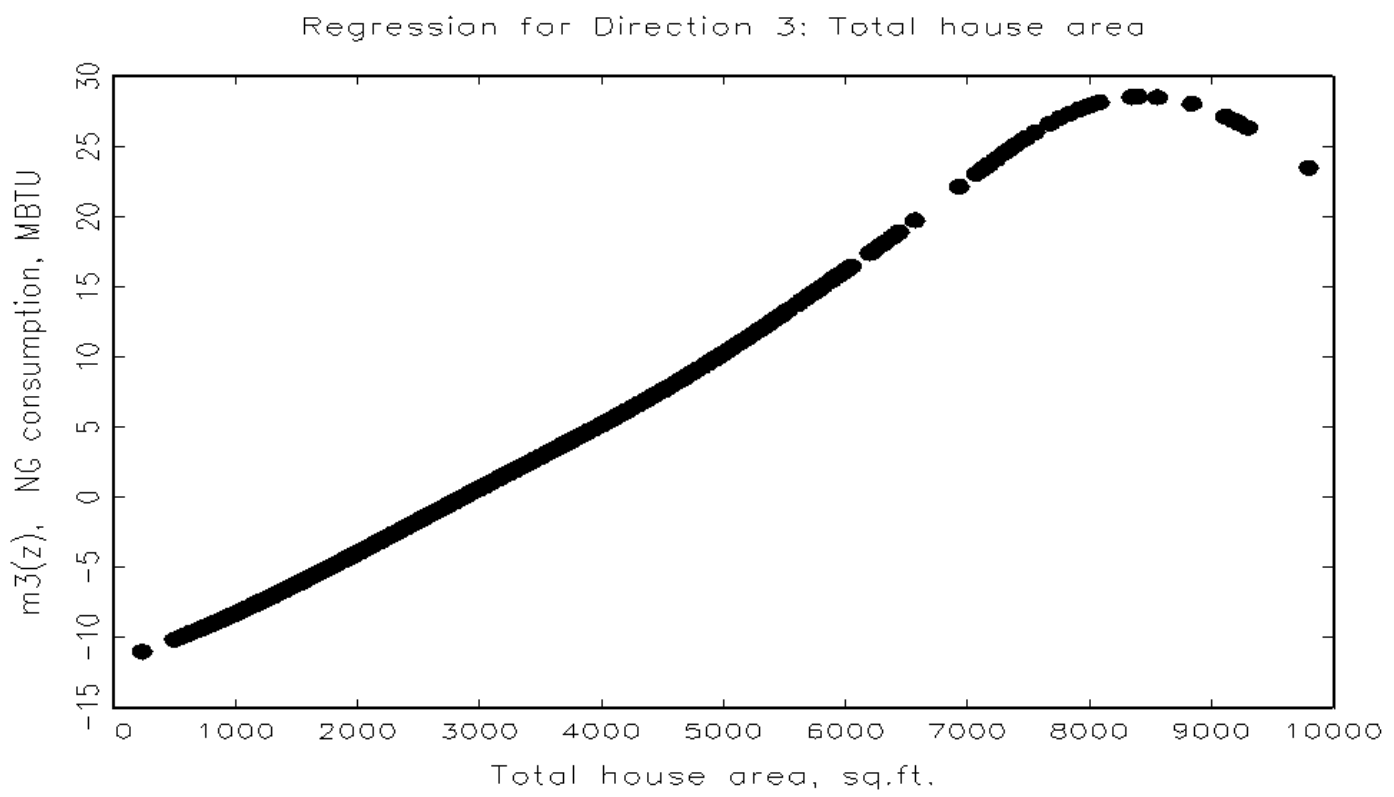

Figure 3.1. Impact of House Size on NG Use 


\subsection{Weather}

Direction 1, heating degree days, seems to correctly represent the increase in natural gas intensity as the number of heating degree days goes up (see Figure 3.2). Heating degree days are a characterization of weather. It is worth noting that RECS microdataset has sanitized data for heating and cooling degree days to prevent identification of survey respondents or specific buildings out of the reported sample. Even with the sanitized data, the overall pattern of dependency is reasonable. Annual heating degree days (HDD) are a measure of how cold a building location is relative to the base temperature. The daily HDD is the numerical difference between a day's average temperature and $65^{\circ} \mathrm{F}$, if the average temperature is less than $65^{\circ} \mathrm{F}$. Otherwise it is zero. Annual HDD is the sum of the daily HDD for the year. If the thermal integrity (e.g., insulation levels) of the building is known, it is possible to assess heating requirements from this information. The suggested pattern follows the engineering results that building heating requirements are not linear with respect to temperature. Therefore, natural gas use for heating will also have non-linear dependency on temperature. Although this pattern of dependency is well-known from engineering studies, the primary reason for including this variable is to analyze the impact of other factors on energy demand, while controlling for weather. Cooling degree days also contains sanitized data, and their impact is shown graphically as Direction 2 in Appendix B. The cooling degree day pattern of dependency observed is consistent with engineering studies and suggests a non-linear decrease in natural gas usage as the number of cooling degree days goes up.

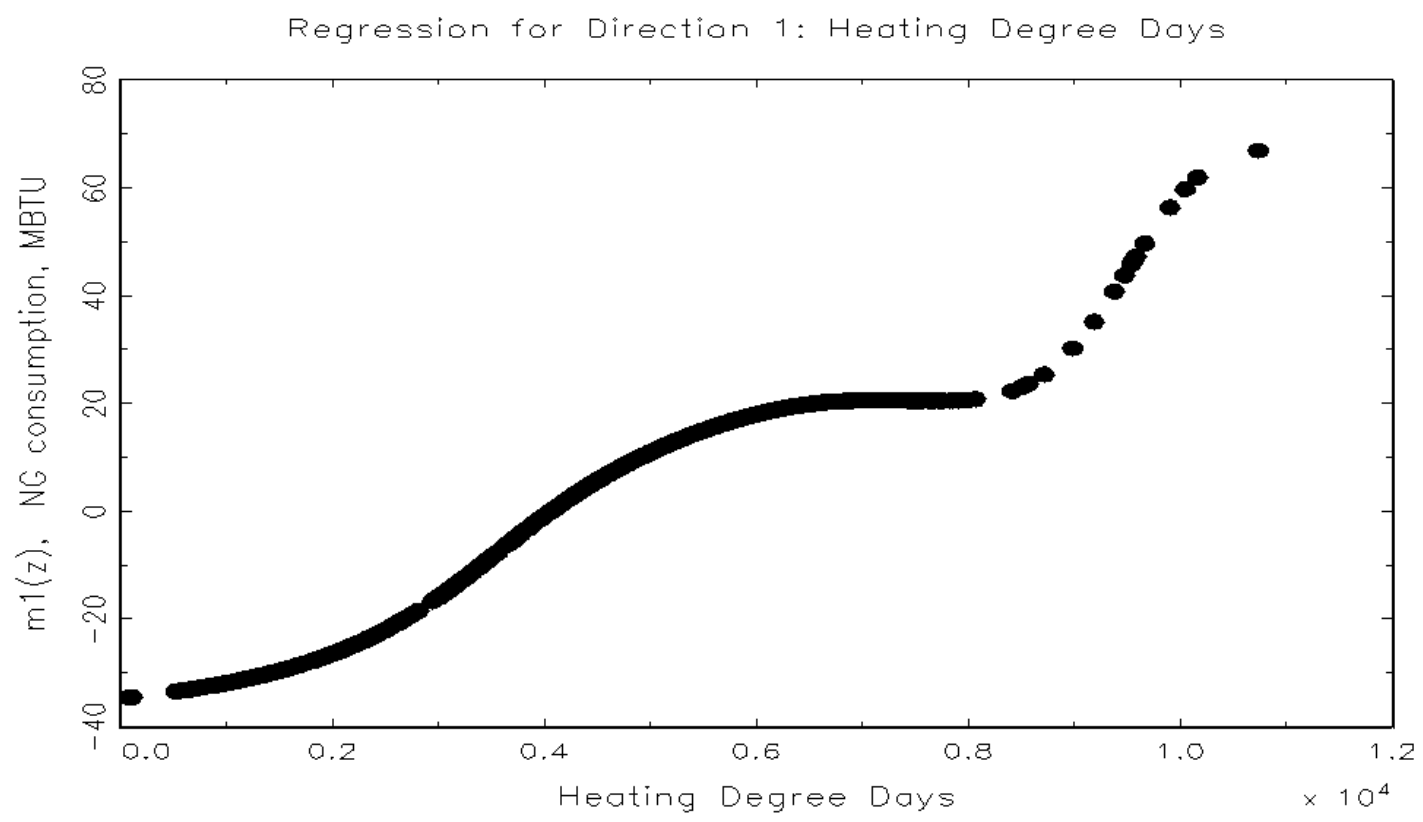

Figure 3.2. Impact of Heating Degree Days on NG Use

\subsection{Fuel and Equipment/Appliance Choice}

Figure 3.3 presents results related to primary heating systems and the choice of fuels (Direction 18). As expected, NG as primary heating fuel (category 1) would result in the highest NG intensity. If the heating degree days data were not sanitized, it would have been possible to approximately identify the climate zone associated with a particular set of observations. There is a dependency between the climate 
zone and choice of fuel for heating that could impact this result. The lowest NG usage is for the houses heated with kerosene or fuel oil. Natural gas consumption for houses that use electricity as primary fuel goes up by $15 \mathrm{MBtu}$. This could be explained by the fact that some houses with piped natural gas available use electric-source equipment as their primary heating system. The latter use NG for auxiliary heat. Therefore, in this particular case, NG would be used complimentary to electricity. A similar explanation is valid for increase in NG use by $10 \mathrm{MBtu}$ for dwellings using wood and solar energy as a primary heating fuel. Although these are categorical variables, dotted lines connecting results are added on the graphic presented in Figure 3.3 as a visual aid.

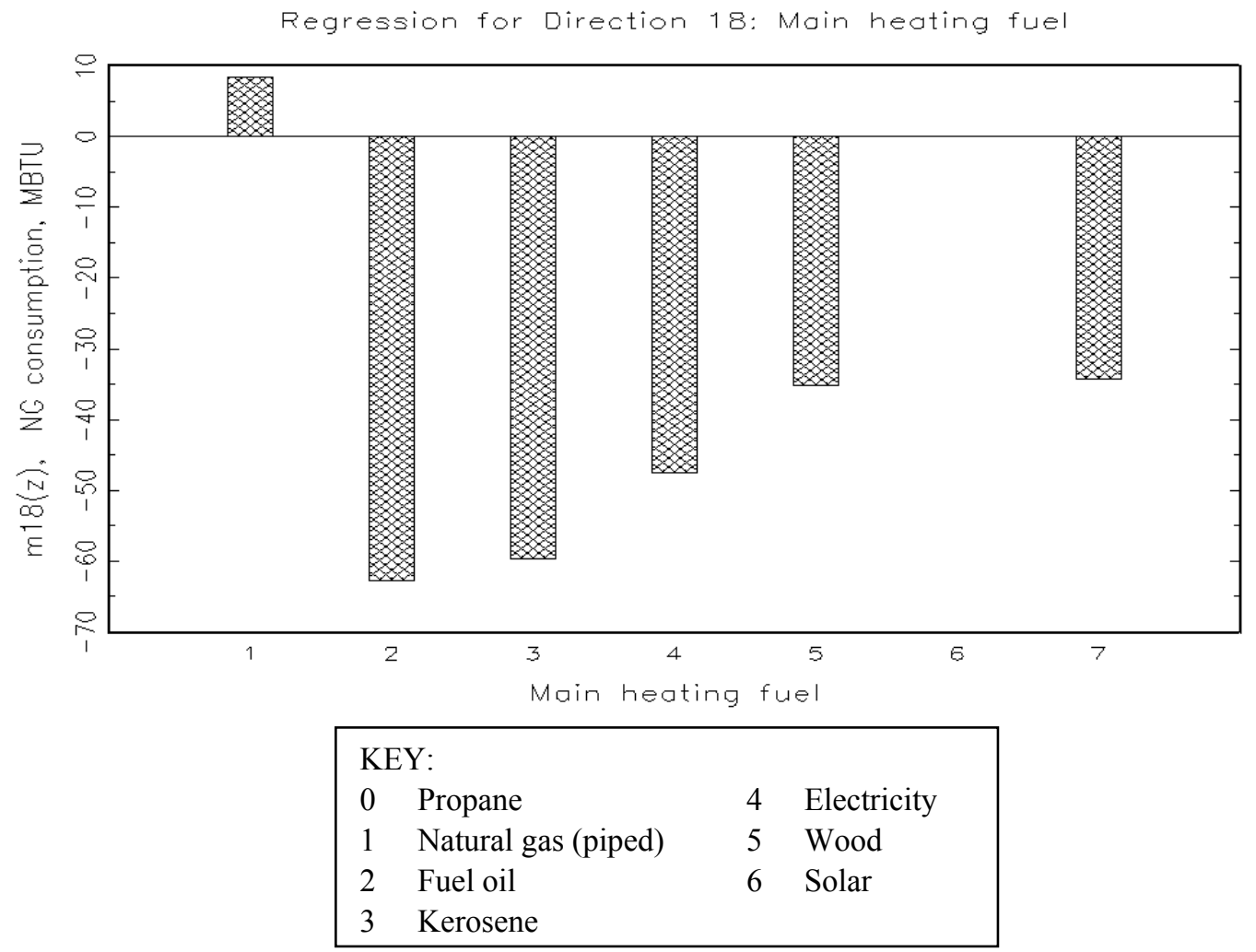

Figure 3.3. Impact of Main Heating Fuel Choice on NG Use

Correlation between the type of heating equipment providing the heat and NG usage is depicted on the graph in Figure 3.4 (Direction 19). The lowest NG usage is suggested where portable electric heaters are used to provide most of the heat (category 9). If the heating load can be met with the portable electric heaters, this would indicate that only very little heating is needed and piped NG is used for water heating and cooking only. Similar explanation is valid for heating stoves burning wood (category 7), portable kerosene heaters (category 10) and cooking stoves used for heating (category 11). The suggestion of highest NG consumption being characteristic of houses with steam/hot water system and radiators/convectors in each room (category 1) is reasonable. High level of NG consumption shown in the graph is expected because this heating system choice impacts natural gas intensity through waterheating requirements, but it is also a manifestation of the climate zone and age/vintage of the house. NG consumption decreases for houses where heat pump is used as a primary equipment, but it is still higher than any other category. This result can also be explained by complimentary use of NG for the auxiliary system that usually turns on as temperatures fall below freezing, as the electric heat pump becomes less 
efficient at these colder temperatures. Relatively low NG consumption, according to the regression results, is associated with using central warm-air furnace system with ducts to individual rooms.

Considering that this is one of the more efficient heating distribution systems, this is an expected result. Properly designed duct systems have a significant impact on how much heat is lost during delivery. The newest houses have ducts located in the air-conditioned and heated spaces, which results in even more efficient distribution of heat, thus reducing NG intensity. In addition, this is a manifestation of multicollinearity between the house age, quality of construction/insulation and income level of the household.

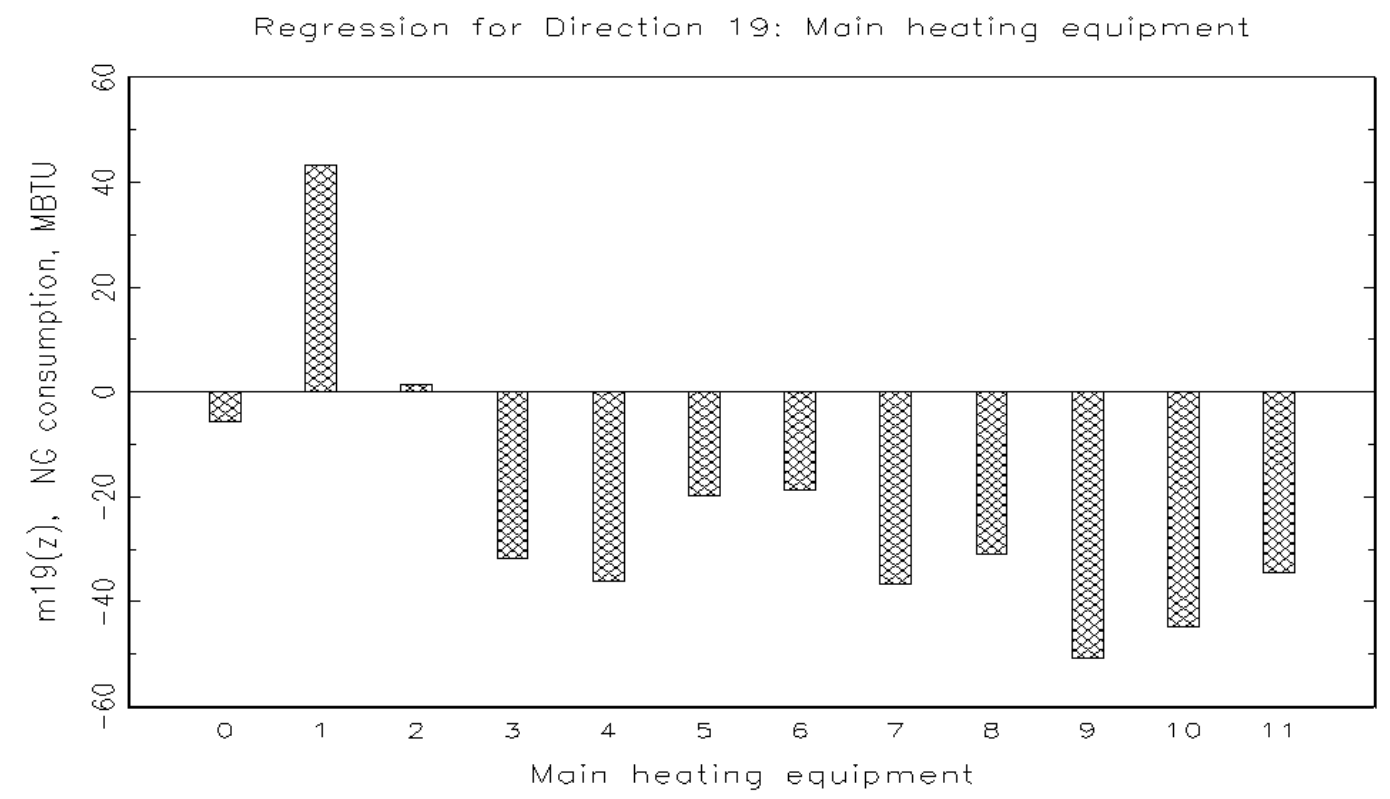

\begin{tabular}{|llll|}
\hline & KEY: & & \\
0 & No heating equipment used & 5 & Built-in floor/wall pipeless furnace \\
1 & Steam/hot water system with & 6 & Built-in room heater burning gas/oil \\
& radiators/convectors in each room or & 7 & Heating stove burning wood/coal \\
& pipes in floors/walls & 8 & Fireplace \\
2 & Heat pump & 9 & Portable electric heater \\
3 & Central warm-air furnace with ducts & 10 & Portable kerosene heater \\
4 & Built-in electric units in room & 11 & Cooking stove used for heating \\
\hline
\end{tabular}

Figure 3.4. Impact of Heating Equipment Choice on NG Use

Results for Direction 20 represents the type of fuel used to heat water for washing or bathing and are presented in Appendix B. As expected, if the primary water heating fuel is NG, its consumption is higher than for other fuels. The overall difference is $24 \mathrm{MBtu}$.

Figure 3.5 (Direction 14) shows the dependency between the NG use and the type of secondary heating equipment installed in the house. Typical secondary heating equipment includes central warm-air furnace with ducts (category 1), steam/hot water system with radiators/convectors in each room or pipes in the floor or walls (category 2), built-in floor/wall pipeless furnace (category 3), built-in room heater (category 4) and wood cooking stove used to heat the house (category 5). Cases of no secondary equipment are included as a category with value 0 . The result for this category is intuitive because the households with no secondary equipment will have all the heating load provided by the main equipment. 
Because the RECS microdataset was filtered to keep only observations with piped natural gas, the result that houses equipped with natural gas intake are more likely to use natural gas as their primary heating fuel is also intuitive. Central warm-air furnace with ducts implies a more efficient heat delivery system; therefore, reduction of the NG consumption for category 1 is also an expected result. The resulting increase in NG consumption that occurs when the secondary heat as built-in room heaters (option 4) is unexpected; however, it is possible that this result is correlated with thermal integrity of the dwelling, because built-in room heaters are more typical for older houses with lower insulation and construction quality.

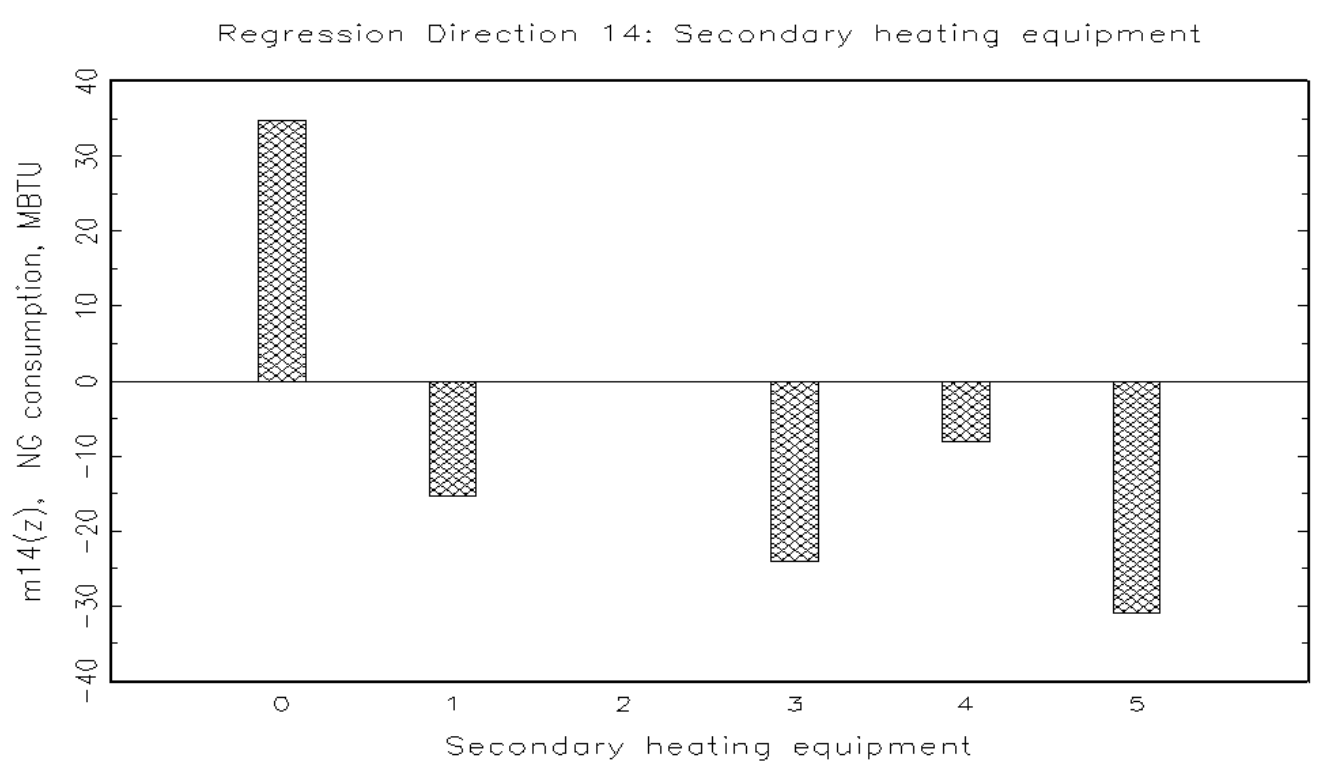
KEY:
$0 \quad$ No secondary heating equipment
1 Central warm-air furnace with ducts
2 Steam/hot water system with radiators in each room or pipes in floor/wall

Figure 3.5. Secondary Heating Equipment Impact on NG

The results related to the impact of fuel choice for stovetops (Direction 12) and clothing dryers (Direction 13) are presented in Appendix B. Direction 12 shows the pattern of association between the NG intensity and type of fuel used by burners for cooking on the stove. The peak value is observed for the household equipped with piped natural gas for cooking. There is no difference between using some other fuel (category 0 ) and bottled propane (category 2). On one hand, these two categories could be combined. However, residents usually refer to both types of fuel (propane and natural gas) generally as gas, so it is worth keeping for clarification. There is a $4 \mathrm{MBtu}$ reduction if the household is using electricity for cooking burners, which is a reasonable result. This result can also be partially attributed to multicollinearity in data, namely if the household has piped natural gas, it is expected that burners would use NG, but so would the water heaters, clothes dryer and potentially other systems. The results related to clothing dryer fuel choice also suggest multicollinearity in the data, where households without dryers are more typical for older neighborhoods with lower construction quality and, therefore, lower thermal integrity. 


\subsection{Controls and Thermostat Settings}

A number of counterintuitive results were observed related to thermostat controls and setting impacts on natural gas usage. Although the reasons for these results are unclear, it is possible that data reporting problems from self-reported data, as well as some unexplained behavioral characteristics, may be the root cause of these results. For example, Direction 6 contains data on the temperature setting during the day in winter when someone is home. Natural gas intensity in this direction seems to misrepresent the direction of dependency. As shown in Figure 3.6, the mean of regressor 6 (option 6 in key) corresponds to the temperature setting of $70^{\circ} \mathrm{F}$. While there is a positive correlation between temperature setting and energy consumption for the range between $55^{\circ} \mathrm{F}$ and $65^{\circ} \mathrm{F}$, there is no reasonable explanation why natural gas consumption drops for the ranges from $65^{\circ} \mathrm{F}$ to $80^{\circ} \mathrm{F}$, when the opposite should be observed.

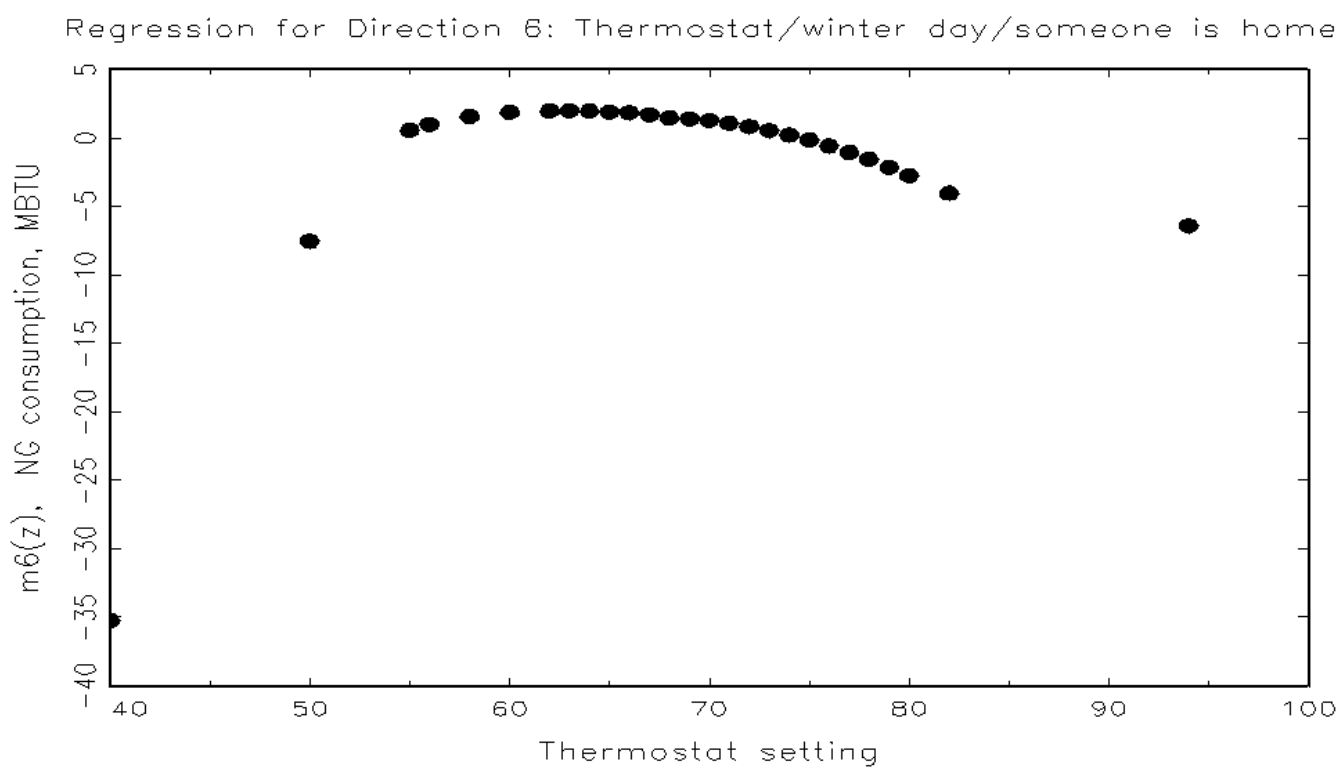

Figure 3.6. Setting During the Winter Day When Someone is Home

The same can be said about the Direction 7, which represents the temperature setting during the day in winter when no one is home and is shown in Figure 3.7. The mean for this regressor is $65^{\circ} \mathrm{F}$. The base temperature for heating is $65^{\circ} \mathrm{F}$, so thermostats set to the mean temperature would mean no additional heating is required on a 0 HDD. Thus, it is not clear why Direction 7 would indicate a drop in the natural gas consumption while the temperature setting is going up. It might be beneficial to replace these two variables with one that would represent the difference between temperature setting when someone is home and temperature setting when someone is not home. The higher the delta, the less energy is consumed while the building is not occupied. There is also an additional factor that leads to misrepresentation of the relationship for this covariate. All temperature settings are self-reported. In fact, studies have found that persons often report lower-than-actual thermostat settings, even when they know that their settings are being recorded, as shown by Lutzenhiser (1993). No actual readings of the thermostat are taken. As saving energy becomes a more widely-publicized topic, respondents understate heating temperature settings, as well as misreport the way programmable thermostats are used, to fall within the range they perceive as socially acceptable. On the other hand, data on natural gas consumption comes directly from the bill and reflects actual consumption levels. Therefore, even restructuring the variable may not produce a desirable result using existing data. 


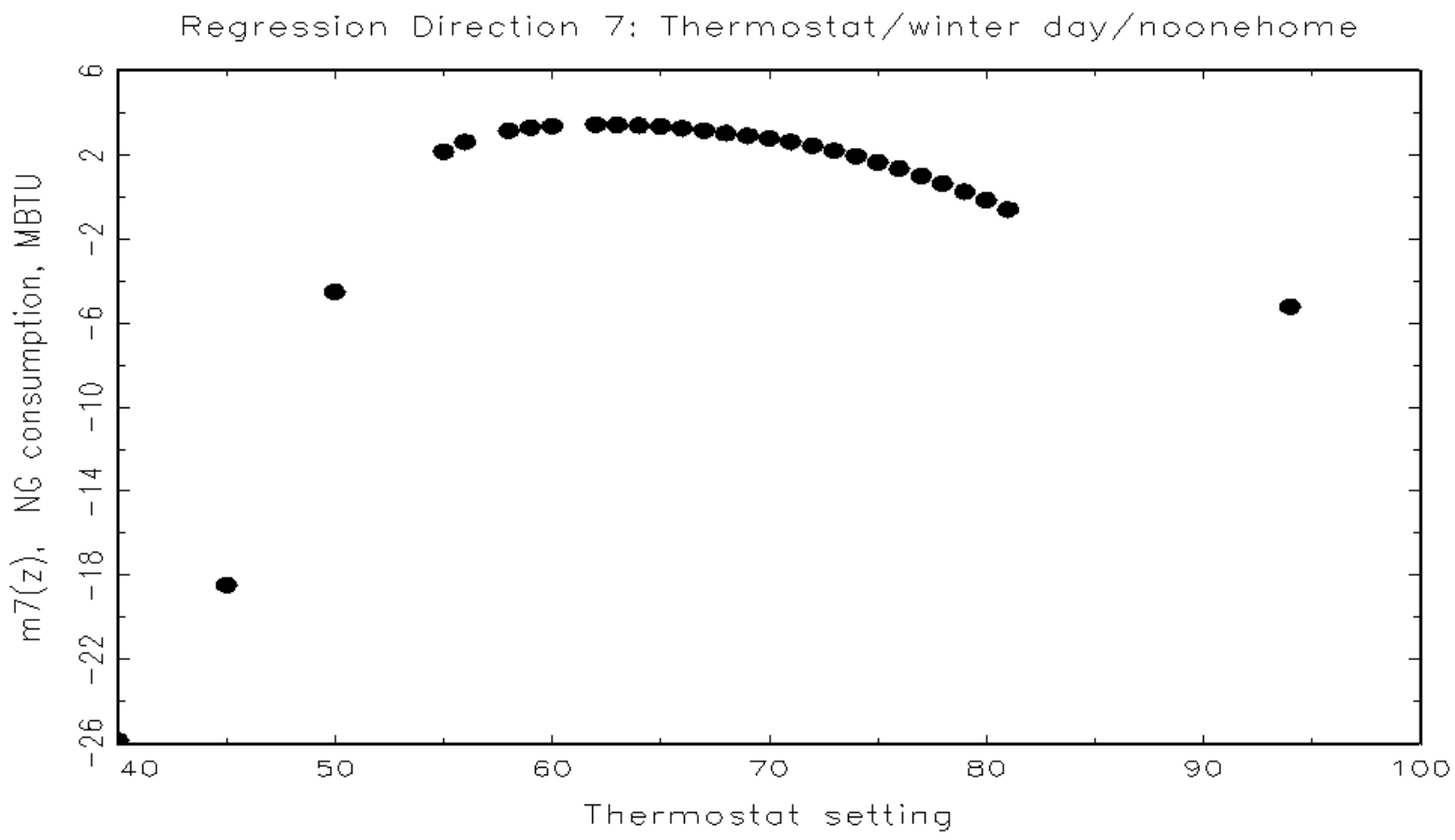

Figure 3.7. Setting During the Winter Day When No One is Home

Direction 8 represents association between the level of natural gas intensity and temperature during the sleeping hours in winter and is presented in Appendix B. As the setting goes up from 50F to $70 \mathrm{~F}$ so does the NG consumption. The slight drop in the gas usage around that point is unexpected. The concern with temperature setting being self-reported is pertinent here as well, because the owners tend to misreport lowering the thermostat settings. So the houses that are set at much higher temperatures, but underreport to be closer in line with culturally-accepted $65-70^{\circ} \mathrm{F}$ level, will drive the result for this average level much higher than what it should be. The estimated natural gas consumption will be inflated for the misreported temperature and underestimated for the higher temperature intervals that would otherwise correspond to that actual heating requirement. This makes the results to the right of the anchor level appear lower than at the average setting, thus erroneously suggesting negative correlation over this interval of temperatures.

Figure 3.8 (Direction 15) describes the relationship between NG consumption and the controls installed in the house. There seems to be no difference in NG consumption if there is a programmable (category 1) or non-programmable (category 0 ) thermostat in the house. These two categories are associated with increased NG demand. The result for category 3 is counterintuitive because it suggests that absence of thermostats is characterized by a significant reduction in NG consumption. Both the direction of change and the magnitude of $16 \mathrm{MBtu}$ are counterintuitive. The explanation might be that absence of thermostat is dictated by a warm climate zone and is an indicator of a non-heated dwelling or very little heating is needed. Although the sample was filtered to retain only the residential buildings that are heated, houses that are in need of very little heating and may not be equipped with thermostats are included in the sample. 


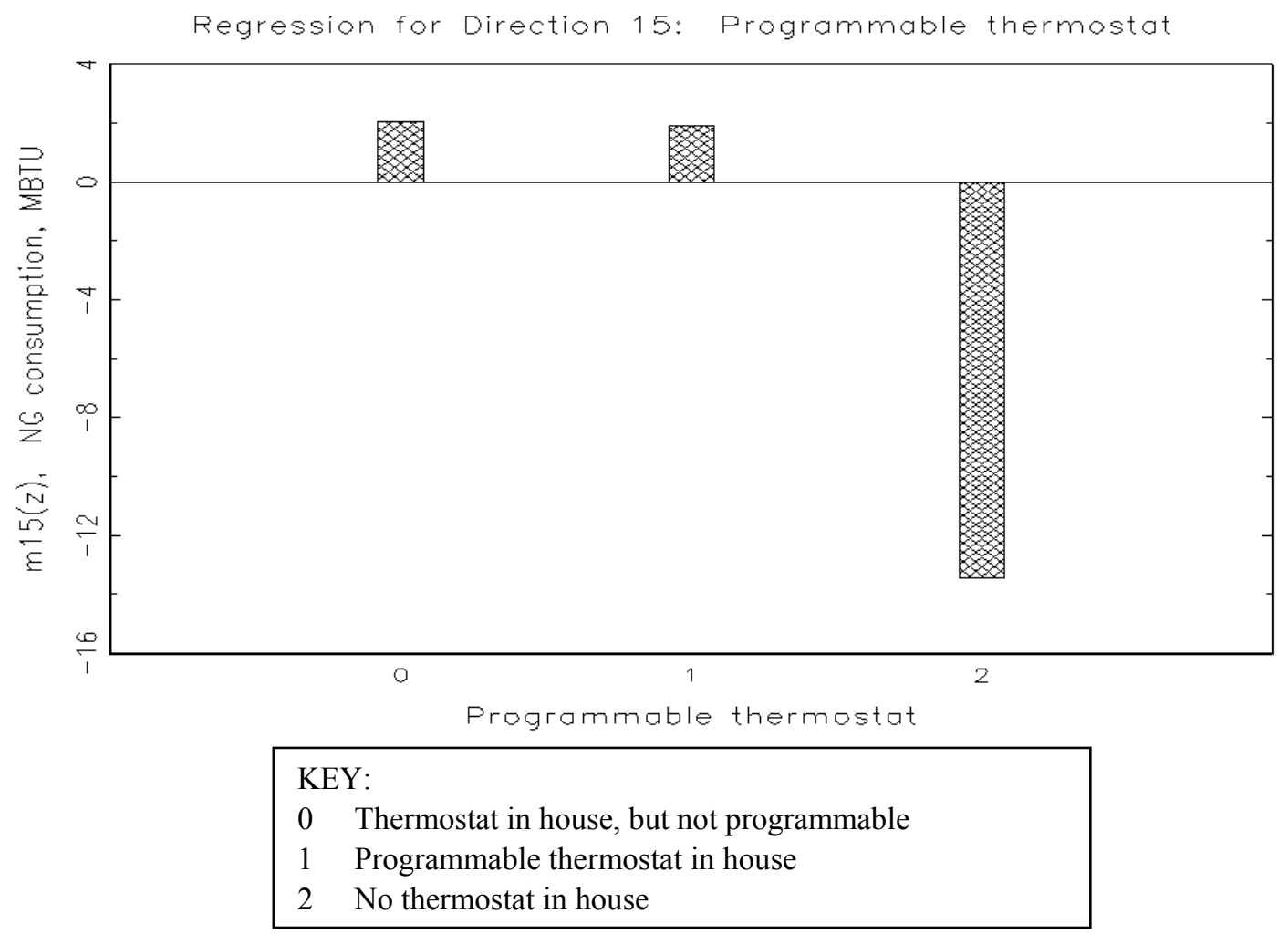

Figure 3.8. Impact of Thermostat and Programmable Thermostat on NG Use

Behavioral information is contained in Directions 16 and 17, which deal with programming thermostats to lower temperature for heat setting at night and, correspondingly, when no one is home. The results of these regressions are found in Appendix B. The result of Direction 16 is counterintuitive because it suggests that programming the thermostat to lower temperature automatically is associated with higher NG use. Neither the direction of change, nor magnitude (3 MBtu) are intuitive. Direction 17 also produced a counterintuitive pattern. It indicates that the highest NG consumption is for the houses with thermostats preprogrammed to lower settings when no one is home during the day. Then it drops by about $1 \mathrm{MBtu}$ for the houses that have no thermostats, and drops down even further for houses where the temperature is not lowered. For detailed analysis of these two variables, more refined data is needed. To separate the behavioral impact, it is necessary to also account for climate. Thermal integrity of the building usually is strongly correlated with the climate. In turn, in more severe climate conditions, where NG intensities are the highest, the inhabitants are more likely to adjust thermostats up or down from the base setting.

Figure 3.9 (Direction 27) shows the impact that the number of thermostats in the house (from zero to six) has on NG use. The drop in the NG consumption between the category with no thermostat and one thermostat by $1 \mathrm{MBtu}$ is reasonable. Then the consumption increases by $17 \mathrm{MBtu}$ for houses with two thermostats. The highest level is registered for three-thermostat houses, leading the previous group by about $2 \mathrm{MBtu}$. This could be explained by the fact that this variable contains redundant information because number of thermostats is linked to the house size. In addition, the number of thermostats might be a representation of inefficient heating systems with individual dials in each room in older houses. For each additional thermostat after three, the consumption drops. 


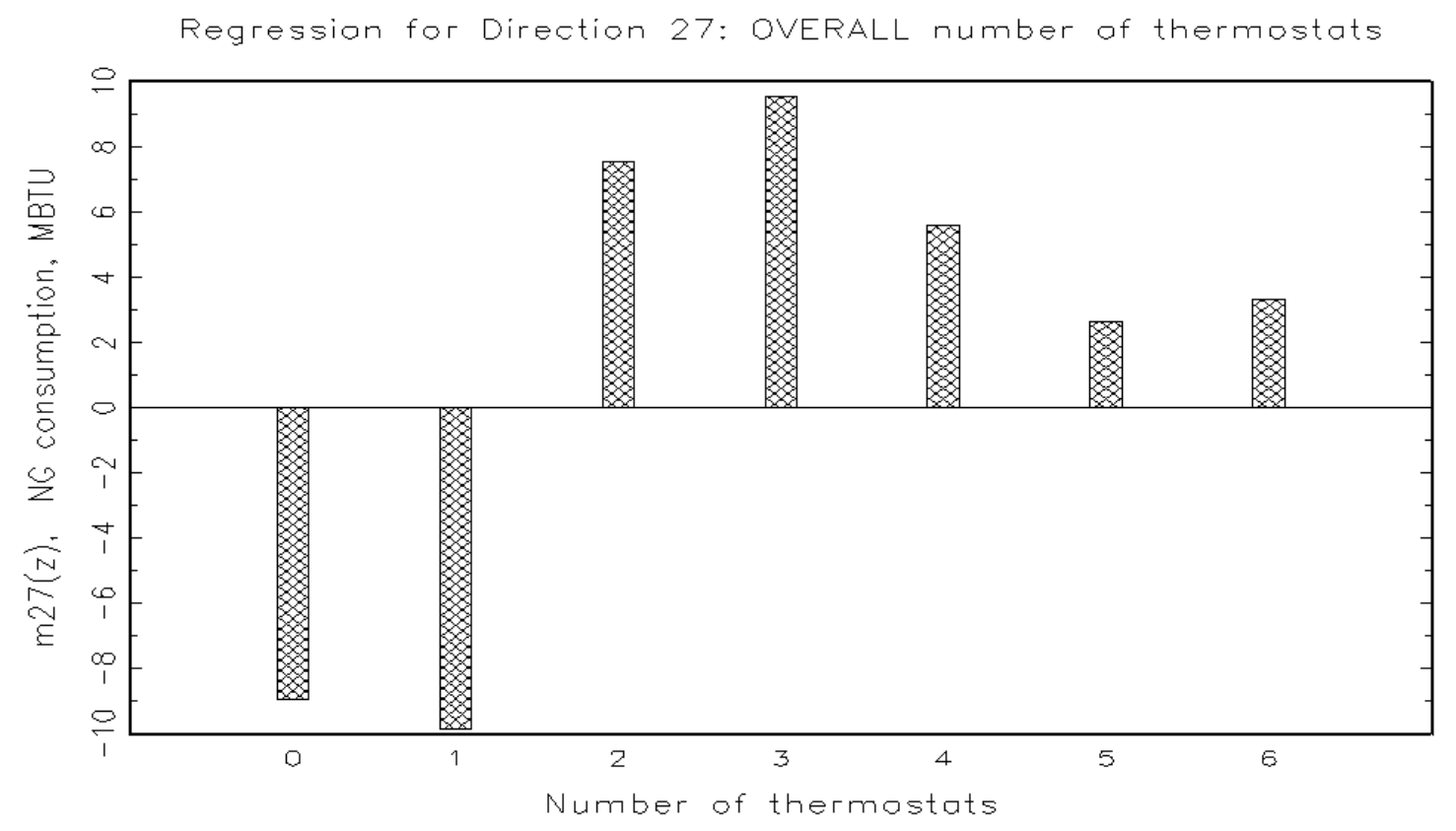

Figure 3.9. Impact of Number of Thermostats on NG Use

\subsection{Prices and Billing Structure}

The modeling results suggest a positive relationship between electricity price and NG use (Direction 4), which is expected considering that electricity is the primary NG substitute in residential buildings. Increases in electricity prices encourage switching to $\mathrm{NG}$ as the primary fuel for the household. The results for own price effect (i.e., price of NG) on NG (Direction 5) is negative, as expected. Increased NG price results in reductions of NG consumption. Both of these price effects are shown in Appendix B.

Direction 21 is of particular interest because it provides some insight on the relationship between the method of how NG is billed and its consumption level. As shown in Figure 3.10, if the household sees the full bill and pays it all, it seems to suggest the lowest result among all categories. Paying the utility bill in full corresponds to category 0 . The consumption increases significantly, on the order of $16 \mathrm{MBtu}$, if all of the payment gets included in rent (category 1) or the household faces only a portion of the total bill for rented dwelling (category 2). This increase could be attributed to differences in willingness to pay for various technology options or invest in energy efficiency between the renters and the owners residing in the house. The result also suggests the difference in NG consumption resulting from the signal of NG prices not reaching the consumer, or a behavioral difference resulting from the "paid for" attitude of the consumer that pays a lump sum irrespective of the actual usage. Such a result is consistent with currently ongoing research on residential energy efficiency. 


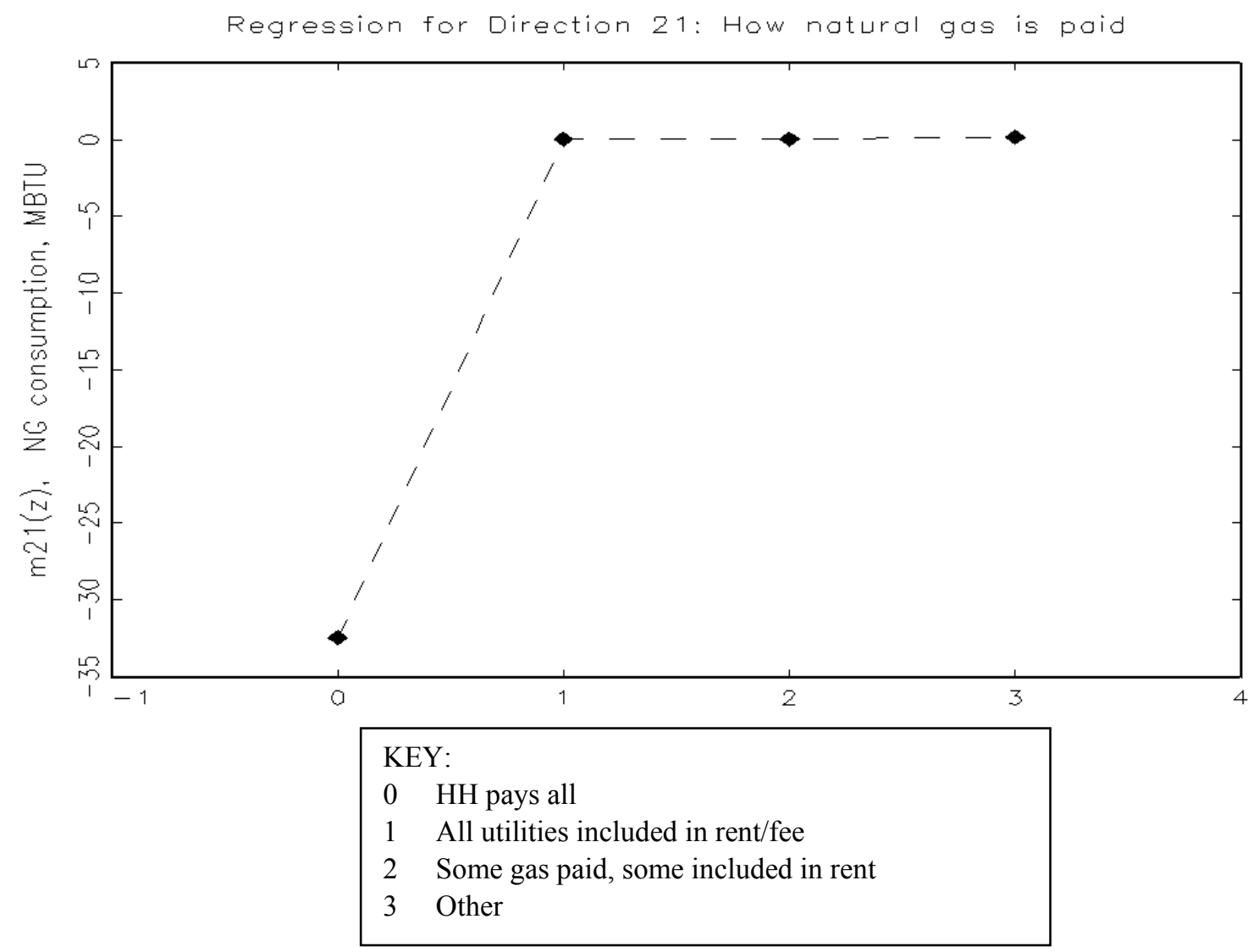

Figure 3.10. Impact of How NG is Paid on NG Use

\subsection{Home Construction Attributes}

\subsubsection{Building Shell}

Figure 3.11 (Direction 9) shows the impact of the exterior wall construction material on NG use. All other things held equal, the change of the wall type variable leads to the expected change in the NG intensity. The lowest NG consumption is shown for stucco, concrete block and stone. By stucco, residents usually refer to either the synthetic cladding that is applied over polystyrene panels, which provide extra insulation, or to cement plaster (lime sand and Portland cement). If installed properly, the latter seals the house, but not as thoroughly as synthetic systems. Concrete block and stone will serve as thermal mass storage, slowing down heat loss. The highest NG consumption is shown for houses with aluminium/vinyl/steel siding or wood shingles. This is consistent not only with the properties of each material and construction methods associated with it, but also with the vintage of the homes that would have these materials installed. In turn, there is a strong correlation between house vintage and quality of wall insulation. 


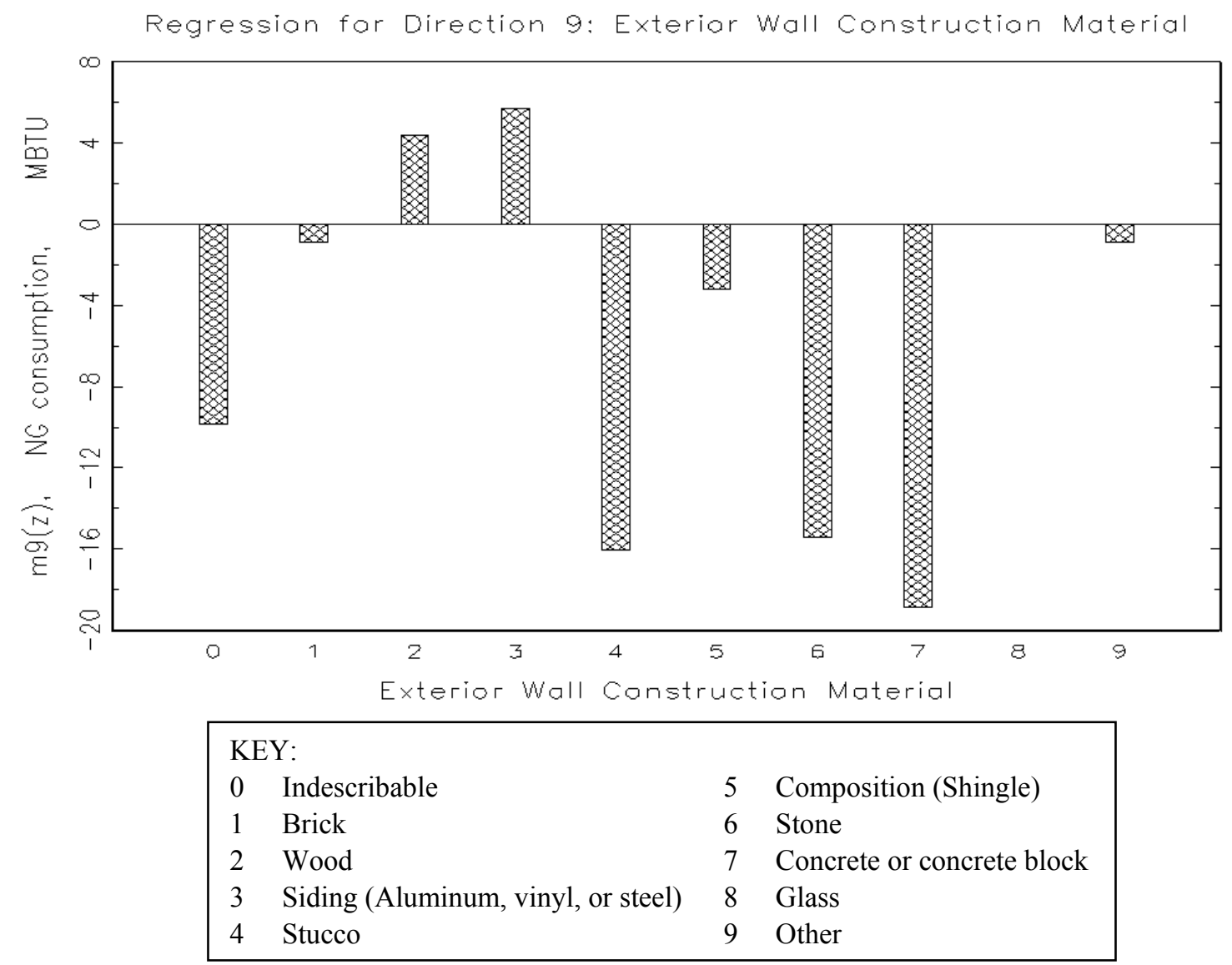

Figure 3.11. Secondary Heating Equipment Impact on NG

Direction 29 analyzes the building shell component heat load contributions by looking at the windows with various glazing and insulating characteristics. In Figure 3.12, the left side of the chart shows the increase in the natural gas consumption across the first three categories (single-paned glass, double-paned glass and double-paned glass with low-E coating). This result is somewhat counterintuitive because it would be expected that number of window panes (e.g., single-paned versus double-paned) should be negatively correlated with energy demand, because improved windows have higher energy efficiency. One possible explanation might be the size difference between older single-paned windows and newer double-paned. There is a trend to increase size of windows or incorporating additional windows when retrofits are implemented. Also, newer houses tend to have a higher number of windows, which would also increase heat loss and result in the higher NG consumption. In addition, this can also be affected by the climate. Unfortunately the information on window quantity and sizes is not available to test either one of the assertions. Climate information is not included either. NG consumption goes down for categories with triple-pane glass (category 3) and triple-pane glass with low-E coatings (category 4 and 5), which is expected. 


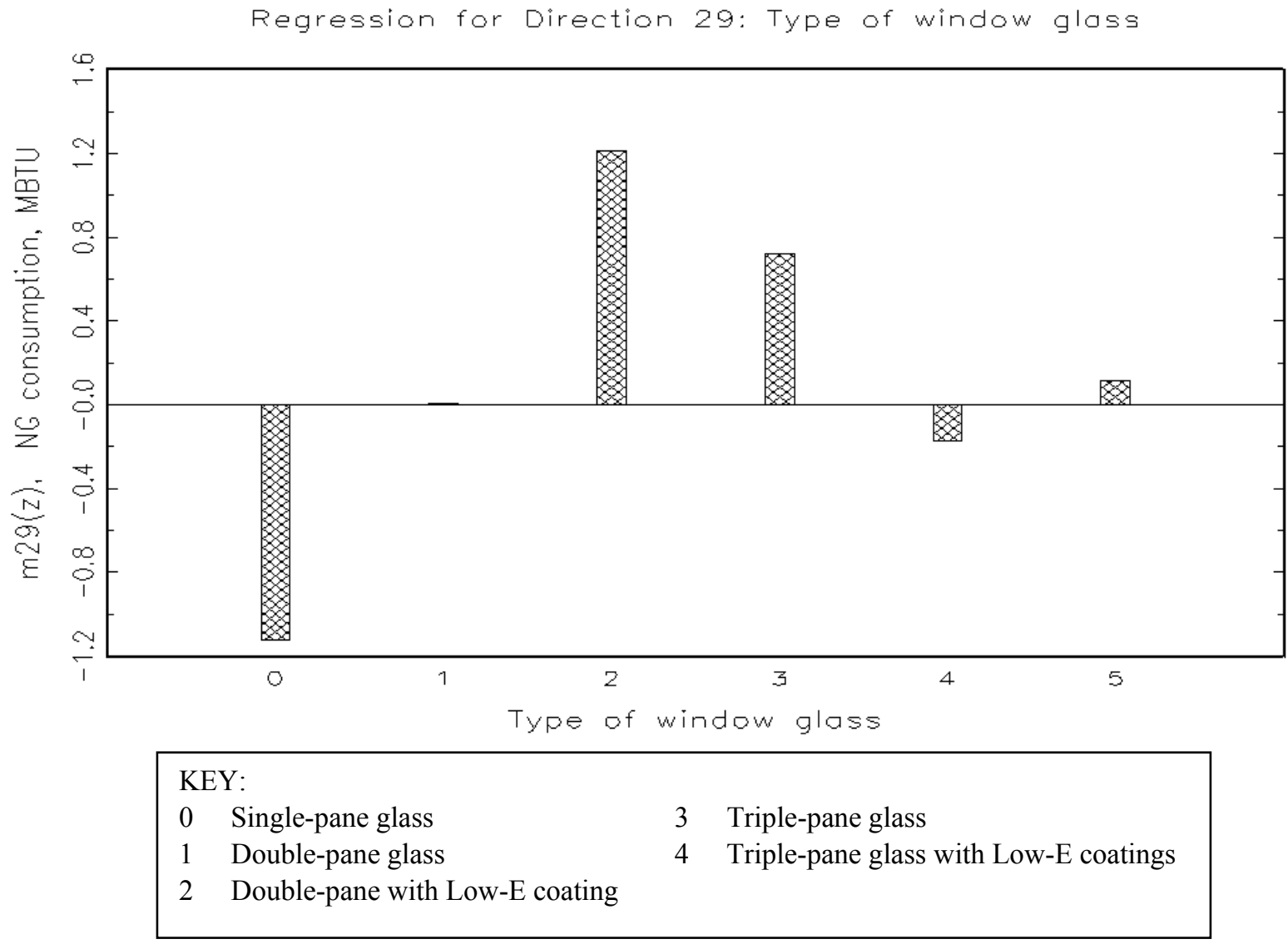

Figure 3.12. Impact of Type of Window Glass on NG Use

\subsubsection{Size and Design}

Figure 3.1 (Direction 3), which is described in detail at the beginning of the results section, shows the dependency between NG intensity and the total square footage of the house. The suggested relationship is linear over the range of square footage where the most observations are concentrated. So the natural gas demand grows linearly for households between 900 and 6000 s.f. Consumption plateaus after 8000 s.f.; however, this occurrence should not be given much emphasis because there are very few points in this range.

Direction 10 examines the impact of whether or not a home has a garage or heated garage on NG use. The results of the Direction 10 regression were reasonable and are presented in Figure 3.13. Category 0 corresponds to the house with no garage. Category 1 represents the houses where there is a garage, but it is not heated. Attached garage provides additional buffer between the heated part of the house and the environment, thus slowing down heat loss. The results suggest that heating the garage will increase natural gas consumption by up to $14 \mathrm{MBtu}$. Complete interpretation of this increase also depends on whether garage space is included in the total square footage of the house. Also, this regressor is picking up additional effects impacting NG use. Absence of a garage is more typical of older neighborhoods with lower housing prices. They often share similar quality of construction, amount of insulation and level of equipment. Therefore, fairly high NG intensity for houses with no garage is not an unexpected result. 


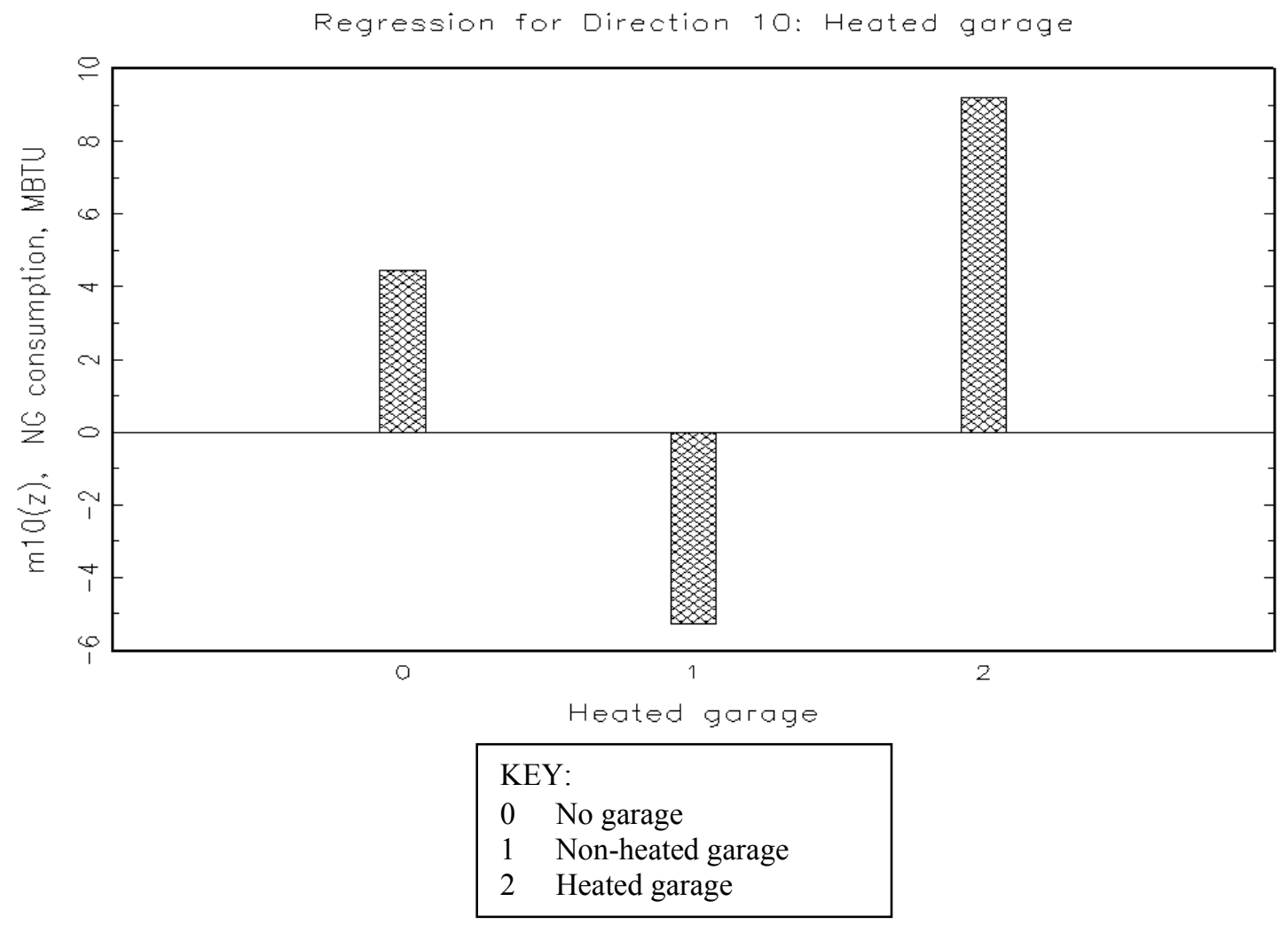

Figure 3.13. Impact of Heating Garage on NG Use

Direction 23 characterizes the impact from the number of stories in the building, and the results are presented in Appendix B. The lowest NG consumption is for the one-story building, followed by the split level house and two-story structure. The highest level is for the three-story dwellings. As the number of stories increases, the structure design tends to change towards narrower buildings. This leads to a much higher exchange surface, which explains higher NG intensity for buildings in this category. It is necessary to note that all apartment complexes were excluded from the sample. The results cover only single-family detached housing units.

Direction 24 produced rather interesting results that are shown in Figure 3.14. Category 3, where the entire basement is heated during winter shows highest NG consumption. The second highest demand for NG is shown for the houses that have a basement but do not heat any portion of it (category 1). It is followed by the houses where there is a basement and portion of it is heated. This result appears counterintuitive, but may have reasonable explanation. Unheated basements are typical for older houses with unfinished basements. If a portion of it is heated, it is likely that the thermal integrity of the basement has been improved. The difference between these two categories is $2 \mathrm{MBtu}$. This directional result could be different if the regressor is restructured as a binary versus ordered categorical variable, such that it does not attempt to account for a particular portion of the basement which measurement is not defined. Also, if the retrofit information were available, it would be possible to analyze its correlation with the vintage of the house. 


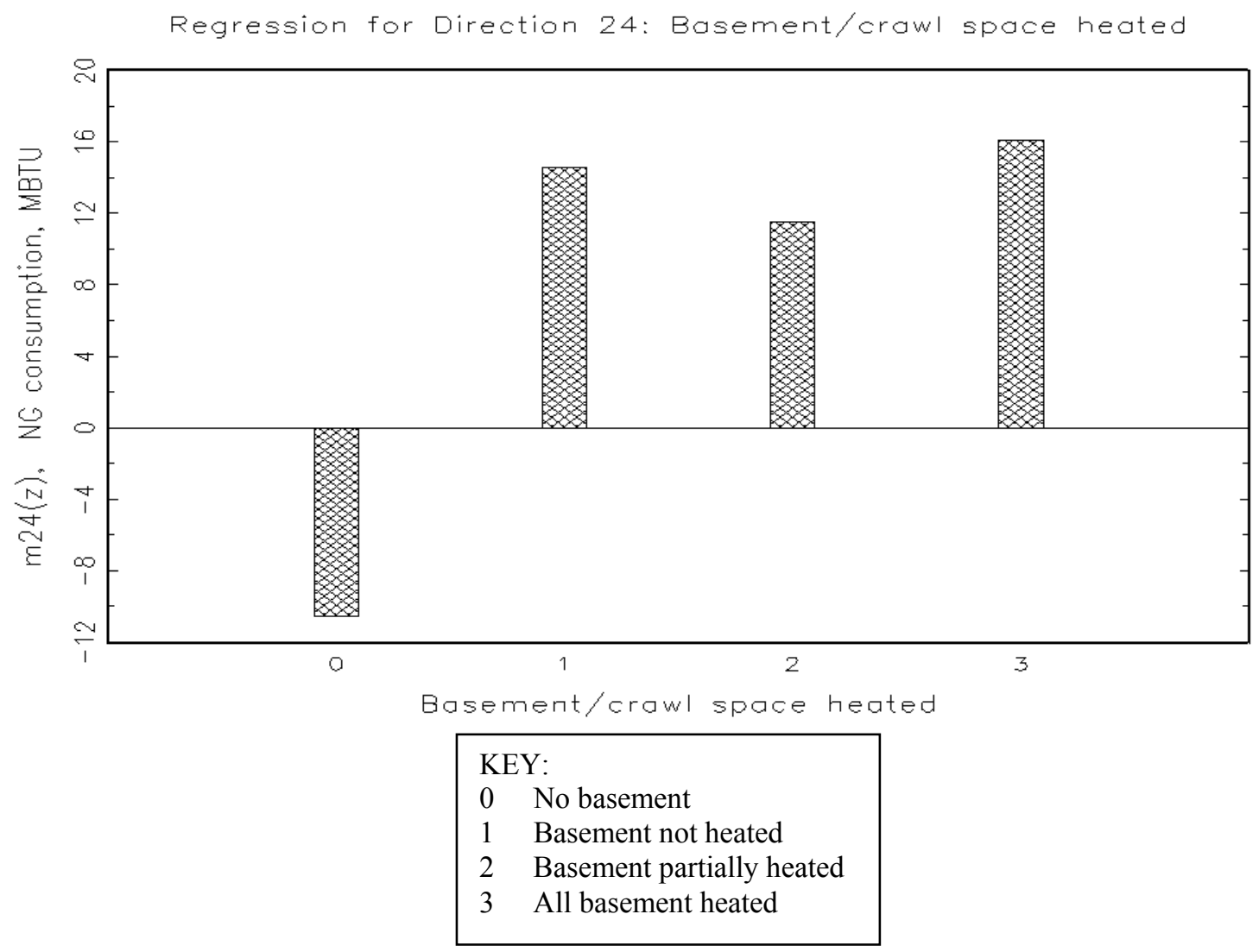

Figure 3.14. Impact of Basement/crawl space on NG Use

Direction 25 describes the portion of the attic that is warm, and the results are reasonable. It suggests a linear relationship between the fraction of attic that is heated and NG consumption, and the results are shown in Appendix B. The difference between a house with no attic versus a house with an unheated attic is approximately $4 \mathrm{MBtu}$. Usually no attic implies a flat roof with not much room for insulation. Just the presence of an attic has a favorable effect, because it provides a buffer zone slowing down the heat loss in addition to allowing better insulation. This is followed by the partially heated attic with increase in NG demand by about $8 \mathrm{MBtu}$. The highest NG consumption is shown for fully heated attic, which would be expected.

No particular pattern of dependency between number of rooms not heated during the winter and the NG demand can be derived from the results of Direction 28 (see Figure 3.15). On the surface it would seem likely that this variable should have an inverse impact on NG consumption, because more rooms that are unheated in winter would imply that less NG should be consumed. However, any unheated space that is not zoned appropriately can contribute to the heating load of a house. 


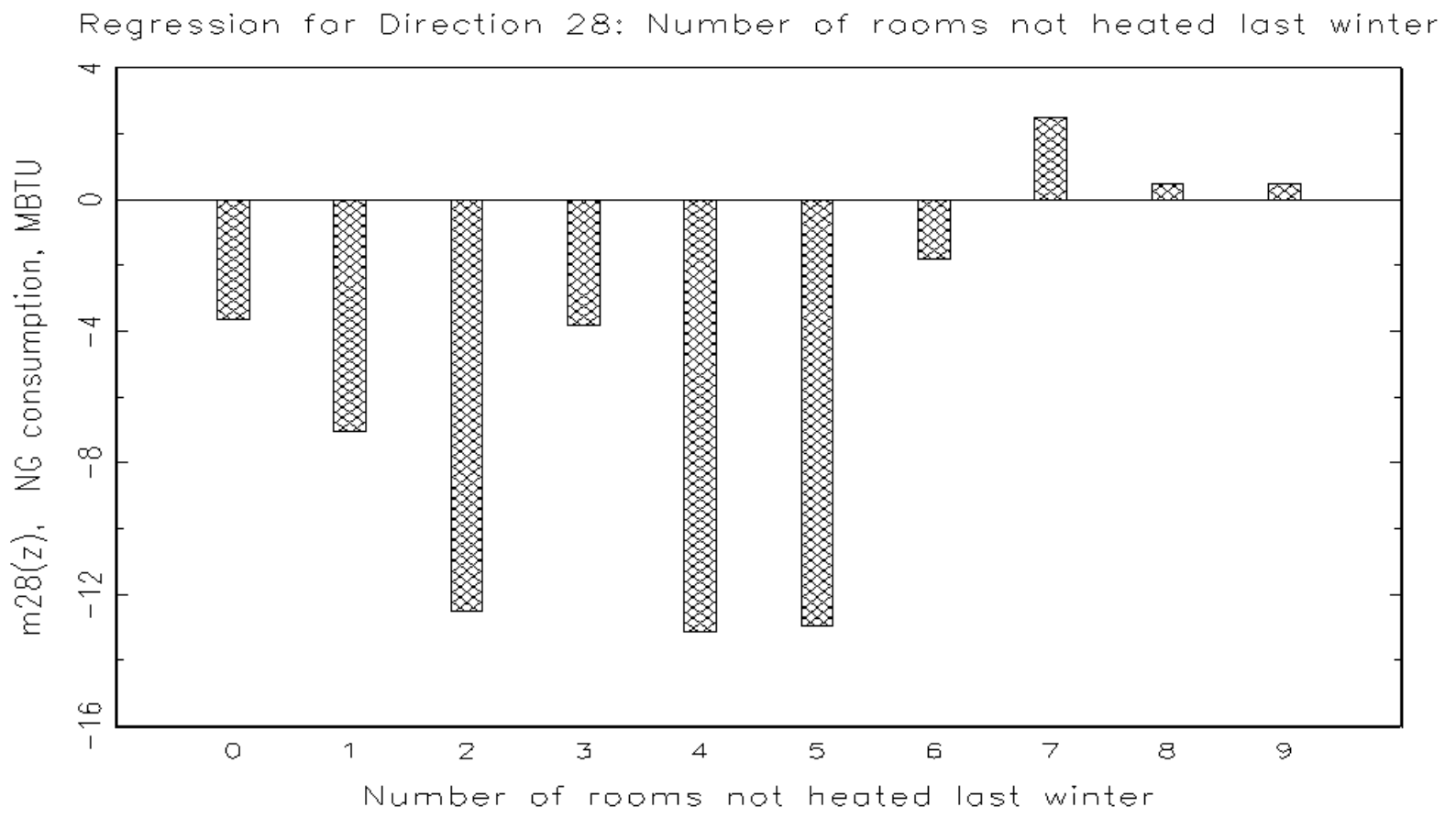

Figure 3.15. Impact of Number of Rooms Not Heated on NG Use

\subsection{Vintage}

Regression results for house vintage and NG use (Direction 26) are reasonable, and are presented in Figure 3.16. The highest NG consumption is shown for category 0 that represents houses built before 1940. NG demand decreases for the houses built in the 1940s by about $10 \mathrm{MBtu}$, which is followed by the 1950s vintage. There is an increase in the NG consumption of housing built between 1960 and 1969, up from the level shown for 1950 vintage by 5 MBtu, which may be attributable to changes in construction practices. For houses built between 1970 and 1989, the NG consumption decreases by 8 MBtu, which corresponds to improvements in thermal integrity. This trend reverses for dwellings built after 1990, which can be attributed to several factors. First and foremost, this is the period when houses with high ceilings gained popularity. In addition, this market trend was accompanied by a shift in the design away from standard rectangular houses to designs with less conventional angles and additional coves. The latter contributes to lower overall energy efficiency of the house, and the effect is reinforced by the ceiling height, leading to even more drastic efficiency loss. 


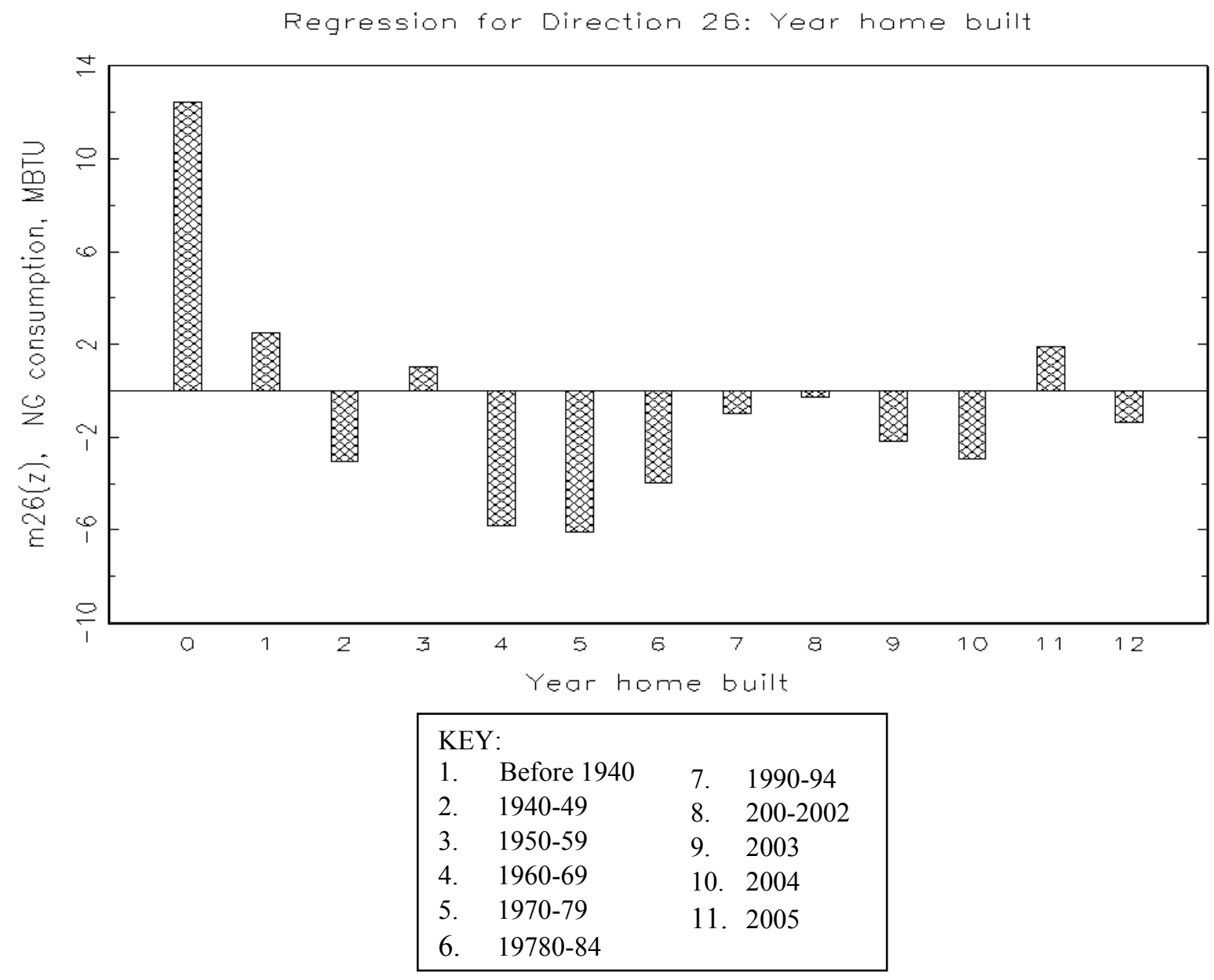

Figure 3.16. Impact of House Age on NG Usage

\subsection{Home Ownership}

Figure 3.17 (Direction 11) identifies the relationship between the NG intensity and ownership of the house. The result is reasonable because owned houses have lower energy consumption compared to rented (the middle) and occupied without payment (the highest). The difference between three categories is around $4 \mathrm{MBtu}$, with delta between the second and the third category being over $1 \mathrm{MBtu}$. This is consistent with previously documented results of the Caravan Opinion Research Corporation (ORC) 2007 surveys. These surveys showed a higher willingness to invest in the energy-saving solutions and high overall concern about the energy efficiency of the residential structure being more typical for the landlords than the renters. There is also a difference in investment decisions associated with primary dwellings versus rentals or additional houses used by relatives or friends without rent payment. 


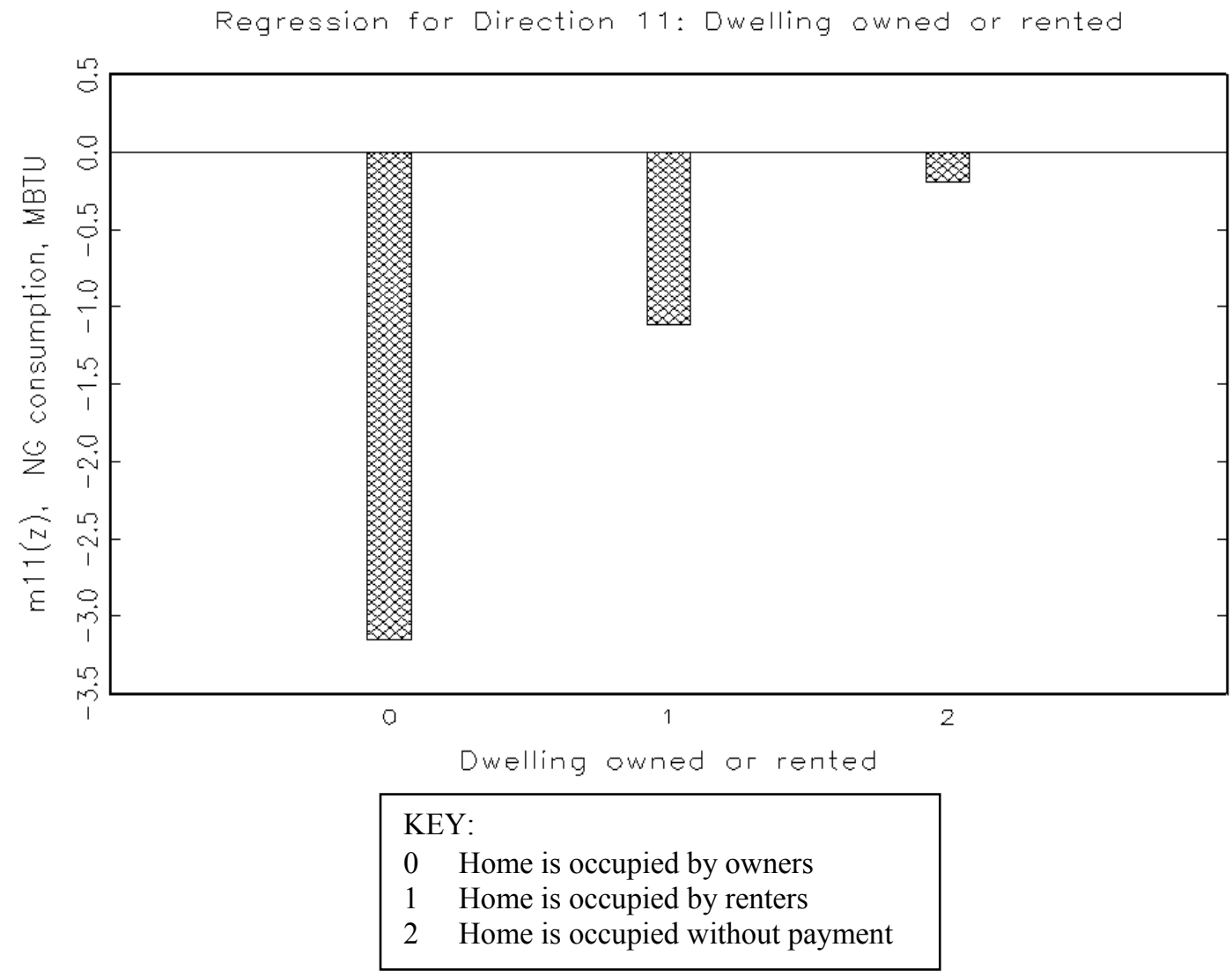

Figure 3.17. Impact of Ownership/Rental Status on NG Use

\subsection{Occupancy}

Direction 22 picks up the difference in the natural gas intensity because of someone staying at home the whole day versus the house being unoccupied during working hours. There is approximately a 1.5 MBtu delta resulting from someone reportedly occupying the house during the day. The results are shown in Appendix B. Figure 3.18 (Direction 30) describes the relationship between NG consumption and number of people living in the house. The result is reasonable considering that NG demand would likely increase with each consecutive inhabitant. The magnitude of change is also reasonable because marginal change decreases with each consecutive occupant. Gas consumption drops by 3 MBtu as the number of inhabitants grows from 5 to 7 , suggesting that results could plateau after a certain number of residents representing economies of scale in NG usage -- a reasonable result considering heating requirements would not change with each consecutive inhabitant and natural gas consumption associated with water heating, cooking and dryer use would go up at a smaller rate. 


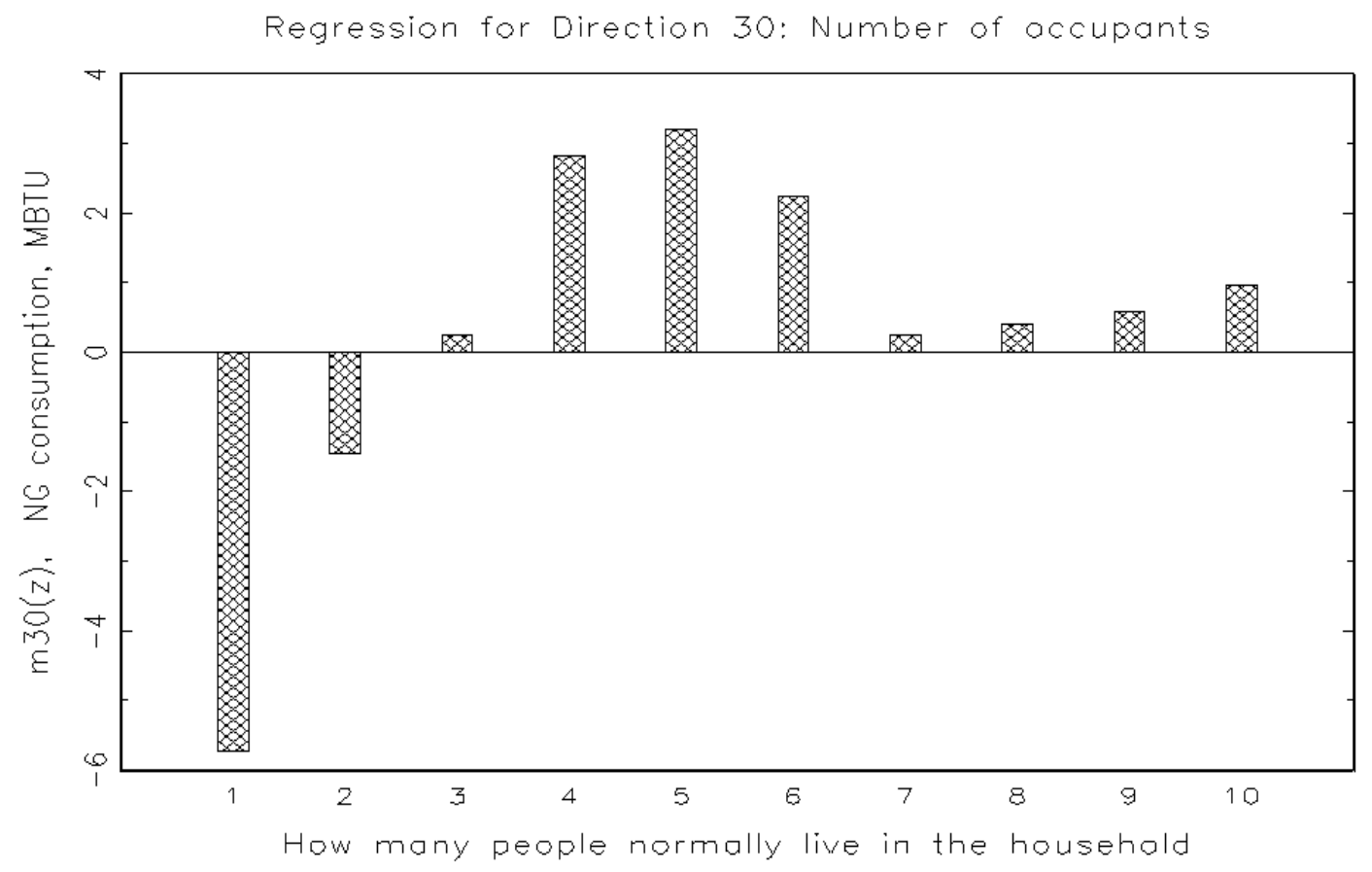

Figure 3.18. Impact of Number of Occupants on NG Use ( $0=$ none, up to 10 occupants)

\subsection{Income}

Direction 31 links the income level with the natural gas consumption of the household, and the results are shown in Figure 3.19. It can be concluded that based on the number of categories, this variable should be treated as continuous. Initially there is a slight drop in NG intensity as the income grows from less than $\$ 2500$ to approximately $\$ 25,000$. As income grows, an increase in NG consumption is observed. Categories 11 through 18 correspond to the income interval from $\$ 45,000$ to $\$ 85,000$. Income at these levels would at least be partially linked to the type of the house, quality of construction, level of insulation and types of equipment serving the household, and this would likely be another representation of the multicollinearity in the data. This increase is followed by a drop in NG consumption for income categories in excess of $\$ 85,000$. It can be attributed not only to the direct effect caused by a change in willingness to invest in the energy-efficient solutions, but also a change in level of education and environmental considerations, as well as the shift in the initial quality of occupied homes. 


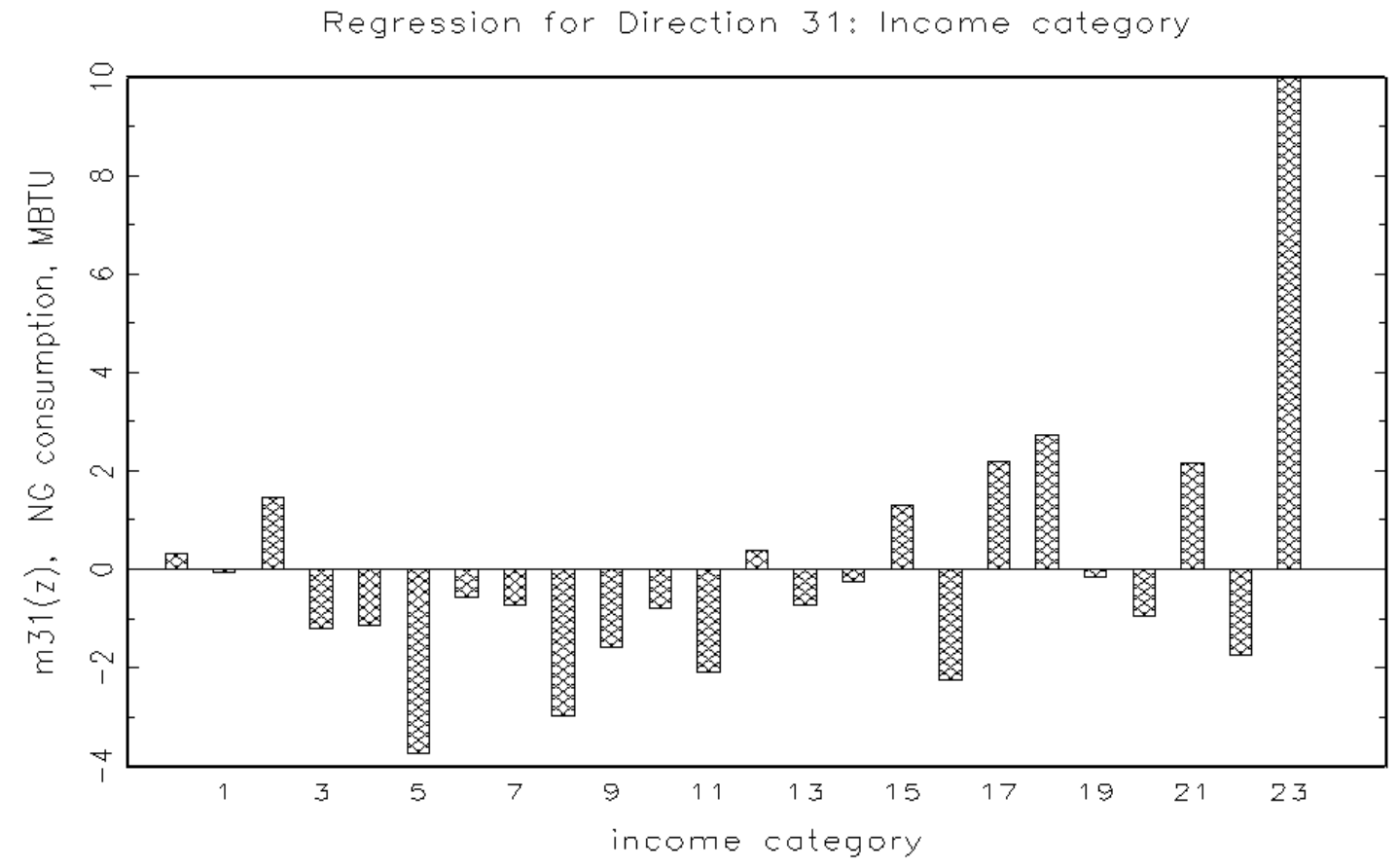

\begin{tabular}{|llllll|}
\hline \multicolumn{1}{|c}{ KEY: } & & & & \\
0 & Less than $\$ 2,500$ & 6 & $\$ 20,000$ to $\$ 24,999$ & 12 & $\$ 50,000$ to $\$ 54,999$ \\
1 & $\$ 2,500$ to $\$ 4,999$ & 7 & $\$ 25,000$ to $\$ 29,999$ & 13 & $\$ 55,000$ to $\$ 59,999$ \\
2 & $\$ 5,000$ to $\$ 7,499$ & 8 & $\$ 30,000$ to $\$ 34,999$ & 14 & $\$ 60,000$ to $\$ 64,999$ \\
3 & $\$ 7,500$ to $\$ 9,999$ & 9 & $\$ 35,000$ to $\$ 39,999$ & 15 & $\$ 65,000$ to $\$ 69,999$ \\
4 & $\$ 10,000$ to $\$ 14,999$ & 10 & $\$ 40,000$ to $\$ 44,999$ & 16 & $\$ 70,000$ to $\$ 74,999$ \\
5 & $\$ 15,000$ to $\$ 19,999$ & 11 & $\$ 45,000$ to $\$ 49,999$ & 17 & $\$ 75,000$ to $\$ 79,999$ \\
\hline
\end{tabular}

Figure 3.19. Impact of Income on NG Use 



\subsection{Conclusions}

This study employs an econometric approach to analyzing natural gas consumption intensity of residential buildings that can be used in combination with simulations for describing the impact of various household and structure attributes on energy demand. The econometric approach employed uses a local linear smooth backfitting estimator, which is extended to include categorical variables. Satisfactory results were obtained for the majority of the covariates, and the estimation technique was able to accommodate a correlated set of mixed data.

Nonparametric regression estimation revealed patterns of dependency that could not have been achieved by parametric analysis. Some of the results were suggestive of particular parametric relationships. However, these relationships were only sustained over a portion of the regressor range, because the overall result has the appearance of several superpositioned parametric associations depending on what interval of the regressor support is considered.

This analysis could be extended by combining smooth backfitting regression with stochastic frontier estimation via the method suggested by Fan, Li and Weersink (1996) and, more importantly, by using the generalized profile likelihood framework of Severini and Wong (1992). The comparison can be done across residential buildings or groups of residential buildings based on the ranked efficiency score. The regression portion of the analysis would provide the ability to interpret the efficiency scores from the energy management view point because a combination of efficiency scores along with each directional regression result allows further investigation of possible causes. This approach could also provide information on the selection of building technologies and engineering and behavioral solutions that could potentially improve the level of energy intensity of residential buildings. One of the issues with using the suggested approach is to clearly understand how a production frontier can be defined within the context of natural gas usage by residential buildings. If it was possible to isolate only the information that is related to heating, then the thermostat setting could be used as a proxy for the output. The efficiency of maintaining the dwelling at that temperature while all other inputs, attributes and characteristics vary could be compared through ranking. Clusters of houses with similar ranking would provide an insight into what primary features, behavioral characteristics, and house attributes impact the ability to maintain residential buildings at a set temperature.

The benefit of the current analysis is three-fold. The main result, which is the directional impact of each covariate, can be utilized for in-sample prediction to approximate energy demand of a residential building whose characteristics are described by the regressors used in this analysis, but a certain combination of their particular values does not exist in the real world. The only caution is that the best estimates are for the interior of the intervals, where the regressors take values. The closer the values are to the end-points of the regressor range, the less accurate the results.

The second benefit is the information on how natural gas demand might change once a particular characteristic or attribute is altered. For continuous variables, the local linear framework applied in this study produces the values of the slope at each observation as part of the estimation procedure. As far as the categorical variables are concerned, the slope estimates are not calculated as part of the procedure, but they can be easily computed by comparing change in the natural gas usage while moving from one category to another for each of the regressors. For example, results on wall construction material suggest that the natural gas consumption goes down by about $8 \mathrm{MBtu}$ for houses with composite (shingle) siding 
versus houses with vinyl siding. Properly installed stucco siding may reduce the gas consumption even further (by about $10 \mathrm{MBtu}$ ). Jointly with the cost estimates of such improvements, these results can be used as a quick tool for benefit-cost analysis of residential upgrades and retrofits under a fixed budget.

The third and the most obvious result follows along the lines of the previously discussed benefit, but with a very particular implication. It shapes the message that changing, for example, the thermostat temperature setting several degrees up or down while holding everything else fixed has a very tangible effect on natural gas usage and related household energy expenditures. Another behavioral result is the relationship between natural gas consumption and billing method. Seeing the full bill and paying it in full corresponds to the lowest energy consumption level. The consumption increases significantly if a household faces only portion of the bill, or if the full payment is included in rent and the actual consumer never sees either the amount of natural gas consumed, or associated monthly expenditures. The link is obvious, the link is measurable, and the result is produced by a nonparametric estimation procedure without imposing a particular specification on the shape of that relationship.

The primary objective of this analysis was to investigate the applicability of a particular nonparametric methodology to quantifying the impact of behavioral variables using econometric methods. Behavioral aspects of energy usage are largely treated by traditional parametric models as an unobservable effect. If good-quality microdata is available on behavioral aspects of energy usage, it is possible to extend this nonparametric analysis to a larger number of regressors and encompass the relationship between behavioral changes and energy usage at a more refined level.

\section{General Conclusion}

This study investigated the relationship between natural gas demand and characteristics of the dwelling, demographic characteristics of occupants and behavioral variables. The existing modeling literature, whether it relies on parametric specifications or engineering simulation, does not accommodate inclusion of a behavioral component. This study attempts to bridge that gap and investigate the applicability of additive nonparametric regression to this task. The results of this analysis can be used for three primary purposes. The first one is an in-sample prediction for approximating energy demand of a residential building whose characteristics are described by the regressors in this analysis, but a certain combination of their particular values does not exist in the real world. The second potential application is for benefit-cost analysis of residential upgrades and retrofits under a fixed budget, because the results of this study contain information on how natural gas consumption might change once a particular characteristic or attribute is altered. The third purpose is to establish a relationship between natural gas consumption and changes in behavior of occupants. Although information on behavioral variables is generally limited, results of the analysis identify what information would be helpful to further research. 


\subsection{References}

Baker, P., R. W. Blundell and J. Micklewright. 1989. Modelling household energy expenditures using micro-data. Economic Journal 99, 720-738.

Caravan Opinion Research Corporation, 2007. Study \#716287.

Crawley, Drury B, Linda K Lawrie, Curtis O Pedersen, Frederick C Winkelmann, Michael J Witte, Richard K Strand, Richard J Liesen, Walter F Buhl, Yu Joe Huang, Robert H Henninger, Jason Glazer, Daniel E Fisher, Don B Shirey III, Brent T Griffith, Peter G Ellis and Lixing Gu. 2004. Energy Plus: New, Capable, and Linked. Journal of Architectural and Planning Research 21, 4 (Winter 2004).

DOE-2, 1993. BDL Summary Version 2.1E. LBNL, 34946, Lawrence Berkeley National Laboratory, Berkeley, CA

Fan, Y., Q. Li, and A. Weersink. 1996. Semiparametric estimation of stochastic production frontier models. Journal of Business and Economic Statistics 14, 460-468.

García-Cerruti, L. 2000. Estimating elasticities of residential energy demand from panel county data using dynamic random variables models with heteroskedastic and correlated error terms. Resource and Energy Economics 22, 355-366.

Halvorsen, B. and B. Larsen. 2001. The flexibility of household electricity demand over time. Resource and Energy Economics 23, 1-18.

Holtedahl, P. and F. Joutz. 2004. Residential electricity demand in Taiwan. Energy Economics 26, 201224.

Kamerschen, D. and D. Porter. 2004. The demand for residential, industrial and total electricity, 19731998. Energy Economics 26, 87-100.

Larsen, B. and R. Nesbakken. 2004. Household electricity end-use consumption: results from econometric and engineering models. Energy Economics 26, 179-200.

Lutzenhiser, L. 1993. Social and behavioral aspects of energy use. Annual Review of Energy Economics 18, 247-89.

Madlener, R. 1996. Econometric analysis of residential energy demand: a survey. Journal of Energy Literature 2, 3-32.

Mammen, E., O. Linton, and J. P. Nielsen. 1999. The existence and asymptotic properties of a backfitting projection algorithm under weak conditions. Annals of Statistics 27, 1443--1490.

Narayan, P. and R. Smyth. 2005. The residential demand for electricity in Australia: an application of the bounds testing approach to cointegration. Energy Policy 33, 467-474. 
Nesbakken, R. 2001. Energy consumption for space heating: discrete-continuous approach.

Scandinavian Journal of Economics 103, 165-184.

Nielsen J.P. and S.Sperlich. 2005. Smooth backfitting in practice. Journal of the Royal Statistical Society: Series B (Statistical Methodology) 67, 43-61.

Racine, J. S. and Q. Li. 2004. Nonparametric estimation of regression functions with both categorical and continuous data. Journal of Econometrics 119, 99-130.

Racine, J.S., Q. Li., and X. Zhu. 2004. Kernel estimation of multivariate conditional distributions. Annals of Economics and Finance 5, 211-235.

Schmalensee, R. and T. M. Stoker. 1999. Household gasoline demand in the United States. Econometrica 67, 645-662.

Severini T.A., W.H. Wong, Pro.le Likelihood and Conditionally Parametric Models Annals of Statistics, Vol. 20, No. 4 (Dec., 1992), pp.1768-1802

U.S. Department of Energy. 2005. ENERGY PLUS, Input Output Reference, Washington, D.C.

U.S. Department of Energy. 2009. Energy Information Administration (DOE/EIA). Annual energy outlook 2009 with projections to 2030. DOE/EIA-0383 (2009). Washington, D.C.

U.S. Department of Energy. 2009. Energy Information Administration (DOE/EIA). Residential Energy Consumption Survey 2005, Washington D.C.

Yatchew, A. and J. No. 2001. Household gasoline demand in Canada. Econometrica 69, 1697-1709. 
Appendix A

\section{Detailed Methodology}





\section{Appendix A}

\section{Detailed Methodology}

\section{A.1 Smooth backfitting for continuous data}

The regression model considered here is of the following form:

$$
E\left(Y \mid X_{1}=x_{1}, \ldots, X_{d}=x_{d}\right)=m_{0}+\sum_{j=1}^{d} m_{j}\left(x_{j}\right)
$$

where $\left(Y, X_{1}, \ldots, X_{d}\right)$ is a random vector in $\mathbb{R}^{d+1}$ and we assume that there is a random sample $\left\{y_{i}, x_{i 1} \ldots, x_{i d}\right\}_{i=1}^{n}$ of $\left(Y, X_{1} \ldots, X_{d}\right), m_{0}$ is an unknown scalar parameter, $m_{j}\left(x_{j}\right)$ is a sufficiently smooth function for all $j$, and $\theta_{j}$ is the first order derivative of $m_{j}\left(x_{j}\right)$. Also, for identification purposes, $E\left(m_{j}\left(x_{j}\right)\right)=0$.

Let $K_{h}\left(x_{i j}-x_{j}\right)=\frac{1}{h} K\left(\frac{x_{i j}-x_{j}}{h}\right)$ be a kernel function such that $\int K(\phi) d \phi=1, \int \phi K(\phi) d \phi=$ $0, \int \phi^{2} K(\phi) d \phi=1$. Bandwidth is defined as $h=h(n)$ such that $h \rightarrow 0$ and $n h \rightarrow \infty$ as $n \rightarrow \infty$, and conditions B(1), B(2')-B(4') of Mammen et al. (1999) are met. The backfitting estimator is obtained by minimizing the following objective function

$$
\int \sum_{i=1}^{n}\left[y_{i}-m_{0}-\sum_{j=1}^{d} m_{j}\left(x_{j}\right)-\sum_{j=1}^{d} \theta_{j}\left(x_{j}\right)\left(x_{i j}-x_{j}\right)\right]^{2} \times \prod_{j=1}^{d} K_{h}\left(x_{i j}-x_{j}\right) d x
$$

The minimization is done with respect to $m_{0}, m_{1} \ldots m_{d}$ and all first derivatives $\theta_{j}\left(x_{j}\right)$.

Let

$$
\begin{aligned}
& \widehat{p}_{j}\left(x_{j}\right)=n^{-1} \sum_{i=1}^{n} K_{h}\left(x_{i j}-x_{j}\right), \hat{p}_{j}^{j}\left(x_{j}\right)=n^{-1} \sum_{i=1}^{n} K_{h}\left(x_{i j}-x_{j}\right)\left(x_{i j}-x_{j}\right), \\
& \widehat{p}_{j}^{j j}\left(x_{j}\right)=n^{-1} \sum_{i=1}^{n} K_{h}\left(x_{i j}-x_{j}\right)\left(x_{i j}-x_{j}\right)\left(x_{i j}-x_{j}\right), \\
& \widehat{p}_{j k}\left(x_{j}, x_{k}\right)=n^{-1} \sum_{i=1}^{n} K_{h}\left(x_{i j}-x_{j}\right) K_{h}\left(x_{i k}-x_{k}\right), \\
& \widehat{p}_{j k}^{k}\left(x_{j}, x_{k}\right)=n^{-1} \sum_{i=1}^{n} K_{h}\left(x_{i j}-x_{j}\right) K_{h}\left(x_{i k}-x_{k}\right)\left(x_{i k}-x_{k}\right), \\
& \widehat{p}_{j k}^{j k}\left(x_{j}, x_{k}\right)=n^{-1} \sum_{i=1}^{n} K_{h}\left(x_{i j}-x_{j}\right) K_{h}\left(x_{i k}-x_{k}\right)\left(x_{i j}-x_{j}\right)\left(x_{i k}-x_{k}\right),
\end{aligned}
$$


Let

$$
\begin{aligned}
& A= \frac{n^{-1} \sum_{i=1}^{n} K_{h}\left(x_{i j}-x_{j}\right) y_{i}}{\widehat{p}_{j}\left(x_{j}\right)}-\sum_{k \neq j}^{d} \int \widetilde{m}_{k}\left(x_{k}\right) \frac{\widehat{p}_{j k}\left(x_{j}, x_{k}\right)}{\widehat{p}_{j}\left(x_{j}\right)} d x_{k} \\
&-\sum_{k \neq j}^{d} \int \widetilde{\theta}_{k}\left(x_{k}\right) \frac{\widehat{p}_{j k}^{k}\left(x_{j}, x_{k}\right)}{\widehat{p}_{j}\left(x_{j}\right)} d x_{k}-\widetilde{m_{0}}\left(x_{j}\right), \\
& B= \frac{n^{-1} \sum_{i=1}^{n} K_{h}\left(x_{i j}-x_{j}\right)\left(x_{j}-X_{i j}\right) y_{i}}{\widehat{p}_{j}^{j}\left(x_{j}\right)}-\sum_{k \neq j}^{d} \int \widetilde{m_{k}}\left(x_{k}\right) \frac{\widehat{p}_{j k}^{j}\left(x_{j}, x_{k}\right)}{\widehat{p}_{j}^{j}\left(x_{j}\right)} d x_{k} \\
&-\sum_{k \neq j}^{d} \int \widetilde{\theta_{k}}\left(x_{k}\right) \frac{\widehat{p}_{j k}^{j k}\left(x_{j}, x_{k}\right)}{\widehat{p}_{j}^{j}\left(x_{j}\right)} d x_{k}-\widetilde{m_{0}}(x) \\
& C=\frac{\widehat{p}_{j}^{j}\left(x_{j}\right)}{\widehat{p}_{j}\left(x_{j}\right)}, \quad D=\frac{\widehat{p}_{j}^{j j}\left(x_{j}\right)}{\widehat{p}_{j}^{j}\left(x_{j}\right)}
\end{aligned}
$$

The smooth backfitting estimates of $\widetilde{m_{0}}, \widetilde{m_{j}}$ and $\widetilde{\theta_{j}}$ are obtained by iteratively solving the two equations below for each regressor $j=1, \ldots, d$

$$
\widetilde{m_{j}}\left(x_{j}\right)=A-\widetilde{\theta_{j}}\left(x_{j}\right) C, \quad \widetilde{\theta_{j}}\left(x_{j}\right)=\frac{A-B}{C-D}
$$

As a consequence of imposing normalization condition, $\widetilde{m_{0}}=n^{-1} \sum_{i=1}^{n} y_{i}$.

A detailed discussion establishing the asymptotic properties of the smooth backfitting estimator for the case of only continuous regressors is presented in Mammen et al. (1999). Their final result is summarized as the convergence in distribution that holds for any $x_{1}, \ldots x_{d}$ with compact support:

$$
\begin{gathered}
n^{2 / 5}\left(\begin{array}{c}
\widetilde{m}_{1}\left(x_{1}\right)-m_{1}\left(x_{1}\right)+v_{n, 1} \\
\vdots \\
\widetilde{m}_{d}\left(x_{d}\right)-m_{d}\left(x_{d}\right)+v_{n, d}
\end{array}\right) \stackrel{d}{\longrightarrow} N\left[\left(\begin{array}{c}
c_{h}^{2} \delta_{1}\left(x_{1}\right) \\
\vdots \\
c_{h}^{2} \delta_{d}\left(x_{d}\right)
\end{array}\right), \operatorname{diag}\left\{v_{j}\left(x_{j}\right)\right\}_{j=1}^{d}\right], \\
\delta_{j}\left(x_{j}\right)=\frac{\int u^{2} K(u) d u}{2}\left\{m_{j}^{\prime \prime}\left(x_{j}\right)-\int m_{j}^{\prime \prime}\left(x_{j}\right) p_{j}\left(x_{j}\right) d x_{j}\right\}, \\
v_{n, j}=\int m_{j}\left(x_{j}\right) K_{h}\left(x_{j}-u\right) p_{j}(u) d u d x_{j}, \\
v_{j}\left(x_{j}\right)=c_{h}^{-1} c_{k} \sigma_{j}^{2}\left(x_{j}\right) / p_{j}\left(x_{j}\right),
\end{gathered}
$$

with $c_{k}=\int K(u)^{2} d u, c_{h}$ is a constant such that $n^{1 / 5} h \rightarrow c_{h}$. Second derivative of $m_{j}\left(x_{j}\right)$ is 
represented by $m_{j}^{\prime \prime}\left(x_{j}\right), \quad p_{j}(u)$ is the marginal density, and $\sigma_{j}^{2}\left(x_{j}\right)=\operatorname{var}\left[Y-m(x) \mid X_{j}=x_{j}\right]$ can be consistently estimated from the residuals $\widetilde{\varepsilon}_{i}=y_{i}-\widetilde{m}\left(x_{i}\right), i=1 \ldots n$.

$$
n^{2 / 5}(\widetilde{m}(x)-m(x)) \stackrel{d}{\longrightarrow} N\left\{c_{h}^{2} \sum_{j=1}^{d} \delta_{j}\left(x_{j}\right), \sum_{j=1}^{d} v_{j}\left(x_{j}\right)\right\},
$$

where $\widetilde{m}(x)$ is a smooth backfitting estimator of $m(x)=m_{0}+\sum_{j=1}^{d} m_{j}\left(x_{j}\right)$ defined as $\widetilde{m}(x)=$ $\widetilde{m_{0}}+\sum_{j=1}^{d} \widetilde{m_{j}}\left(x_{j}\right)$

\section{A.2 Smooth backfitting estimator for mixed data}

In a wide variety of applications, especially dealing with microdata, one of the essential features of a regression estimator is its capability to accommodate continuous and categorical conditioning variables. Traditional approaches for estimating the categorical components have relied either on introducing these variables parametrically or implementing a frequency-based estimation. The major drawback of the first approach is a loss of flexibility induced by a fully nonparametric framework, as well as high likelihood of misspecification. The weakness of the second method stems from the requirement to divide the data into cells corresponding to the values taken by the discrete variables. This necessitates fairly large sample size in order for each cell to contain a reasonable amount of data as described in Li and Racine (2007).

Alternative procedures, such as smooth estimation of joint distributions and smooth regression for discrete data, are based on kernel estimation proposed by Aitchison and Aitken (1976). This latter method received attention in the recent literature as kernel smoothing methods have been gaining popularity. Li and Racine (2003) proposed a refined nonparametric kernel approach for estimating an unknown distribution defined over mixed discrete and continuous variables. Nonparametric estimation of regression functions was investigated by Racine and Li (2004), where specific smoothing techniques were considered for treatment of ordered and unordered categorical data. Structure of the proposed estimator is similar to that of Nadaraya-Watson local constant estimator, but with a different kernel employed for smoothing discrete variables. Li and Racine (2004) expanded the regression framework further by constructing a local linear nonparametric estimator for mixed data and investigating the theoretical properties of cross-validated bandwidth selection. In addition, they derived the rate of convergence of the cross-validated bandwidths and established asymptotic normality of the resulting nonparametric regression estimator. These results provide a foundation for incorporating categorical regressors into the local linear smooth backfitting estimator (SBE) and using least squares cross-validation to select bandwidth for both continuous and categorical regressors. 
Let $x_{j}, j=1, \ldots, d$, denote continuous regressors and $x_{t}, t=1, \ldots T$ denote the categorical variables. Discrete $x_{i t}, i=1, \ldots n$, takes values $\left\{0,1,2, \ldots, c_{t}-1\right\}$. For the local linear regression estimator Li and Racine (2004) propose using a variation of the Aitchison and Aitken (1976) kernel defined as

$$
L\left(x_{i t}, x_{t}, \lambda_{t}\right)=\left\{\begin{array}{c}
1, \text { if } x_{i t}=x_{t} \\
\lambda_{t}, \text { if } x_{i t} \neq x_{t}
\end{array} \quad t=1, \ldots T .\right.
$$

This weight function does not add up to one, which cannot support the interpretation of marginal density $p_{t}\left(x_{t}\right)$ estimated by $\widehat{p}_{t}\left(x_{t}\right)=n^{-1} \sum_{i=1}^{n} L\left(x_{i t}, x_{t}, \lambda_{t}\right)$ as a proper density. It has been shown by $\mathrm{Li}$ and Racine (2004) that it is not the kernel shape, but rather the selection of the bandwidth parameter that has critical impact on the quality of resulting estimates. Therefore, to accommodate interpretation of weighting functions in smooth backfitting estimation as densities, another option is to use the kernel shape suggested by Aitchison and Aitken (1976) for the distribution estimation, namely

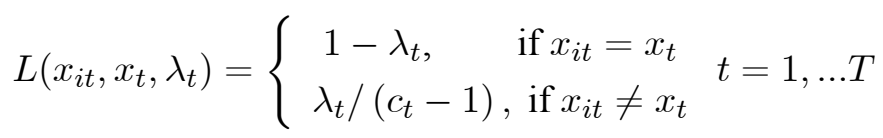

for unordered categorical regressors. The range of $\lambda_{t}$ is $\left[0,\left(c_{t}-1\right) / c_{t}\right]$. This weight function adds up to one. When $\lambda_{t}$ assumes its upper value of $\left(c_{t}-1\right) / c_{t}$, the kernel becomes $L\left(x_{i t}, x_{t}, \lambda_{t}\right)=$ $1 / c_{t}$ regardless of whether $X_{i t}=x_{t}$ or not. The resulting density estimator becomes unrelated to $x_{t}$ thus smoothing it out. Alternatively, it is possible to use the weighting function that does not add up to one along with the normalization $p=p_{t}\left(x_{t}\right) / \sum p_{t}\left(x_{t}\right)$. For ordered categorical variable $x_{t}$ the kernel of Li and Racine (2004)

$$
L\left(x_{i t}, x_{t}, \lambda_{t}\right)=\left\{\begin{array}{c}
1, \quad \text { if } x_{i t}=x_{t} \\
\lambda_{t}\left|x_{i t}-x_{t}\right|, \text { if } x_{i t} \neq x_{t}
\end{array}\right.
$$

is utilized along with the above-mentioned normalization. The range of $\lambda_{t}$ for ordered variables is $[0,1]$. If $\lambda_{t}$ takes its upper value the kernel becomes a uniform weight function. If $\lambda_{t}=0$, the kernel turns into an indicator function. An alternative is to use the kernel

$$
L\left(x_{i t}, x_{t}, \lambda_{t}\right)=\left\{\begin{array}{c}
1-\lambda_{t}, \quad \text { if }\left|x_{i t}-x_{t}\right|=0 \\
\frac{1-\lambda_{t}}{2} \lambda_{t}\left|x_{i t}-x_{t}\right|, \quad \text { if }\left|x_{i t}-x_{t}\right| \geq 1
\end{array},\right.
$$

where $x_{t}$ is a categorical variable and $x_{i t}, i=1, \ldots n$, takes values $\left\{0,1,2, \ldots, c_{t}-1\right\}$, as proposed by Wang and van Ryzin (1981).

The multivariate discrete data kernel is defined as $\prod_{t=1}^{T} L\left(x_{i t}, x_{t}, \lambda_{t}\right)$, with joint density of discrete variables being estimated by $\widehat{p}\left(x_{1}, \ldots x_{T}\right)=n^{-1} \sum_{i=1}^{n} \prod_{t=1}^{T} L\left(x_{i t}, x_{t}, \lambda_{t}\right)$. The multivariate kernel for 
mixed data is

$$
W\left(x_{i j}, x_{j}, h, x_{i t}, x_{t}, \lambda_{t}\right)=\sum_{i=1}^{n} \prod_{j=1}^{d} K_{h}\left(x_{i j}-x_{j}\right) \prod_{t=1}^{T} L\left(x_{i t}, x_{t}, \lambda_{t}\right) .
$$

The local linear estimator for continuous and discrete data suggested by Li and Racine (2004) has the following structure:

$$
\begin{aligned}
\widehat{s}(x)= & {\left[\begin{array}{c}
\widehat{m}(x) \\
\widehat{\theta}(x)
\end{array}\right]=\left[\sum_{i=1}^{n} W\left(x_{i j}, x_{j}, h, x_{i t}, x_{t}, \lambda_{t}\right)\left(\begin{array}{cc}
1 & \left(x_{i j}-x_{j}\right) \\
\left(x_{i j}-x_{j}\right) & \left(x_{i j}-x_{j}\right)^{2}
\end{array}\right)\right]^{-1} } \\
& \times \sum_{i=1}^{n} W\left(x_{i j}, x_{j}, h, x_{i t}, x_{t}, \lambda_{t}\right)\left(\begin{array}{c}
1 \\
\left(x_{i j}-x_{j}\right)
\end{array}\right) y_{i},
\end{aligned}
$$

where $s(x)=\left(m(x), \theta(x)^{\prime}\right)^{\prime}, \theta(x)=\nabla \theta(x)=\left[\partial m(x) / \partial x_{1}, \ldots . \partial m(x) / \partial x_{d}\right]^{\prime}$. The partial derivative is taken only with respect to continuous variables. This estimator has the local constant shape for the discrete variables and local linear shape for the continuous variables.

The local linear smooth backfitting estimator for mixed continuous and categorical data is a projection of the local linear estimator for mixed regressors onto the space of additive functions. The mixed data local linear smooth backfitting estimator $\widetilde{m}^{*}(x)$ is defined as the argument that minimizes the following objective function

$$
\begin{aligned}
& \int \sum_{i=1}^{n}\left[y_{i}-m_{0}-\sum_{j=1}^{d} m_{j}\left(x_{j}\right)-\sum_{t=1}^{T} m_{t}\left(x_{t}\right)-\sum_{j=1}^{d} \theta_{j}\left(x_{i j}-x_{j}\right)\right]^{2} \\
& \times \prod_{j=1}^{d} K_{h}\left(x_{i j}-x_{j}\right) \prod_{t=1}^{T} L\left(x_{i t}, x_{t}, \lambda_{t}\right) d x
\end{aligned}
$$

where the categorical regressors are indexed by t. Derivation of the first order conditions for this setting follows the same logic as for the continuous regressors, where the minimization is performed over $m_{0}, m_{j}\left(x_{j}\right)$ and $m_{t}\left(x_{t}\right)$ while preserving mean zero restriction, and over $\theta_{j}\left(x_{j}\right)$ for the continuous components only.

Using similar notation as before 


$$
\begin{aligned}
& \widetilde{m_{j}}\left(x_{j}\right)=\frac{n^{-1} \sum_{i=1}^{n} K_{h}\left(x_{i j}-x_{j}\right) y_{i}}{\widehat{p}_{j}\left(x_{j}\right)}-\sum_{k \neq j}^{d} \int \widetilde{m_{k}}\left(x_{k}\right) \frac{\widehat{p}_{j k}\left(x_{j}, x_{k}\right)}{\widehat{p}_{j}\left(x_{j}\right)} d x_{k} \\
& -\sum_{t=1}^{T} \int \widetilde{m_{t}}\left(x_{t}\right) \frac{\widehat{p}_{j t}\left(x_{j}, x_{t}\right)}{\widehat{p}_{j}\left(x_{j}\right)} d x_{t}-\sum_{k \neq j}^{d} \int \widetilde{\theta_{k}}\left(x_{k}\right) \frac{\widehat{p}_{j k}^{k}\left(x_{j}, x_{k}\right)}{\widehat{p}_{j}\left(x_{j}\right)} d x_{k} \\
& -\widetilde{m_{0}}(x)-\tilde{\theta}_{j}\left(x_{j}\right) \frac{\widehat{p}_{j}^{j}\left(x_{j}\right)}{\widehat{p}_{j}\left(x_{j}\right)}, \\
& \widetilde{m_{j}}\left(x_{j}\right)=\frac{n^{-1} \sum_{i=1}^{n} K_{h}\left(x_{i j}-x_{j}\right)\left(x_{i j}-x_{j}\right) y_{i}}{\widehat{p}_{j}^{j}\left(x_{j}\right)}-\sum_{k \neq j}^{d} \int \widetilde{m_{k}}\left(x_{k}\right) \frac{\widehat{p}_{j k}^{j}\left(x_{j}, x_{k}\right)}{\widehat{p}_{j}^{j}\left(x_{j}\right)} d x_{k} \\
& -\sum_{t=1}^{T} \int \widetilde{m_{t}}\left(x_{t}\right) \frac{\widehat{p}_{j t}^{j}\left(x_{j}, x_{t}\right)}{\widehat{p}_{j}^{j}\left(x_{j}\right)} d x_{t}-\sum_{k \neq j}^{d} \int \widetilde{\theta_{k}}\left(x_{k}\right) \frac{\widehat{p}_{j k}^{j k}\left(x_{j}, x_{k}\right)}{\widehat{p}_{j}^{j}\left(x_{j}\right)} d x_{k} \\
& -\widetilde{m_{0}}(x)-\widetilde{\theta_{j}}\left(x_{j}\right) \frac{\widehat{p}_{j}^{j j}\left(x_{j}\right)}{\widehat{p}_{j}^{j}\left(x_{j}\right)},
\end{aligned}
$$

where $\widetilde{m_{0}}(x)$ is the same as in continuous SBE setting. The iterative equations are shown below:

$$
\begin{aligned}
\widetilde{m_{j}^{*}}\left(x_{j}\right) & =A-\sum_{t \neq j}^{T} \int \widetilde{m_{t}}\left(x_{t}\right) \frac{\widehat{p}_{j t}\left(x_{j}, x_{t}\right)}{\widehat{p}_{j}\left(x_{j}\right)} d x_{t}-\widetilde{\theta_{j}^{*}}\left(x_{j}\right) C \\
& =A^{*}-\widetilde{\theta_{j}^{*}}\left(x_{j}\right) C \\
\widetilde{m_{j}^{*}}\left(x_{j}\right) & =B-\sum_{t \neq j}^{T} \int \widetilde{m_{t}}\left(x_{t}\right) \frac{\widehat{p}_{j t}^{j}\left(x_{j}, x_{t}\right)}{\widehat{p}_{j}^{j}\left(x_{j}\right)} d x_{t}-\widetilde{\theta}_{j}^{*}\left(x_{j}\right) D \\
& =B^{*}-\widetilde{\theta_{j}^{*}}\left(x_{j}\right) D \\
\widetilde{\theta_{j}^{*}}\left(x_{j}\right) & =\frac{A^{*}-B^{*}}{C-D} .
\end{aligned}
$$


Iterative equation for discrete regressors $x_{t}, t=1, \ldots, T$ is

$$
\begin{aligned}
\widetilde{m_{t}^{*}}\left(x_{t}\right)= & \frac{\sum_{i=1}^{n} L\left(x_{i t}, x_{t}, \lambda_{t}\right) y_{i}}{\widehat{p}_{t}\left(x_{t}\right)}-\sum_{j=1}^{d} \int \widetilde{m_{j}}\left(x_{j}\right) \frac{\widehat{p}_{j t}\left(x_{j}, x_{t}\right)}{\widehat{p}_{t}\left(x_{t}\right)} d x_{j}-\widetilde{m_{0}}(x) \\
& -\sum_{k \neq t}^{T} \int \widetilde{m_{k}}\left(x_{k}\right) \frac{\widehat{p}_{k t}\left(x_{k}, x_{t}\right)}{\widehat{p}_{t}\left(x_{t}\right)} d x_{k}-\sum_{j=1}^{d} \int \widetilde{\theta_{j}}\left(x_{j}\right) \frac{\widehat{p}_{j t}^{j}\left(x_{j}, x_{t}\right)}{\widehat{p}_{t}\left(x_{t}\right)} d x_{j} .
\end{aligned}
$$

The last four equations jointly with the zero-mean condition describe the solution. Analogously to the continuous regressor densities

$$
\begin{aligned}
& \widehat{p}_{t}\left(x_{t}\right)=n^{-1} \sum_{i=1}^{n} L\left(x_{i t}, x_{t}, \lambda_{t}\right), \\
& \widehat{p}_{j t}\left(x_{j}, x_{t}\right)=n^{-1} \sum_{i=1}^{n} K_{h}\left(x_{i j}-x_{j}\right) L\left(x_{i t}, x_{t}, \lambda_{t}\right), \\
& \hat{p}_{j t}^{j}\left(x_{j}, x_{t}\right)=n^{-1} \sum_{i=1}^{n} K_{h}\left(x_{i j}-x_{j}\right) L\left(x_{i t}, x_{t}, \lambda_{t}\right)\left(x_{i j}-x_{j}\right) .
\end{aligned}
$$

The algorithm for computation is as follows:

1. Compute the univariate $\widehat{p}_{j}\left(x_{j}\right), \widehat{p}_{t}\left(x_{t}\right)$ for all regressors $x_{j}$ and $x_{t}, j=1, \ldots d$, and $t=1, \ldots T$; compute $\widehat{p}_{j}^{j}\left(x_{j}\right), \widehat{p}_{j}^{j j}\left(x_{j}\right)$ only for continuous components. Compute bivariate densities.

2. Compute univariate unrestricted $\widehat{m}_{t}\left(x_{t}\right)=\left(\sum_{i=1}^{n} L\left(x_{i t}, x_{t}, \lambda_{t}\right) y_{i}\right) / \widehat{p}_{t}\left(x_{t}\right)$ for all discrete variables and pairs $\left(\widehat{m}_{j}\left(x_{j}\right), \widehat{\theta}_{j}\left(x_{j}\right)\right)$ for all continuous data. Save the results as variables $m_{\text {old }}$ and $\theta_{\text {old }}$.

3. Set the number of smooth backfitting iteration iter to 1 .

(a) For $j=1$ compute expressions $\mathrm{A}^{*}, \mathrm{~B}^{*}, \mathrm{C}, \mathrm{D}$. Obtain $\widetilde{m_{j}^{*}}\left(x_{j}\right)$ and $\widetilde{\theta_{j}^{*}}\left(x_{j}\right)$, save as $m_{\text {new }}$ and $\theta_{\text {new }}$. Repeat this step for the rest of continuous variables $j=2, \ldots d$. To compute expressions $\mathrm{A}^{*}$ and $\mathrm{B}^{*}$, use updated values from $m_{\text {new }}$ and $\theta_{\text {new }}$ for $k<j$. If $k>j$, use corresponding values from $m_{\text {old }}$ and $\theta_{\text {old }}$.

(b) Perform computation for discrete variables in a similar manner, with the conditional mean of categorical $x_{k}$ in A being taken only over unique categories of $x_{k}$.

4. Define a convergence criteria for all $j$ as $\frac{\sum_{i=1}^{n}\left[\widetilde{m_{j}^{\text {new }}}\left(x_{j}\right)-\widetilde{m_{j}^{\text {old }}}\left(x_{j}\right)\right]^{2}}{\sum_{i=1}^{n}\left[\widetilde{m_{j}^{\text {old }}}\left(x_{j}\right)\right]^{2}+\epsilon}<\epsilon$.

5. Set iter $=$ iter +1 , Set $m_{\text {old }}=m_{\text {new }}$ and $\theta_{\text {old }}=\theta_{\text {new }}$, then go to step 3a. Iterate steps 3a through 5 until the convergence criteria is met. 
If $\int \widehat{p_{j, k}^{j, k}}\left(x_{j}, x_{k}\right) d x_{k}=\widehat{p_{j, k}^{j}}\left(x_{j}\right)$ does not hold, it is necessary to include the norming for $\widetilde{m_{j}^{*}}\left(x_{j}\right)$ such that $\widetilde{m_{j}^{*, n}}\left(x_{j}\right)=\widetilde{m_{j}^{*}}\left(x_{j}\right)-\int \widetilde{m_{j}^{*}}\left(x_{j}\right) \widehat{p}_{j}\left(x_{j}\right) d x_{j}$ after every iterative step for each $j=1, \ldots T$. When the value of overall sum $m_{0}+\sum_{j=1}^{d} m_{j}\left(x_{j}\right)+\sum_{t=1}^{T} m_{t}\left(x_{t}\right)$ is the primary point of interest, this normalization could be omitted as suggested in Mammen et al. (1999).

\section{A.3 Bandwidth selection}

Several different methods for selecting bandwidths for SBE estimation were analyzed recently. Mammen and Park (2005) introduced a bandwidth selection method for smooth backfitting based on minimizing penalized sum of squares residuals. They also compared two additional plug-in methods for local linear SBE. It was suggested that the penalized sum of squared residuals was asymptotically equivalent to cross-validation because this holds true for the classical nonparametric regression, as in Hardle et al. (1988).

Leave-one-out least squares cross-validation is recommended for bandwidth selection by Nielsen and Sperlich (2005). It has an implementation advantage for local linear smooth backfitting if the underlying relationship is additive. In this case, the cross-validation procedure can be simplified because the SB estimator has additively separable bias and variance. Bandwidth selection is based on minimizing mean-integrated squared error $M S E\left(h_{1}, \ldots h_{d}, \lambda_{1}, \ldots \lambda_{d}\right)=\int E[\widetilde{m}(x)-m(x)]^{2} p(x) d x$. Because of separability of bias and variance, the mean-integrated squared error for overall regression can be defined as

$$
M S E\left(h_{1}, \ldots h_{d}, \lambda_{1}, \ldots \lambda_{d}\right)=\sum_{j=1}^{d+T} M S E_{j}\left(x_{j}\right),
$$

where $M S E_{j}\left(x_{j}\right)$ is mean-integrated squared error for each regression direction $m_{j}\left(x_{j}\right)$. Thus, the cross-validation problem of minimizing $C V=\sum_{i=1}^{n}\left[y_{i}-\widetilde{m}^{-i}(x)\right]^{2}$, where $\widetilde{m}^{-i}(x)$ is the leaveone-out estimator with observation $\left(y_{i}, x_{i}\right)$ excluded from the computation, can be separated. It reduces to performing an optimal bandwidth search for each directional regression sequentially. Nielsen and Sperlich (2005) suggest taking starting bandwidths $h_{1}, \ldots h_{d}$ that undersmooth for each direction and running the initial SBE estimation. Then the cross-validation criteria is minimized with respect to $h_{j}$ only, where $h_{j}$ is the bandwidth for direction $j$, by using a one-dimensional grid search. Bandwidths for all other directions are kept at their starting values. This is repeated for each direction $j$ individually. It is not necessary to use leave-one-out estimators for all other directions $m_{k}\left(x_{k}\right), k \neq j$, while searching for the optimal bandwidth for the estimation of $m_{j}\left(x_{j}\right)$. In addition, all $\widetilde{m_{k}}\left(x_{k}\right)$ do not need to be estimated at their optimal bandwidth. As shown by Mammen and Park (2005), this procedure results in bandwidths that are optimal for the estimation 
of the overall regression. If the primary focus of the estimation is accuracy of each single additive component, Mammen and Park (2005) suggest using plug-in bandwidths that minimize average weighted squared error (ASE) for each direction defined as

$$
A S E_{j}\left(x_{j}\right)=n^{-1} \sum_{i=1}^{n} w_{j}^{-i}\left(x_{j}\right)\left[\widetilde{m}_{j}\left(x_{j}\right)-\widetilde{m}_{j}^{-i}\left(x_{j}\right)\right]^{2},
$$

where $\widetilde{m}_{j}^{-i}\left(x_{j}\right)$ is the leave-one-out estimator of $m_{j}\left(x_{j}\right)$ and $w_{j}$ is a weight function.

This paper adopts a simpler method for bandwidth selection. Because smooth backfitting requires computing the unrestricted regression estimates, as well as univariate and bivariate densities for continuous and categorical data, we use four different bandwidth selection routines. To estimate densities for categorical variables we use the cross-validation method of Li and Racine (2007), where the bandwidth $\lambda$ is chosen separately for each regressor to minimize

$$
C V_{p}(\lambda)=\sum_{x_{c} \in S_{c}}\left[\widehat{p}\left(x_{c}\right)\right]^{2}-2 n^{-2} \sum_{i=1}^{n} \sum_{v \neq i}^{n} L_{\lambda, i v}
$$

where $L_{\lambda, i v}$ is the previously defined kernel with observation $v=i$ excluded from the computation, $S_{c}=\left\{0, \ldots c_{t}-1\right\}$ is the support of $x_{c}$ and $c$ is the category index. For unrestricted regression estimation for categorical variables, the cross-validation of Li and Racine (2007) is employed. Bandwidth is chosen to minimize

$$
C V_{\text {reg }}(\lambda)=n^{-1} \sum_{i=1}^{n}\left[y_{i}-{\widehat{m_{j}}}^{-i}\left(x_{j}\right)\right]^{2}
$$

for each $j$, where $\widehat{m}_{j}^{-i}\left(x_{j}\right)$ is the leave-one-out Nadaraya-Watson estimator of $m_{j}\left(x_{j}\right)$ defined as ${\widehat{m_{j}}}^{-i}\left(x_{j}\right)=\sum_{v \neq i}^{n} y_{v} L_{\lambda, i v} / \sum_{v \neq i}^{n} L_{\lambda, i v}$ For continuous variables the rule-of-thumb bandwidth selection was used both for estimation of unrestricted univariate regression, as well as densities. Namely, the bandwidth for regression estimation was selected as

$$
h_{j}^{r e g}=n^{-1 / 5}\left\{s^{2} 2 \sqrt{\pi}\left(\max \left(x_{j}\right)-\min \left(x_{j}\right)\right) \cdot\left[\frac{1}{n} \sum_{i=1}^{n}\left(\widehat{b_{3}}+\widehat{b_{4}} x_{j}+0.5 \widehat{b_{5}} x_{j}^{2}\right)^{2}\right]^{-1}\right\}^{1 / 5},
$$

where $b_{3}, b_{4}$ and $b_{5}$ are estimates of coefficients in regressing the dependent variable $y$ on $\beta_{1}+$ $\beta_{2} x_{j}+\beta_{3}\left(0.5 x_{j}^{2}\right)+\beta_{4}\left(\frac{1}{6} x_{j}^{3}\right)+\beta_{5}\left(\frac{1}{24} x_{j}^{4}\right)$, and $s^{2}$ is estimated in a usual manner based on the residual estimates of this regression. The bandwidth for density estimation was computed as hdens $s_{j}=$ $\left(n^{-1 / 5}\right) \cdot 1.01 a(2 \sqrt{\pi})^{-1 / 5}$, and $a=q_{75}\left(x_{j}\right)-q_{25}\left(x_{j}\right)$, where $q_{75}$ and $q_{25}$ are upper and lower quartiles of $x_{j}$, correspondingly. 


\section{A.4 References}

Aitchison, J. and C.G.G. Aitken. 1976. Multivariate binary discrimination by the kernel method. Biometrika 63, 413-420.

Baker, P., R. W. Blundell and J. Micklewright. 1989. Modelling household energy expenditures using micro-data. Economic Journal 99, 720-738.

Buja, A., Hastie, T. and R. Tibshirani. 1989. Linear smoothers and additive models. Annals of Statistics 17, 453--510.

Caravan Opinion Research Corporation, 2007. Study \#716287.

Crawley, Drury B, Linda K Lawrie, Curtis O Pedersen, Frederick C Winkelmann, Michael J Witte, Richard K Strand, Richard J Liesen, Walter F Buhl, Yu Joe Huang, Robert H Henninger, Jason Glazer, Daniel E Fisher, Don B Shirey III, Brent T Griffith, Peter G Ellis and Lixing Gu. 2004. Energy Plus: New, Capable, and Linked. Journal of Architectural and Planning Research 21, 4 (Winter 2004).

DOE-2, 1993. BDL Summary Version 2.1E. LBL, 34946, Lawrence Berkeley National Laboratory, Berkeley, CA

Fan, Y., Q. Li, and A. Weersink. 1996. Semiparametric estimation of stochastic production frontier models. Journal of Business and Economic Statistics 14, 460-468.

García-Cerruti, L. 2000. Estimating elasticities of residential energy demand from panel county data using dynamic random variables models with heteroskedastic and correlated error terms. Resource and Energy Economics 22, 355-366.

Gauss 9.0 User Guide. 2009. Aptech Systems, Inc.

Hall, P., J.S. Racine, and Q. Li. 2004. Cross-Validation and the Estimation of Conditional Probability Densities. Journal of the American Statistical Association 99, 1015-1026.

Halvorsen, B. and B. Larsen. 2001. The flexibility of household electricity demand over time." Resource and Energy Economics 23, 1-18.

Härdle, W., P. Hall and J. S. Marron. 1988. How far are automatically chosen regression smoothing parameters from their optimum? (with discussion). Journal of the American Statistical Association 83, 86--101.

Holtedahl, P. and F. Joutz. 2004. Residential electricity demand in Taiwan. Energy Economics $26,201-224$.

Kamerschen, D. and D. Porter. 2004. The demand for residential, industrial and total electricity,1973-1998. Energy Economics 26, 87-100.

Labandeira, X., J. M. Labeaga and M. Rodriguez. 2006. A residential energy demand system for Spain. The Energy Journal 27, 87-111. 
Labandeira, X., J.M. Labeaga and M. Rodríguez. 2004. Microsimulating the effects of household energy price changes in Spain. Fondazione Eni Enrico Mattei, Working Paper \# 161.

Larsen, B. and R. Nesbakken. 2004. Household electricity end-use consumption: results from econometric and engineering models. Energy Economics 26, 179-200.

Li, Q. and J.Racine. 2003. Nonparametric estimation of distributions with categorical and continuous data. Journal of Multivariate Analysis 86, 266-292.

Li, Q. and J. S. Racine. 2004. Cross-validated local linear nonparametric regression. Statistica Sinica 14, 485-512.

Li, Q. and J. S. Racine. 2007. Nonparametric econometrics: theory and practice. Princeton University Press, 768.

Linton, O. and J.P. Nielsen. 1995. A kernel method of estimating structured nonparametric regression based on marginal integration, Biometrika 82, 93-100.

Lutzenhiser, L. 1993. Social and behavioral aspects of energy use. Annual Review of Energy Economics 18, 247-89.

Madlener, R. 1996. Econometric analysis of residential energy demand: a survey. Journal of Energy Literature 2, 3-32.

Mammen, E. and B. U. Park. 2005. Bandwidth selection for smooth backfitting in additive models. Annals of Statistics 33, 1260--1294.

Mammen, E., Linton, O. and J. P. Nielsen. 1999. The existence and asymptotic properties of a backfitting projection algorithm under weak conditions. Annals of Statistics 27, 1443--1490.

Martins-Filho, C. 2006. Applied microeconomics: course notes. Department of Economics, Oregon State University.

Narayan, P. and R. Smyth. 2005. The residential demand for electricity in Australia: an application of the bounds testing approach to cointegration. Energy Policy 33, 467-474.

Nesbakken, R. 2001. Energy consumption for space heating: discrete-continuous approach. Scandinavian Journal of Economics 103, 165-184.

Newey, W. 1994. Kernel estimation of partial means. Econometric Theory 10, 233-253.

Nielsen J.P. and S.Sperlich. 2005. Smooth backfitting in practice. Journal of the Royal Statistical Society: Series B (Statistical Methodology) 67, 43-61.

Opsomer, J. D. and D. Ruppert. 1997. Fitting a bivariate additive model by local polynomial regression. Annals of Statistics 25, 186--211.

Opsomer, J. D. 2000. Asymptotic properties of backfitting estimators. Journal Multivariate Analysis 73, 166--179. 
Racine, J. S. and Q. Li. 2004. Nonparametric estimation of regression functions with both categorical and continuous data. Journal of Econometrics 119, 99-130.

Racine, J.S., Q. Li., and X. Zhu. 2004. Kernel estimation of multivariate conditional distributions. Annals of Economics and Finance 5, 211-235.

Schmalensee, R. and T. M. Stoker. 1999. Household gasoline demand in the United States. Econometrica 67, 645-662.

Severini T.A., Wong W.H., Pro.le Likelihood and Conditionally Parametric Models Annals of Statistics, Vol. 20, No. 4 (Dec., 1992), pp.1768-1802

U.S. Department of Energy. 2005. ENERGY PLUS, Input Output Reference.

U.S. Department of Energy. 2009. Energy Information Administration (DOE/EIA). Annual energy outlook 2009 with projections to 2030. DOE/EIA-0383 (2009).

U.S. Department of Energy. 2009. Energy Information Administration (DOE/EIA). Residential Energy Consumption Survey 2005.

Wang, M.C., and J. Van Ryzin. 1981. A class of smooth estimators for discrete distributions. Biometrika 68, 301-309.

Yatchew, A. and J. No. 2001. Household gasoline demand in Canada. Econometrica 69, 16971709. 
Appendix B

Complete Set of Graphical Results 



\section{Appendix B}

\section{Complete Set of Graphical Results}

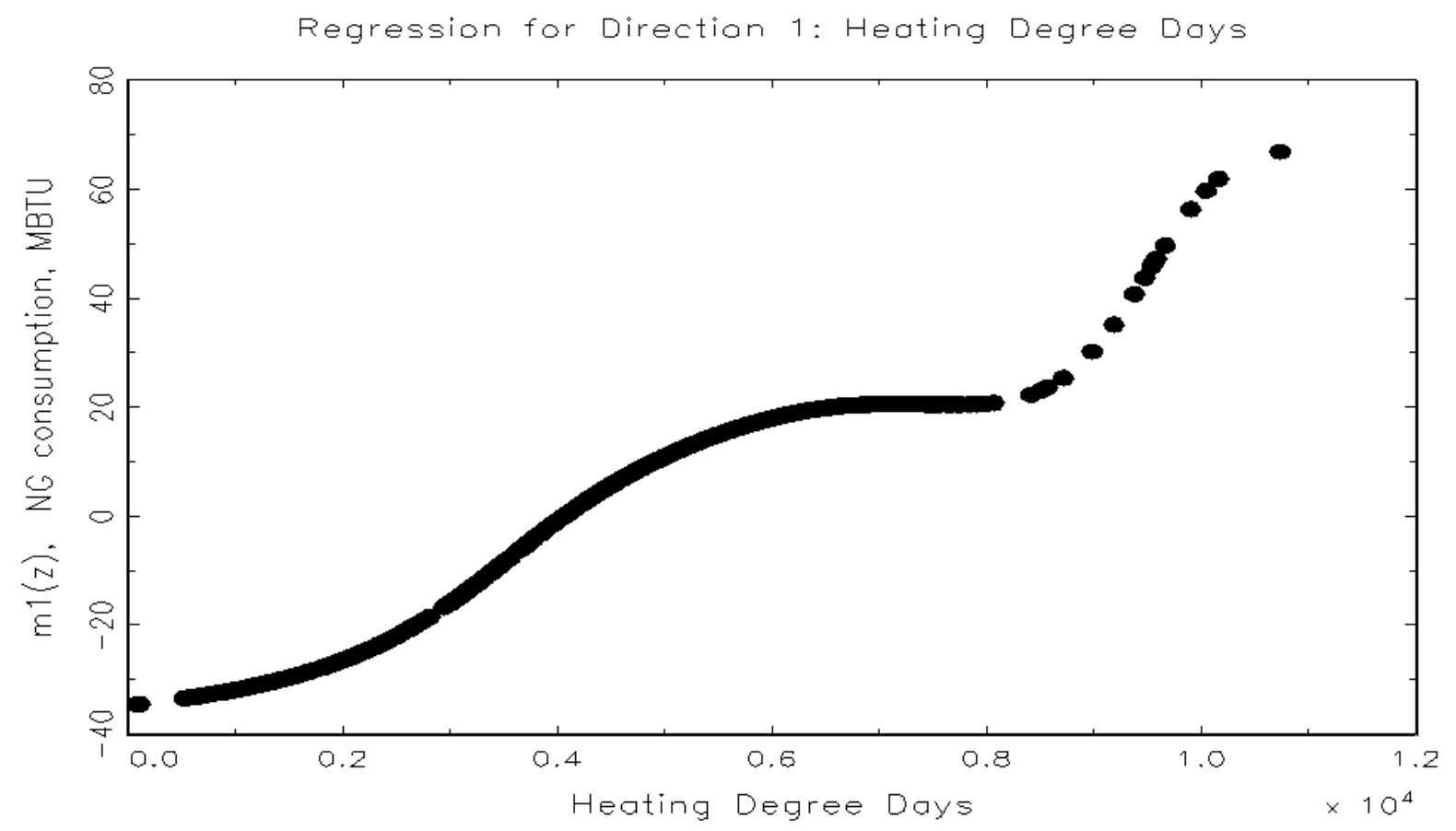

Figure B.1. Heating Degree Days: Base 65, 01 to 12-2005 (Inoculated) 


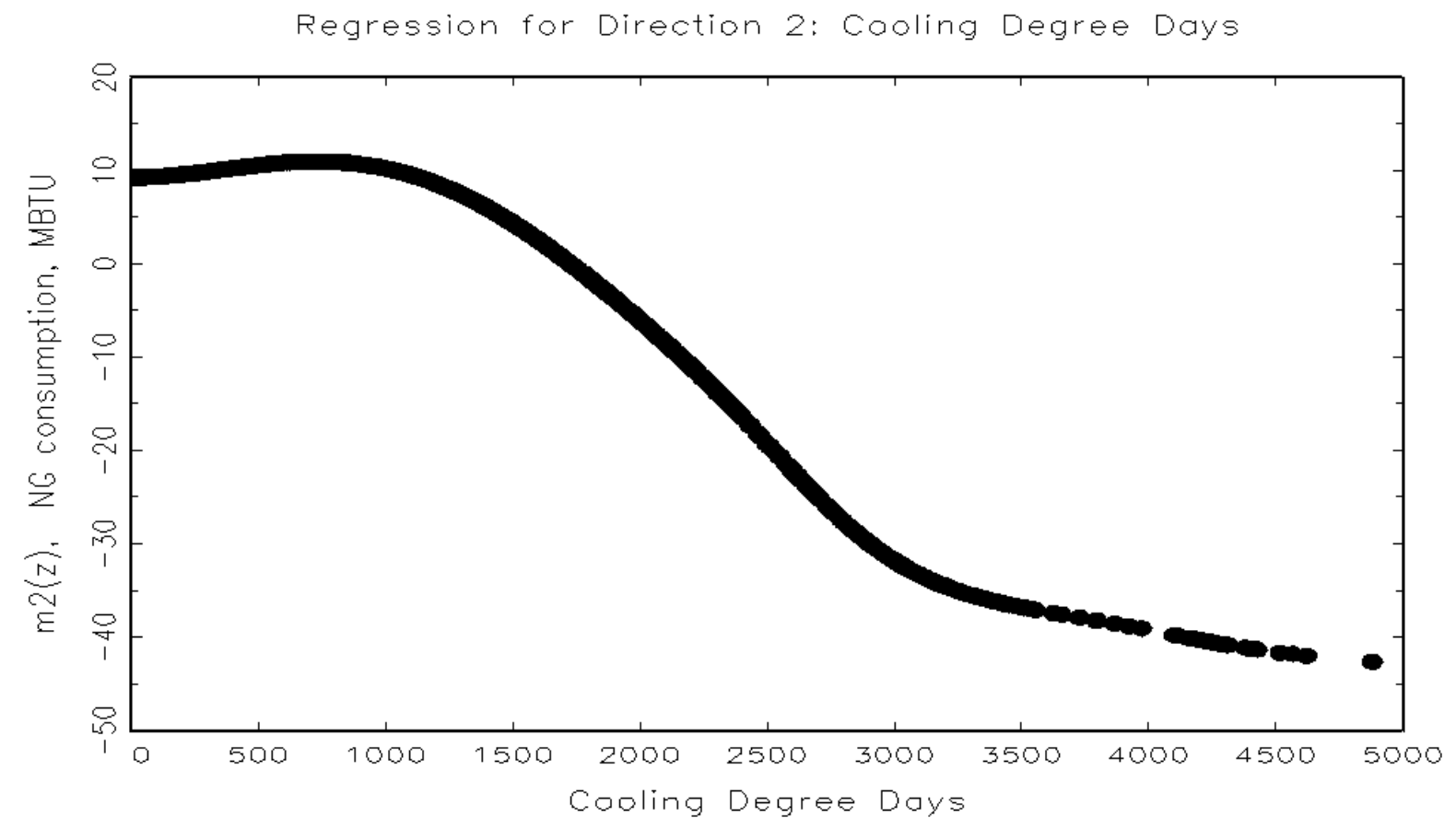

Figure B.2. Cooling DegreeDays: Base 65, 01 to 12-2005 (Inoculated)

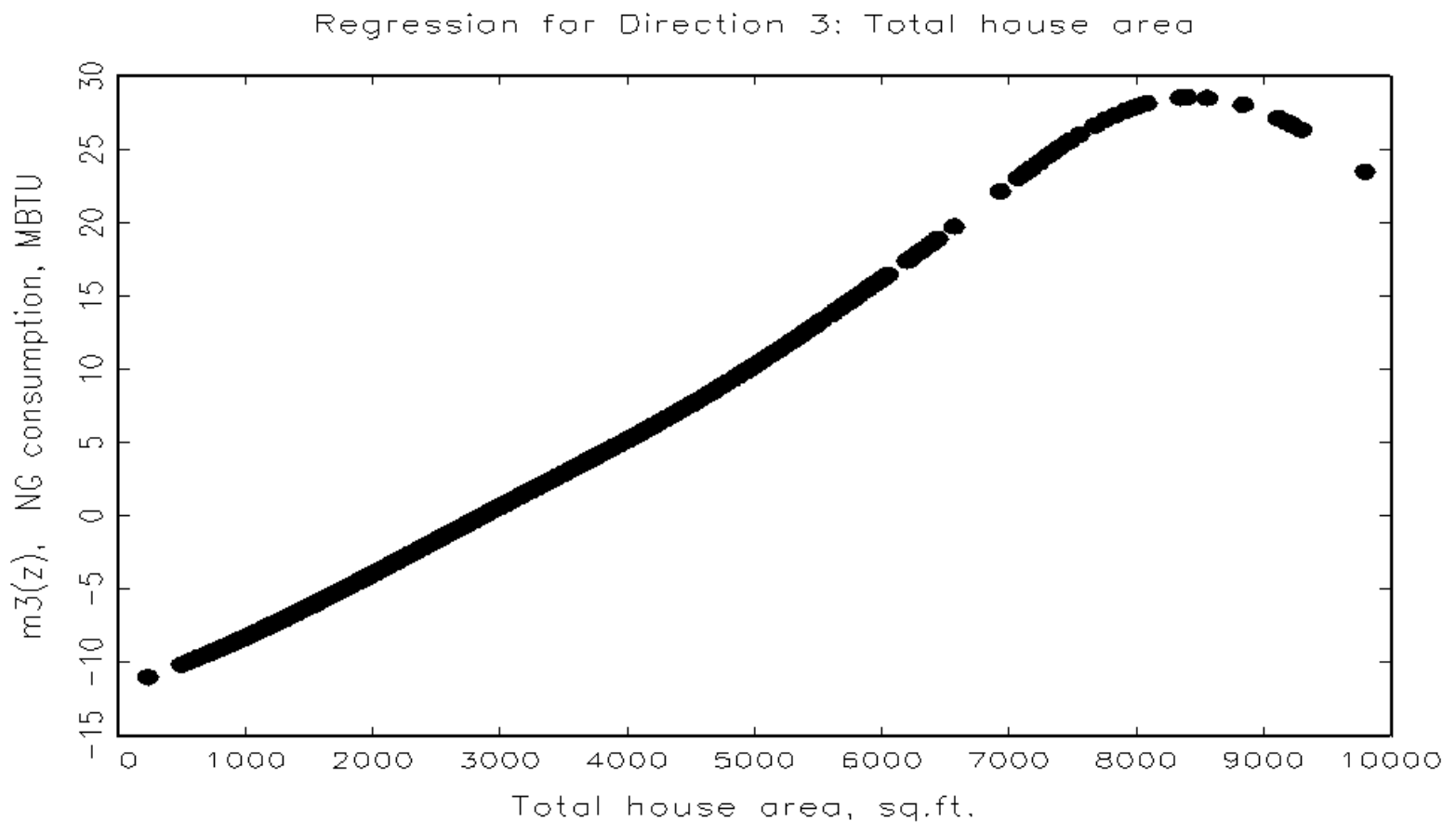

Figure B.3. Total House Area 


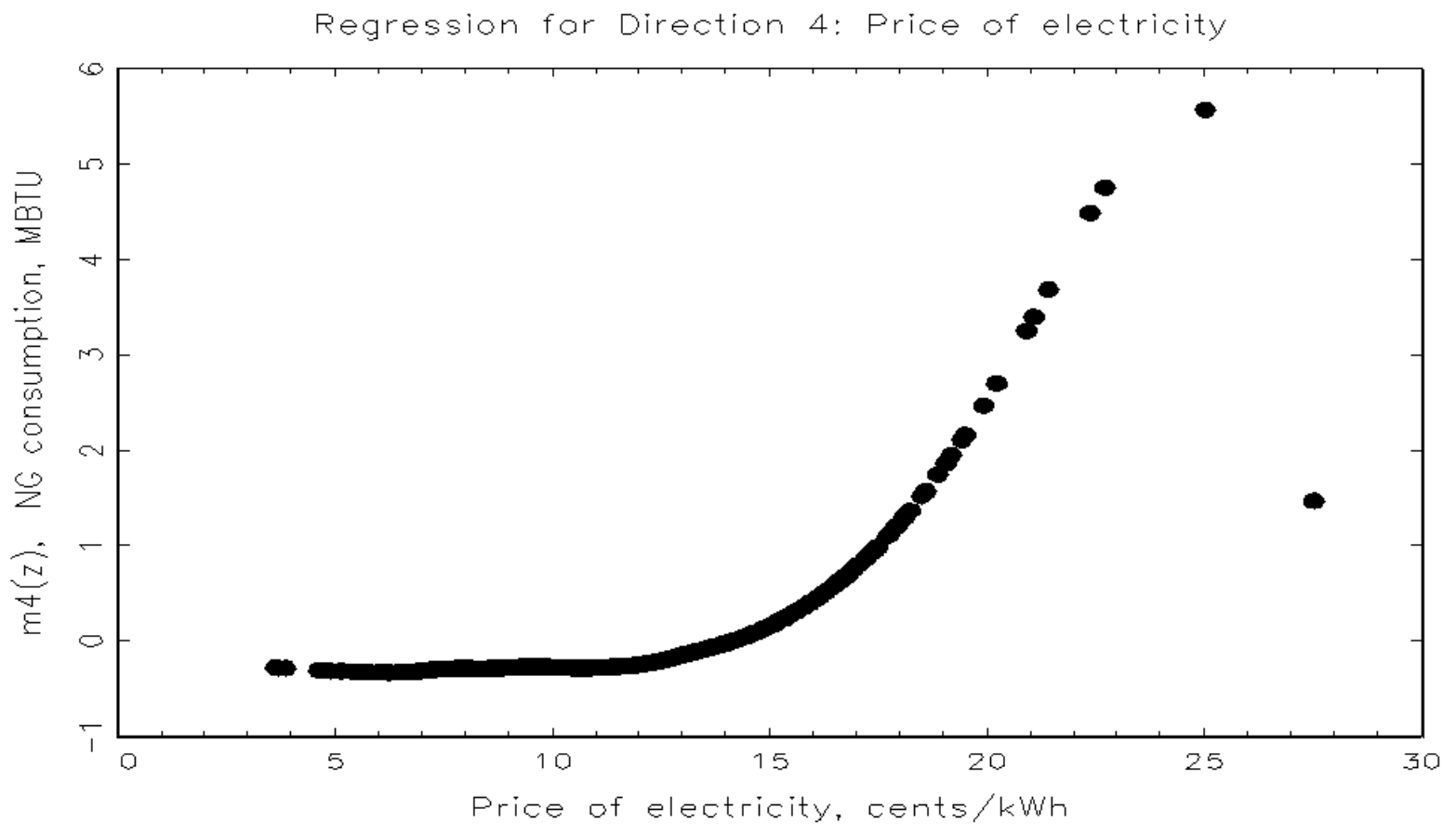

Figure B.4. Price of Electricity

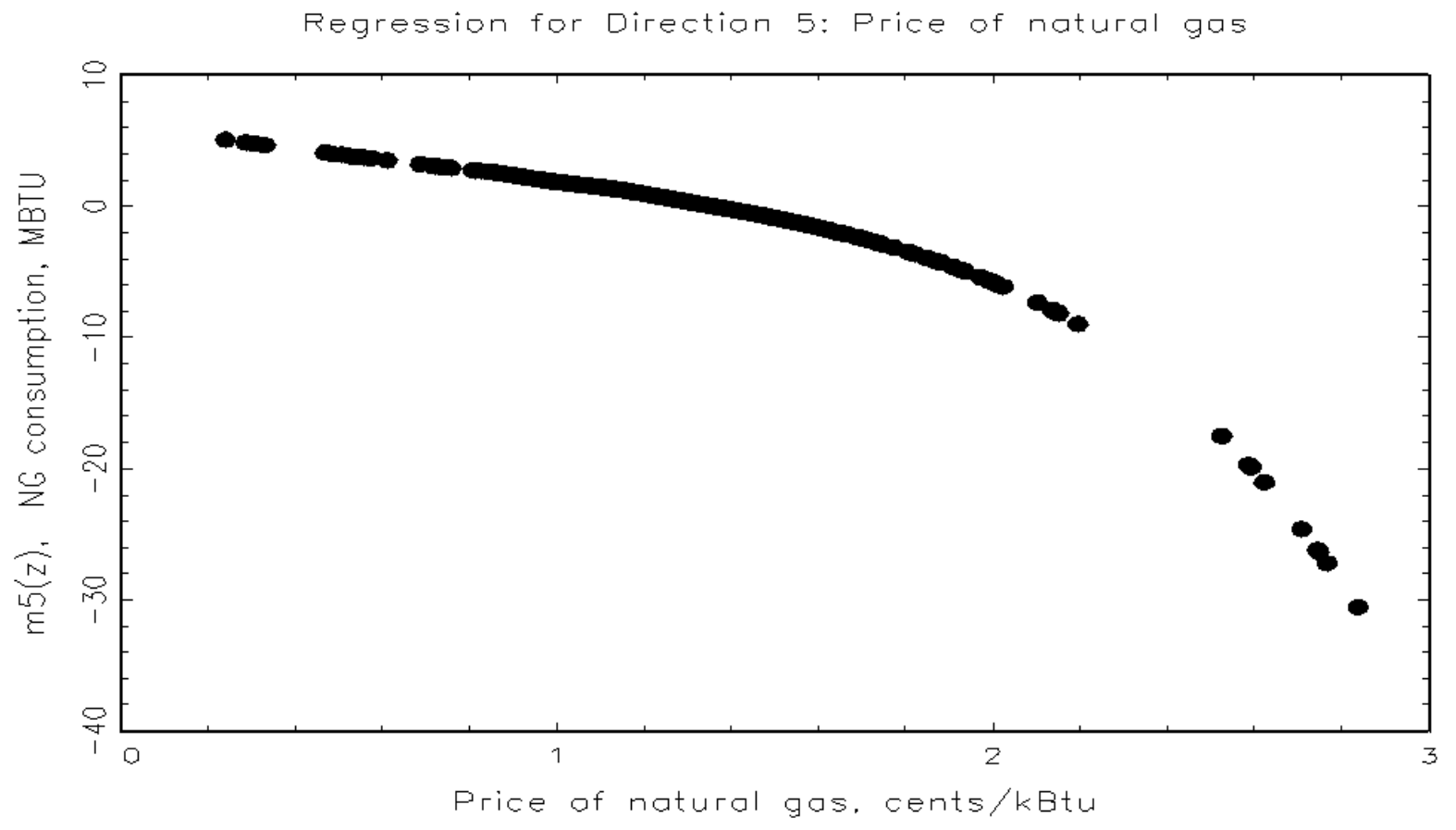

Figure B.5. Price of Natural Gas, Cents/kBtu 


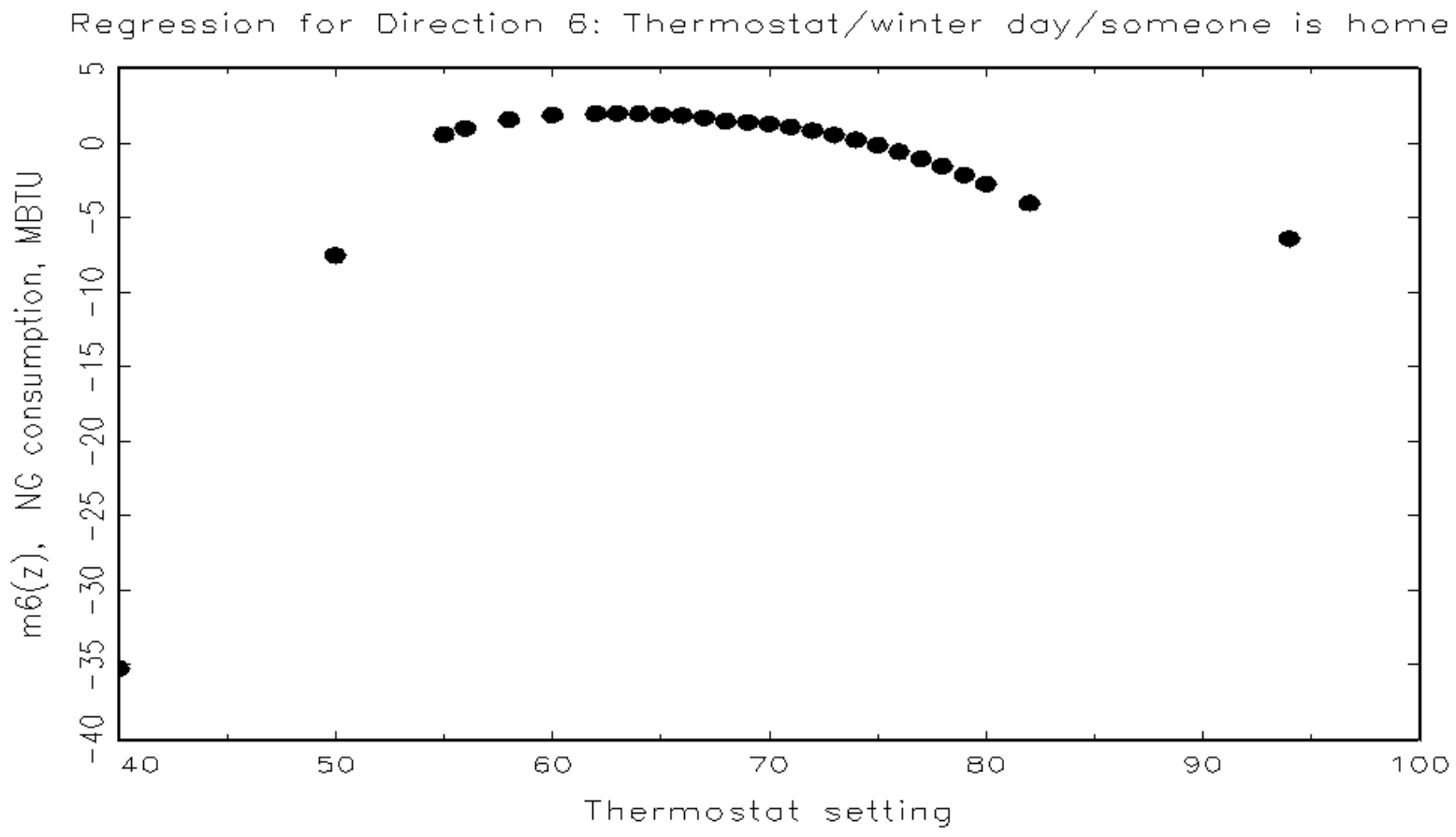

Figure B.6. Setting During the Winter Day When Someone is Home

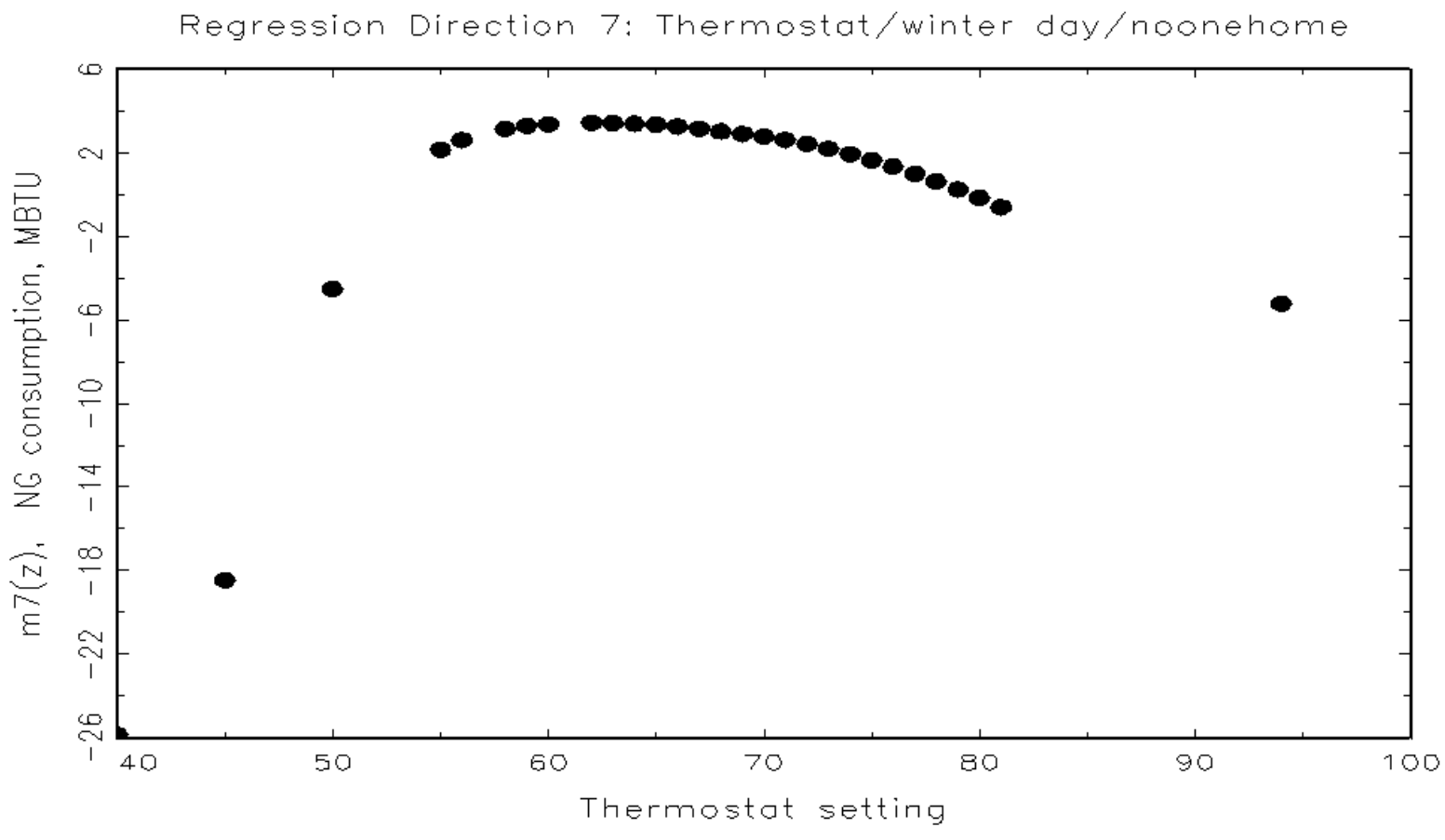

Figure B.7. Setting During the Winter Day When No One is Home 


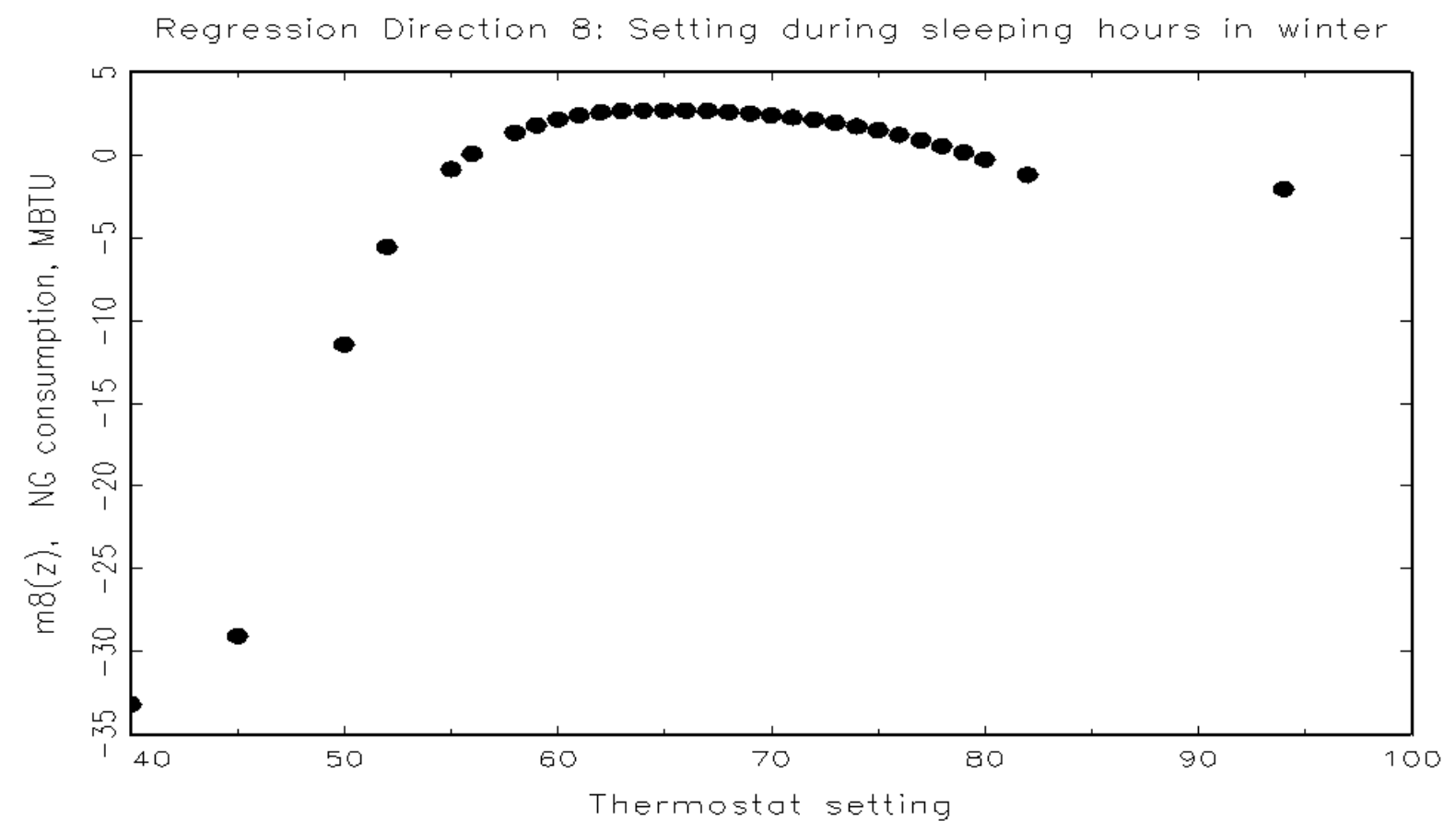

Figure B.8. Setting During Sleeping Hours in Winter 


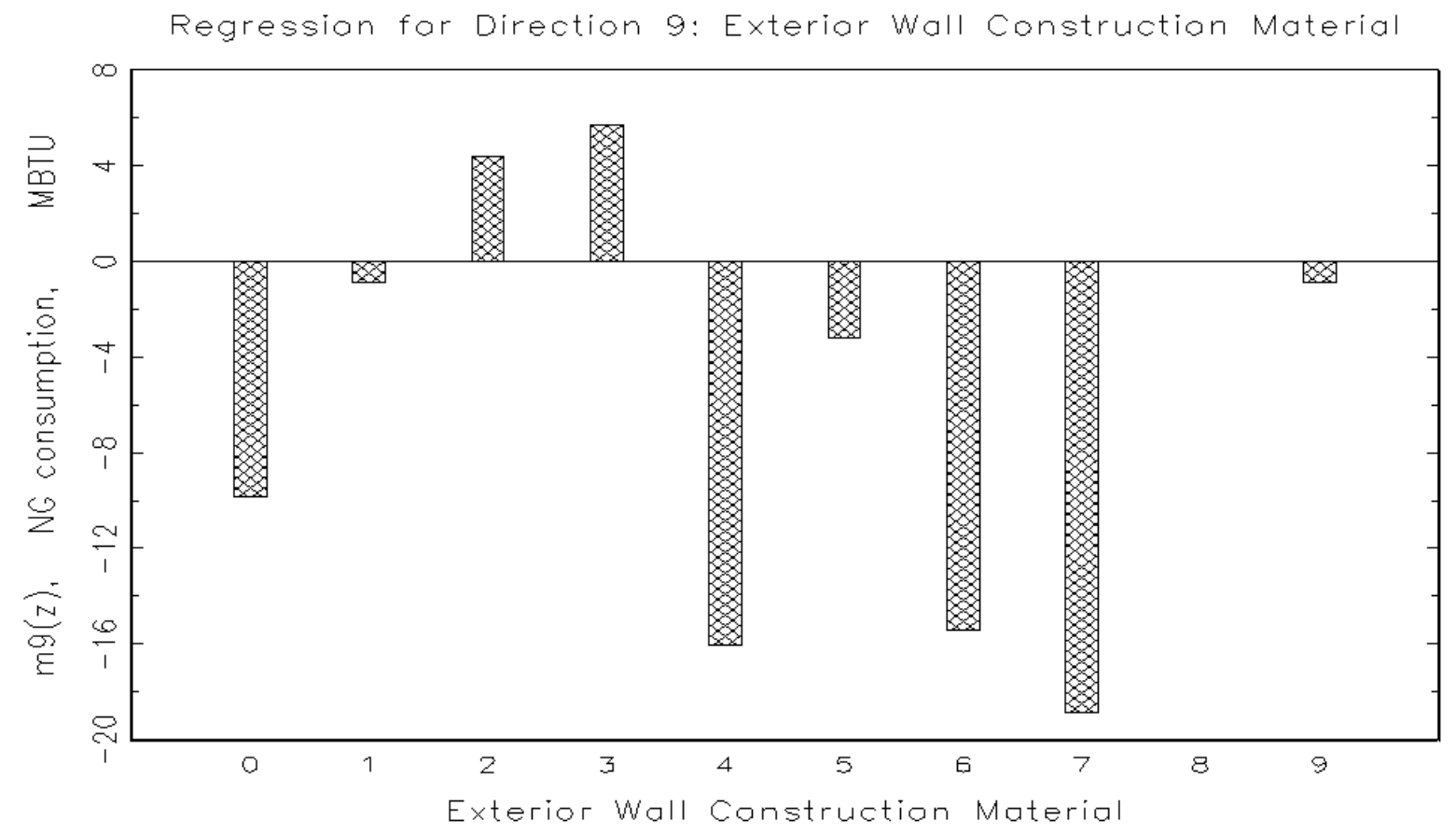

Figure B.9. Exterior Wall Construction Material

0 Indescribable

1 Brick

2 Wood

3 Siding (Aluminum, vinyl, or steel)

4 Stucco

5 Composition (Shingle)

6 Stone

7 Concrete or concrete block

8 Glass

9 Other 
Regression for Direction 10: Heated garage

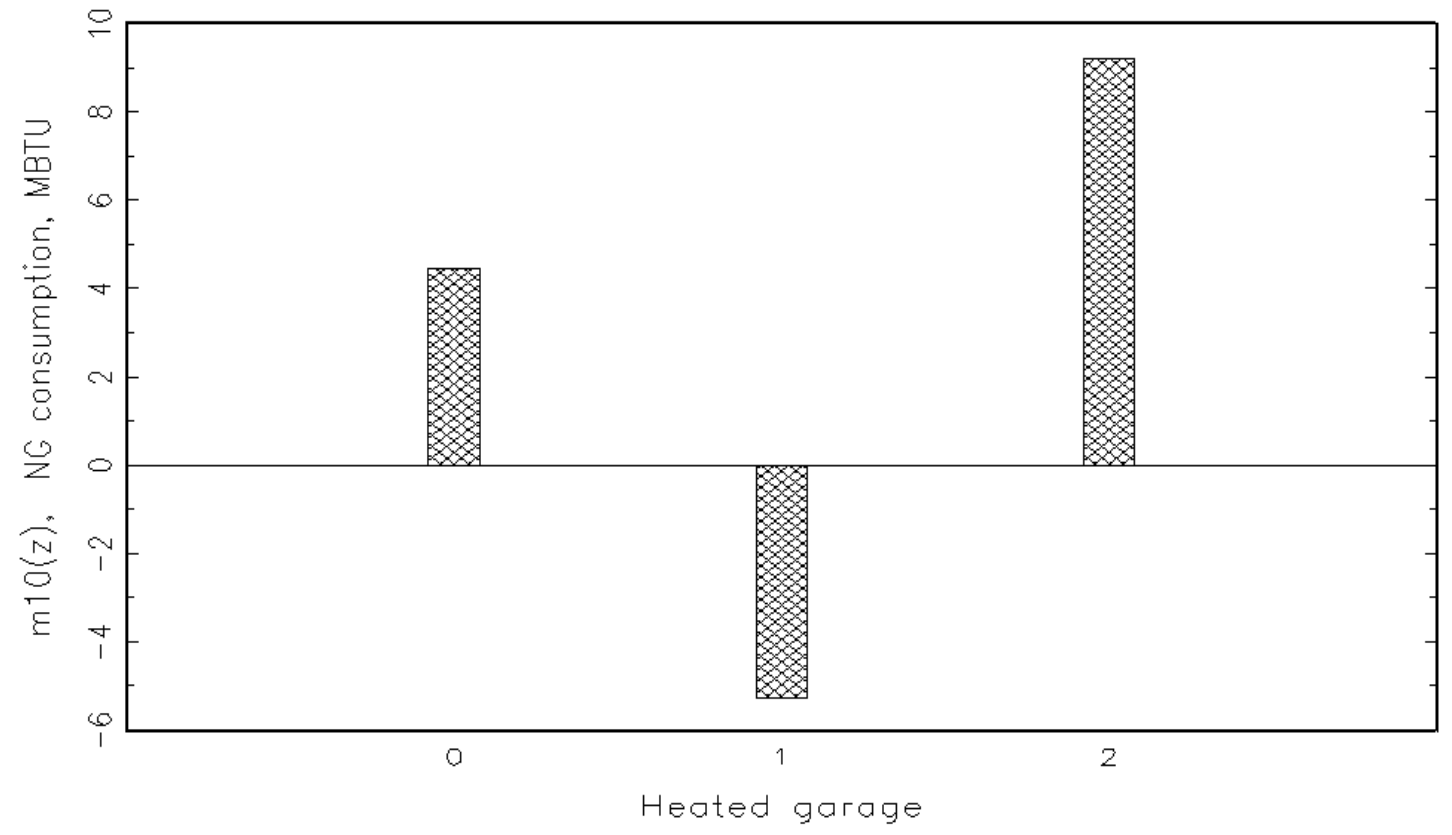

Figure B.10. Is the Garage Heated

0 No garage

1 Not heated

2 Yes

Regression for Direction 11: Dwelling owned or rented

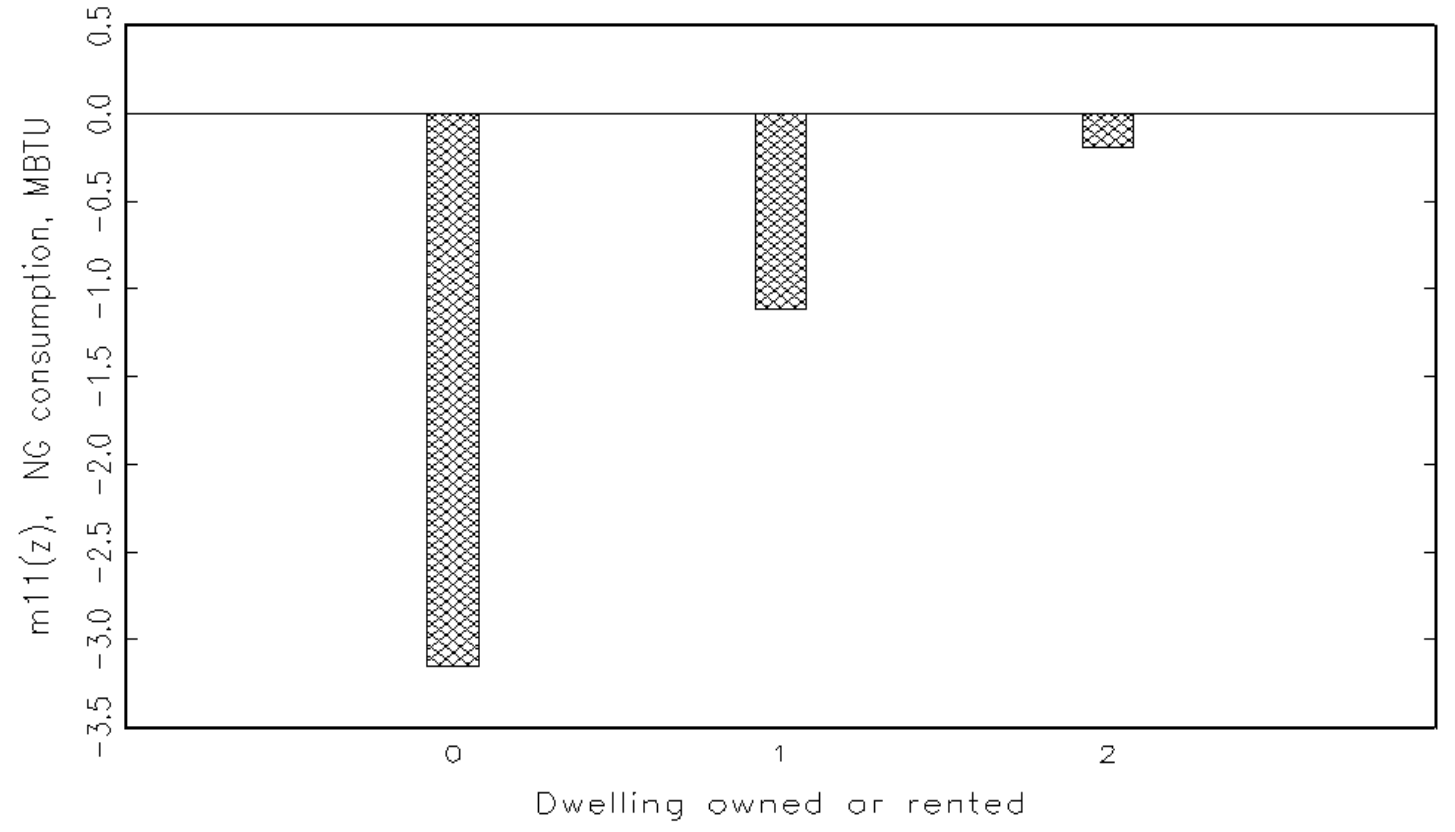

Figure B.11. Dwelling Owned or Rented

0 Own

1 Rent

2 Occupied w/out payment 


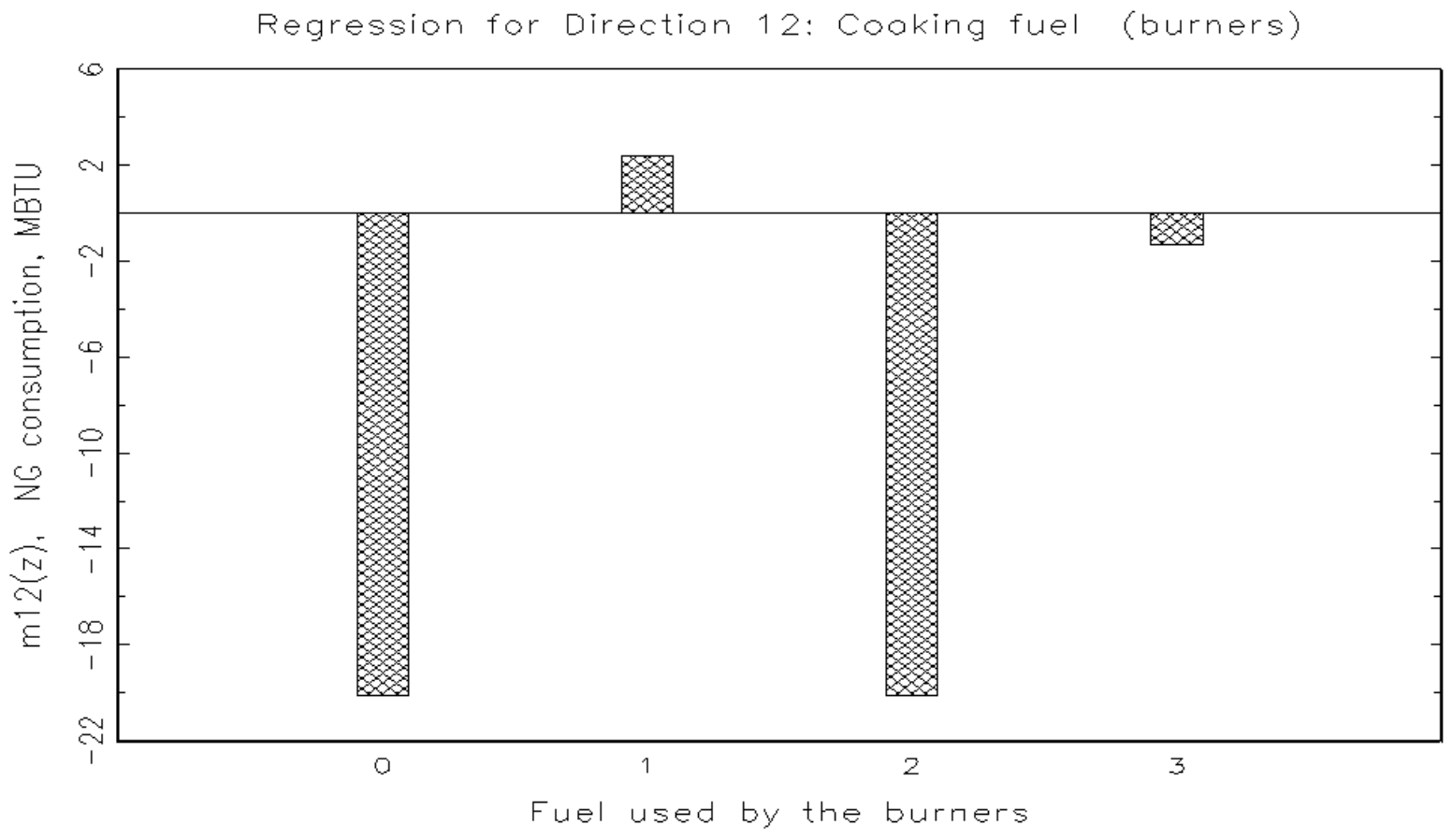

Figure B.12. Fuel Used by the Burners

0 Some other fuel

1 Natural gas from underground pipes,

2 Propane (bottled gas), or

3 Electricity

Regression for Direction 13: Clothes dryer fuel

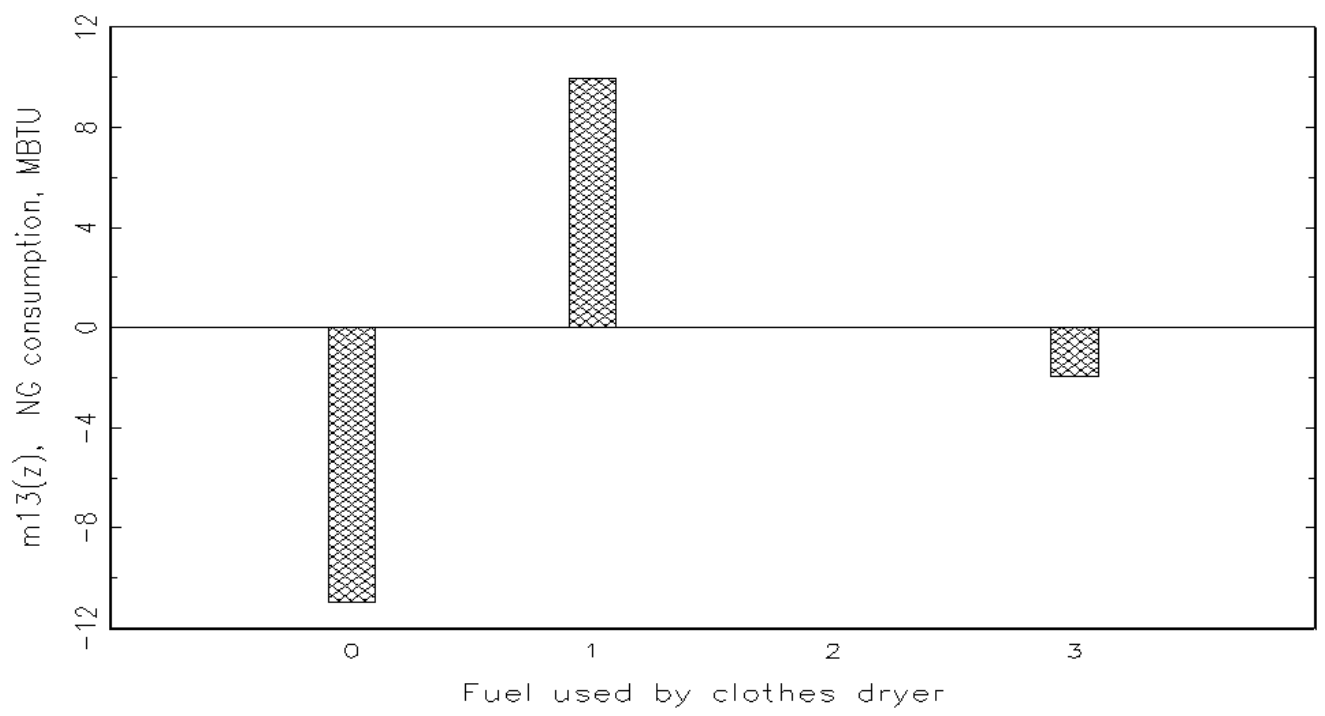

Figure B.13. What Fuel Does Clothes Dryer Use

0 No dryer

1 Natural gas from underground pipes,

2 Propane (bottled gas), or

3 Electricity 


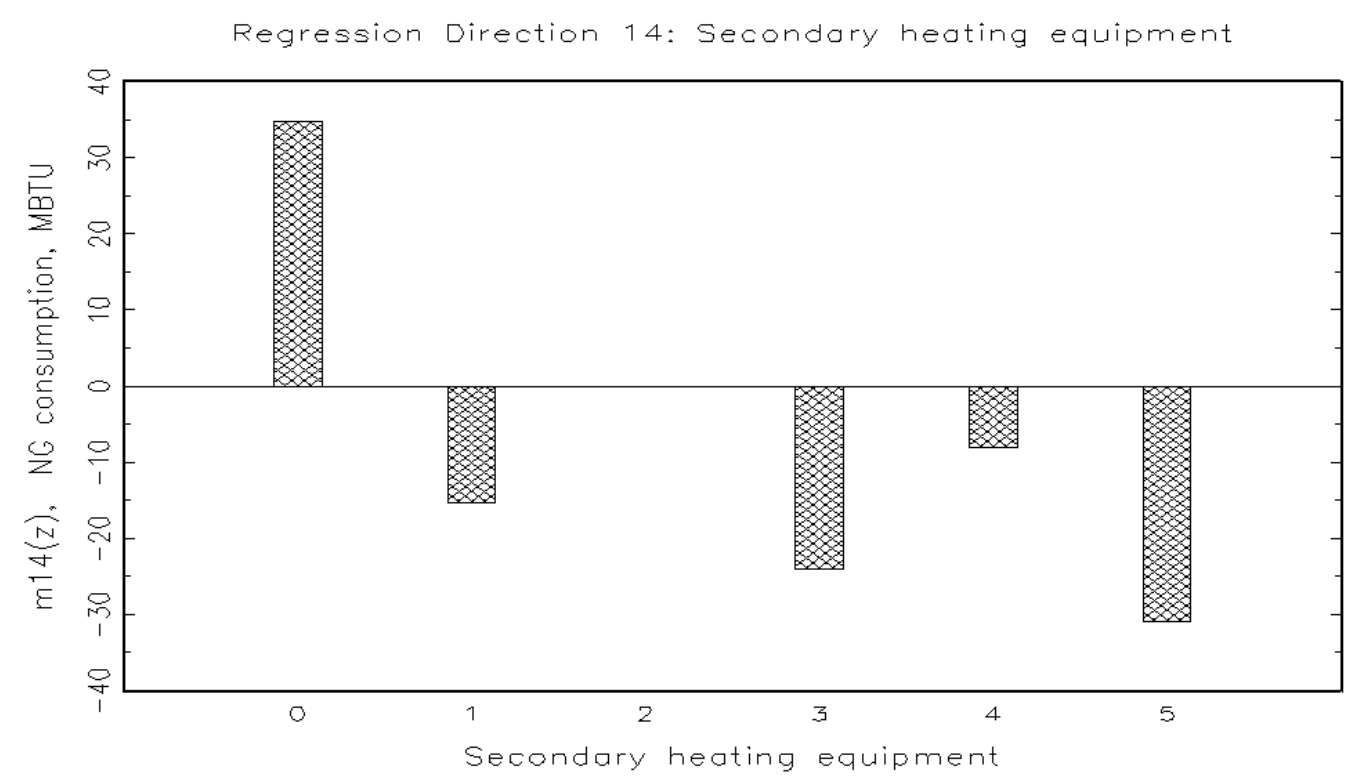

Figure B.14. Combined All Secondary Heating Equipment

0 No secondary heating equipment

1 Central warm-air furnace with ducts to individual rooms other than a heat pump

2 Steam/hot water system with radiators/convectors in each room or pipes in the floor or walls

3 Built-in floor/wall pipeless furnace

4 Built-in room heater burning gas, oil, or kerosene

5 Cooking stove used to heat your home as well as to cook

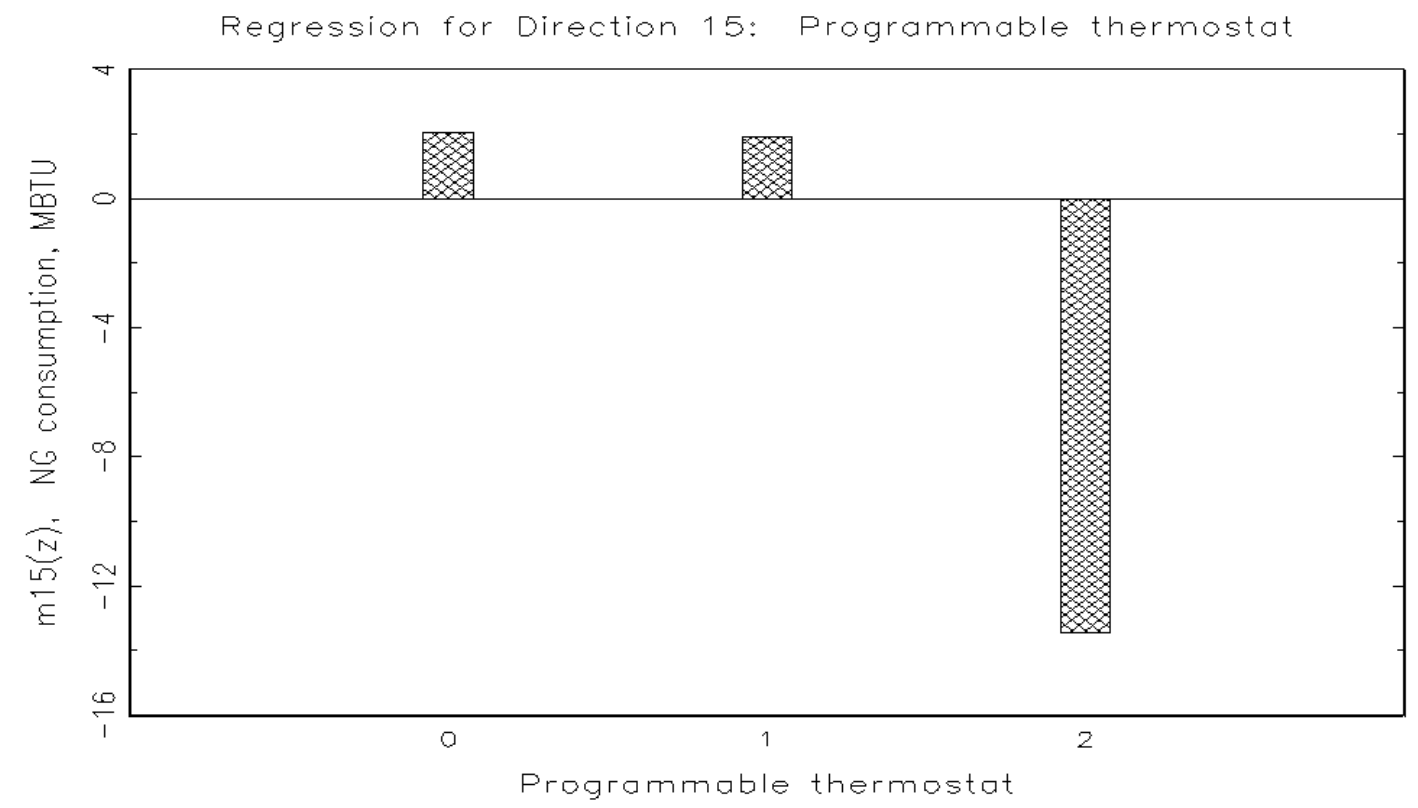

Figure B.15. Is That Thermostat Programmable
0 No
1 Yes
2 No thermostat 


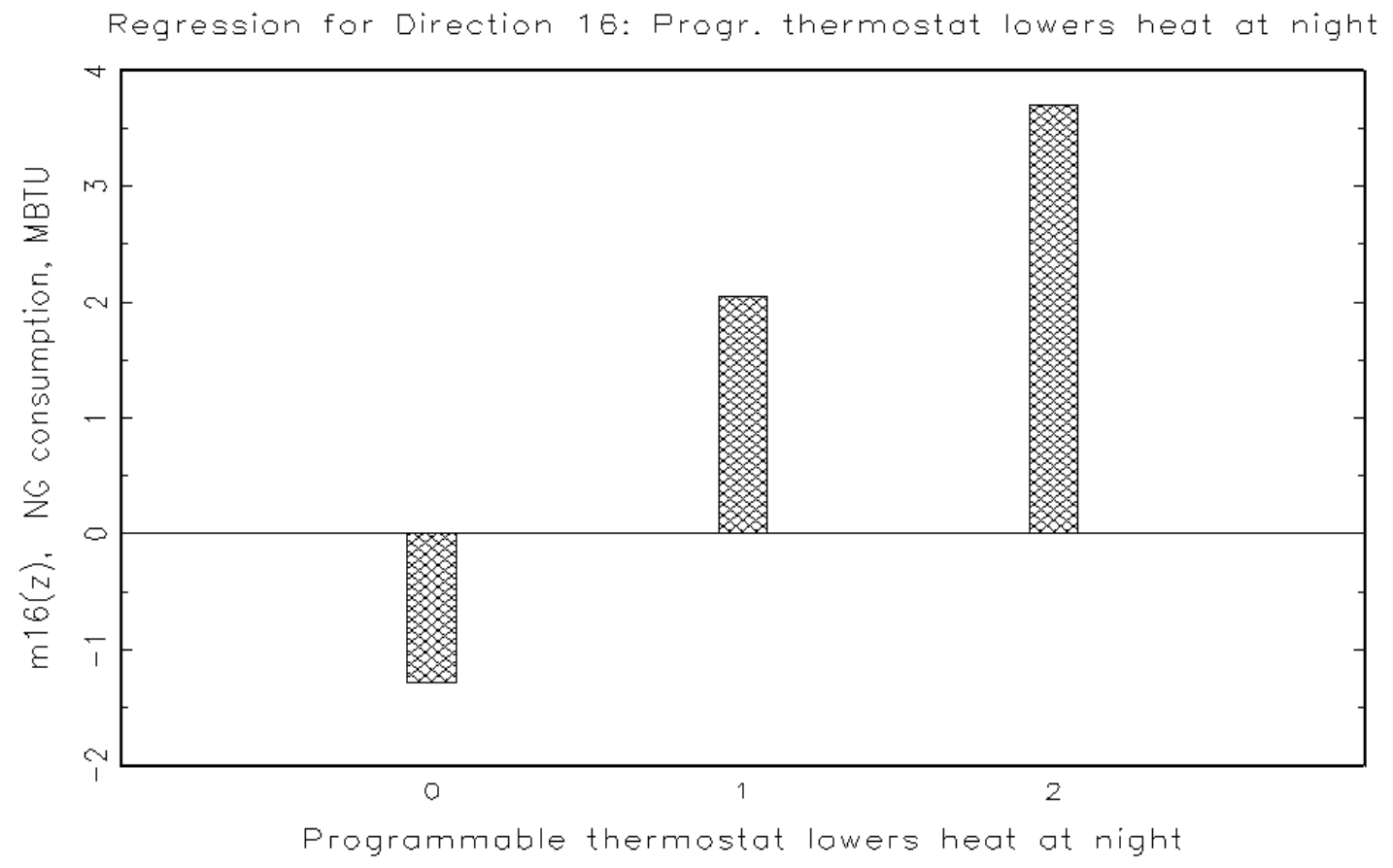

Figure B.16. Programmable Thermostat Lowers Heat at Night

0 No

1 Yes

2 No thermostat or not programmable

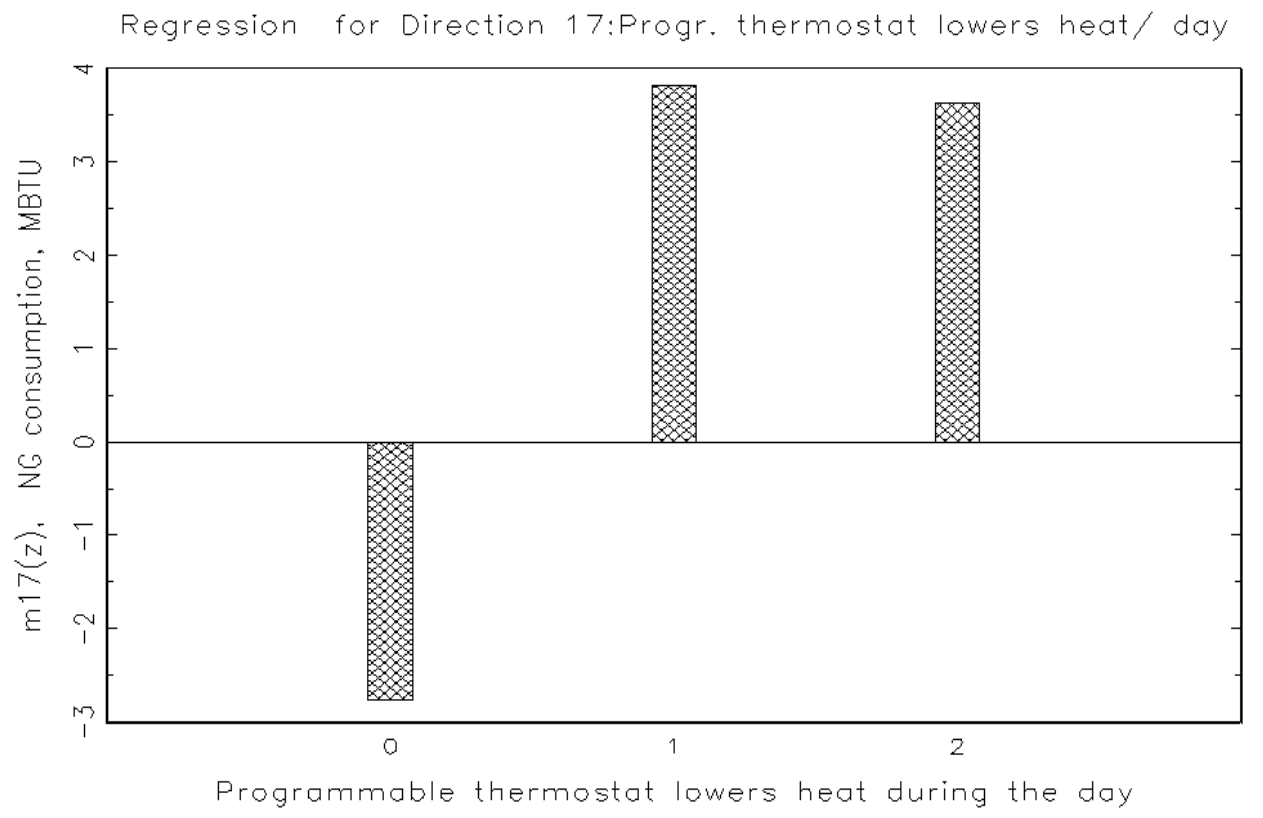

Figure B.17. Programmable Thermostat Lowers Heat During the Day

0 No

1 Yes

2 No thermostat or not programmable 
Regression for Direction 18: Main heating fuel

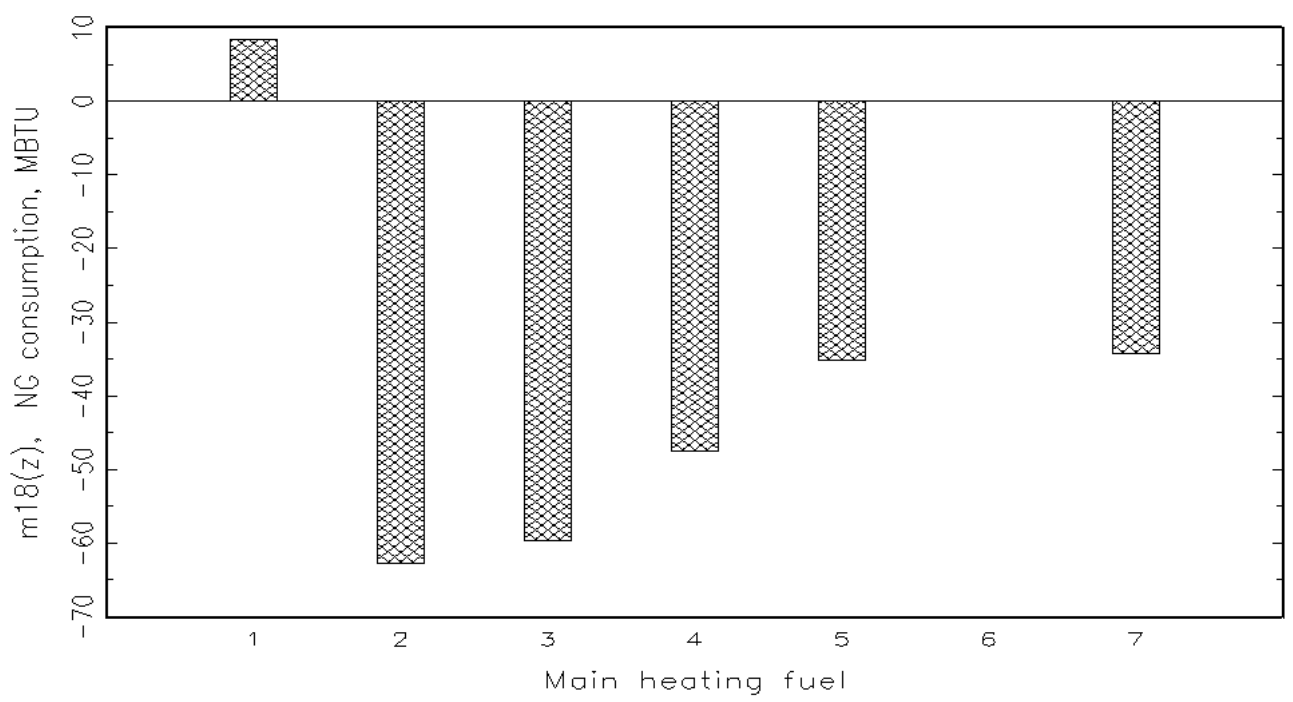

Figure B.18. Main Fuel Used for Heating Home

0 Natural gas from underground pipes

1 Propane (bottled gas)

2 Fuel oil

3 Kerosene

4 Electricity

5 Wood

6 Solar 


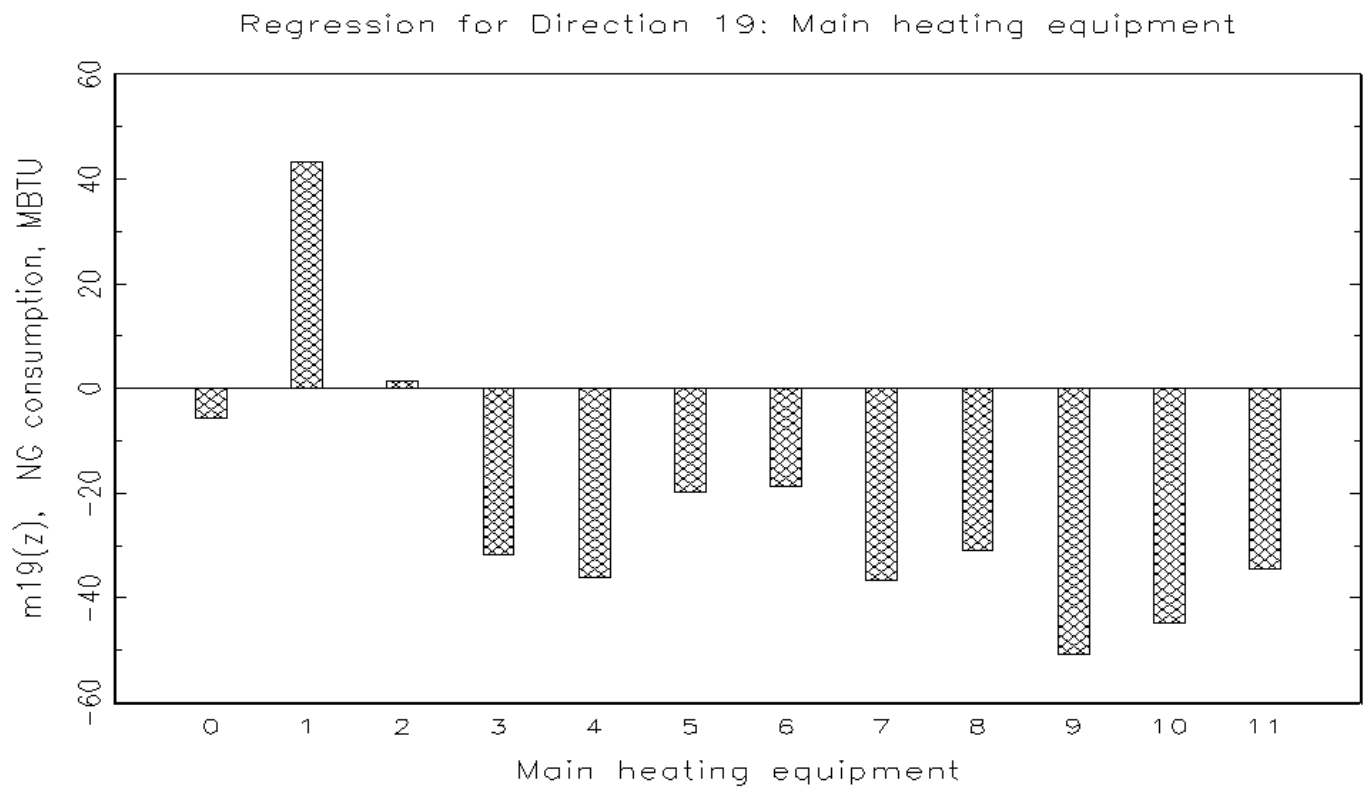

Figure B.19. Type of Heating Equipment Provides the Heat

0 No heating equipment used

1 Steam/hot water system with radiators/convectors in each room or pipes in the floor or walls

2 Central warm-air furnace with ducts to individual rooms other than a heat pump

3 Heat pump

4 Built-in electric units in each room installed in walls, ceiling, baseboard, or floor

5 Built-in floor/wall pipeless furnace

6 Built-in room heater burning gas, oil, or kerosene

7 Heating stove burning wood, coal, or coke

8 Fireplace

9 Portable electric heaters

10 Portable kerosene heaters

11 Cooking stove that is used to heat your home as well as to cook 
Regression for Direction 20: Natural gas for heating water

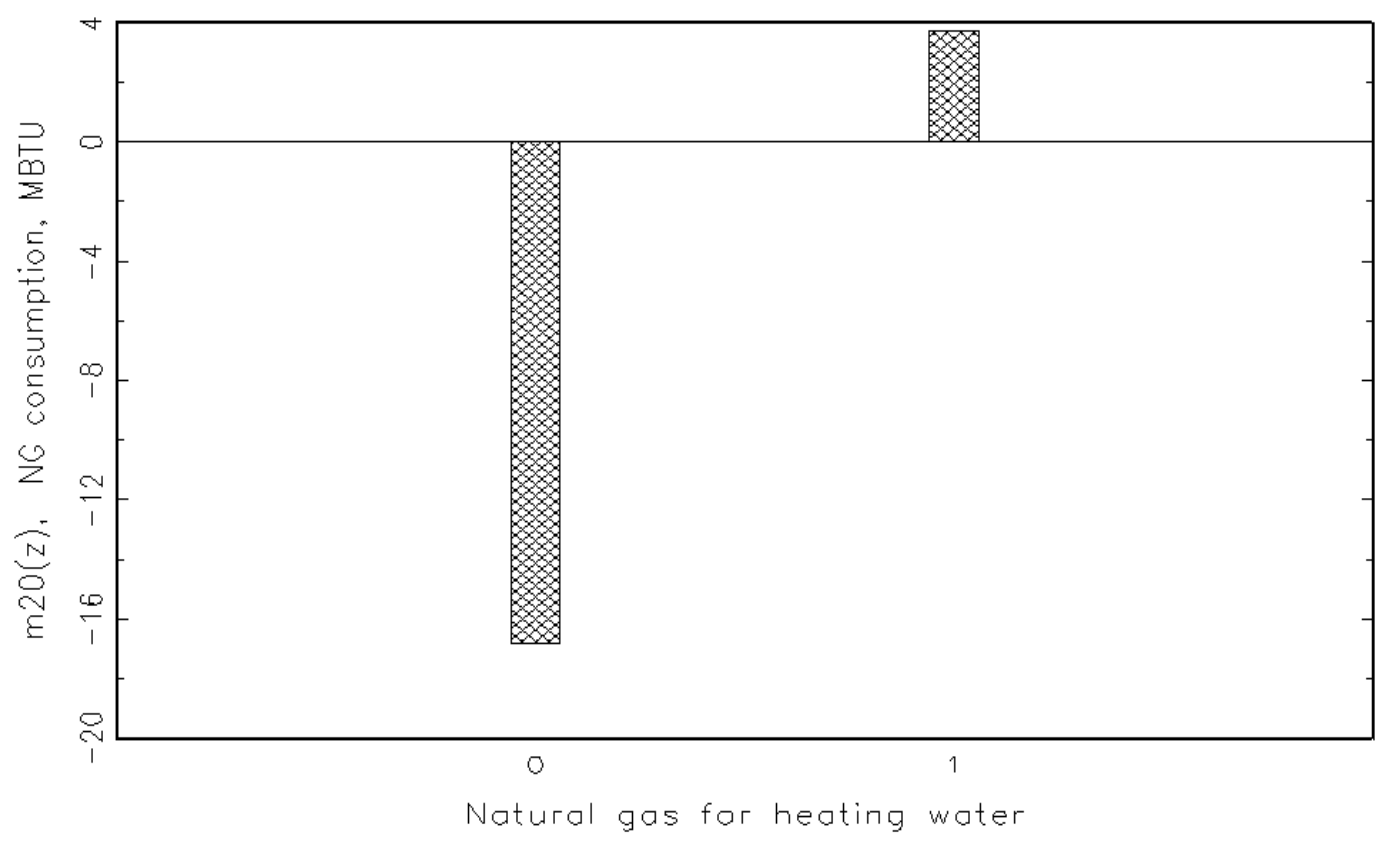

Figure B.20. Natural Gas Used for $\mathrm{H} 2 \mathrm{O}$

$\begin{array}{ll}0 & \text { No } \\ 1 & \text { Yes }\end{array}$

Regression for Direction 21: How natural gas is paid

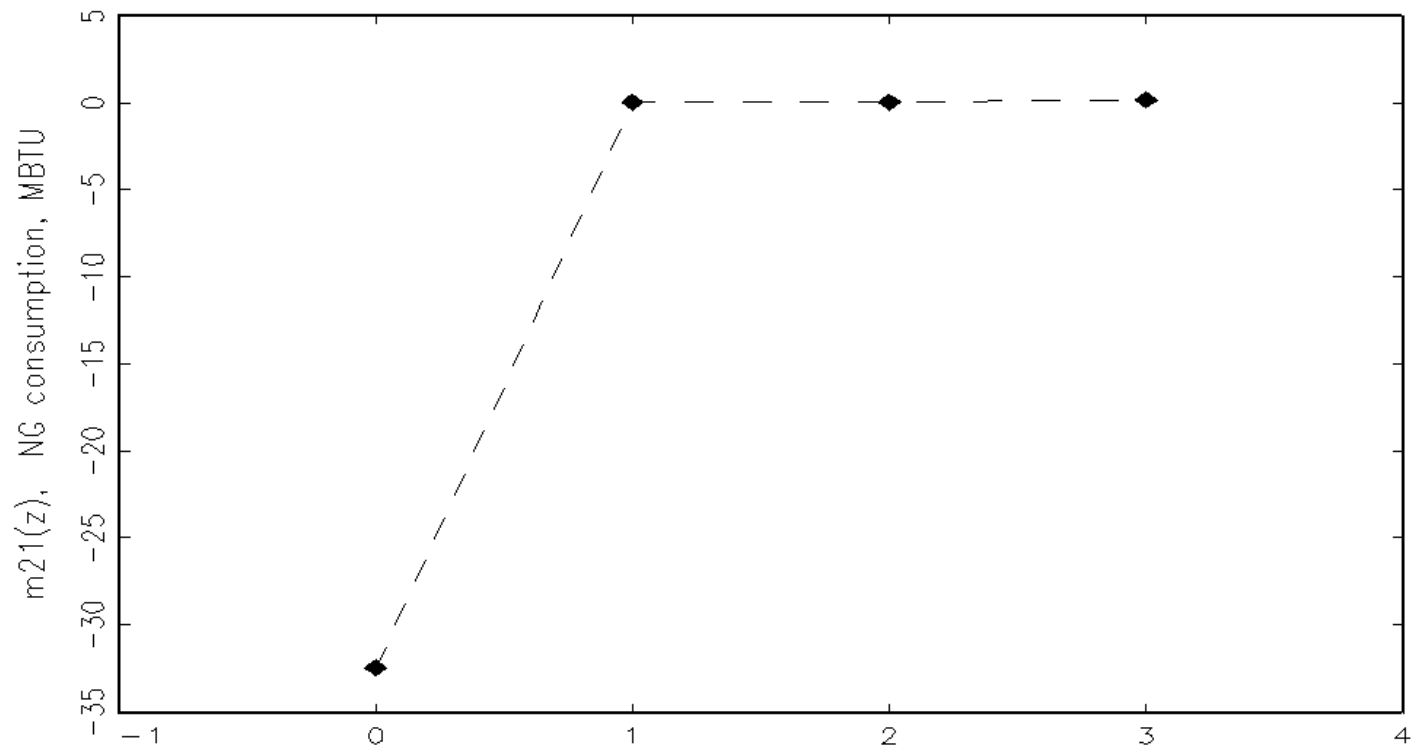

Figure B.21. How Natural Gas is Paid

$0 \mathrm{HH}$ pays all

1 All in rent/fee

2 Some paid, some included in rent

3 Other 
Regression for Direction 22: At home /all day/weekday

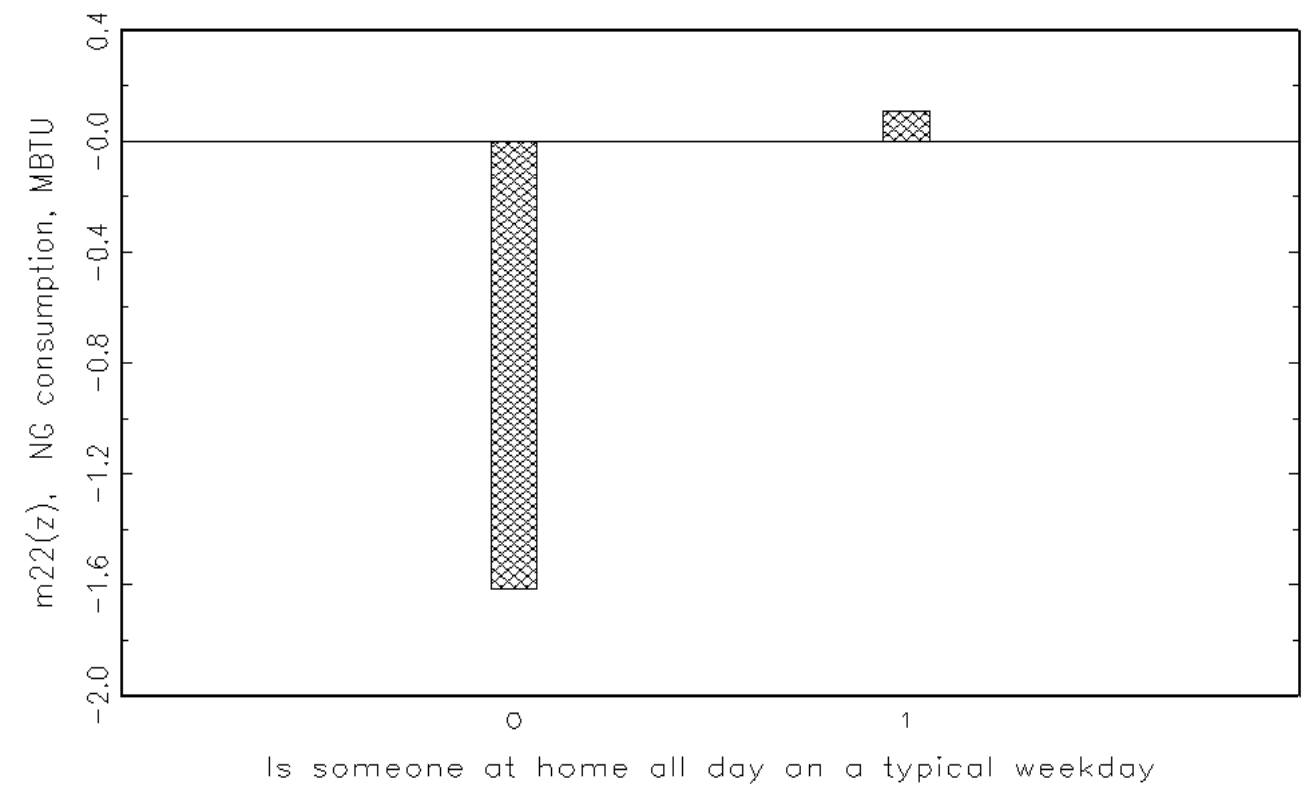

Figure B.22. Is Someone at Home All Day on a Typical Weekday

0 No

1 Yes

Regression for Direction 23: Reported Stories in Housing Unit

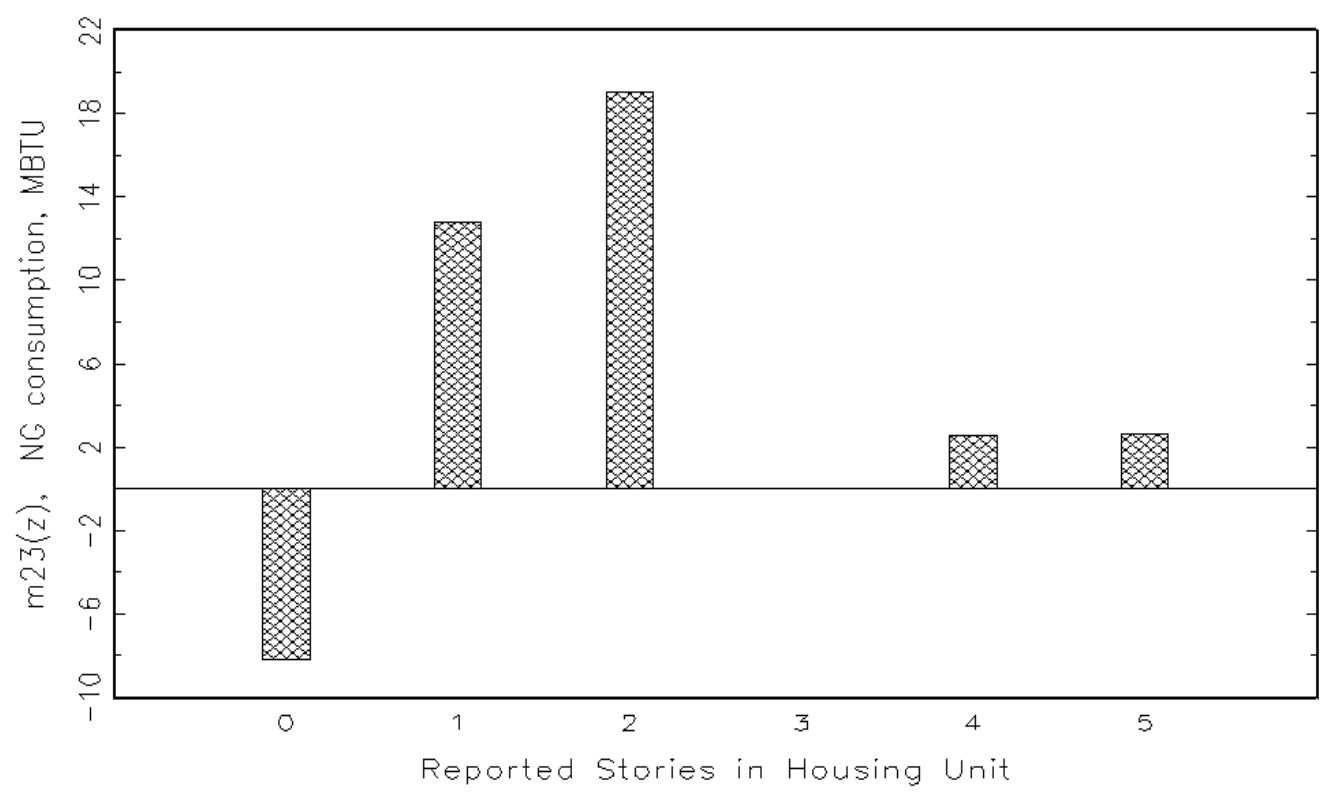

Figure B.23. Reported Stories in Housing Unit

$\begin{array}{ll}0 & \text { One story } \\ 1 & \text { Two stories } \\ 2 & \text { Three stories } \\ 3 & \text { Four or more } \\ 4 & \text { Split level } \\ 5 & \text { Other }\end{array}$




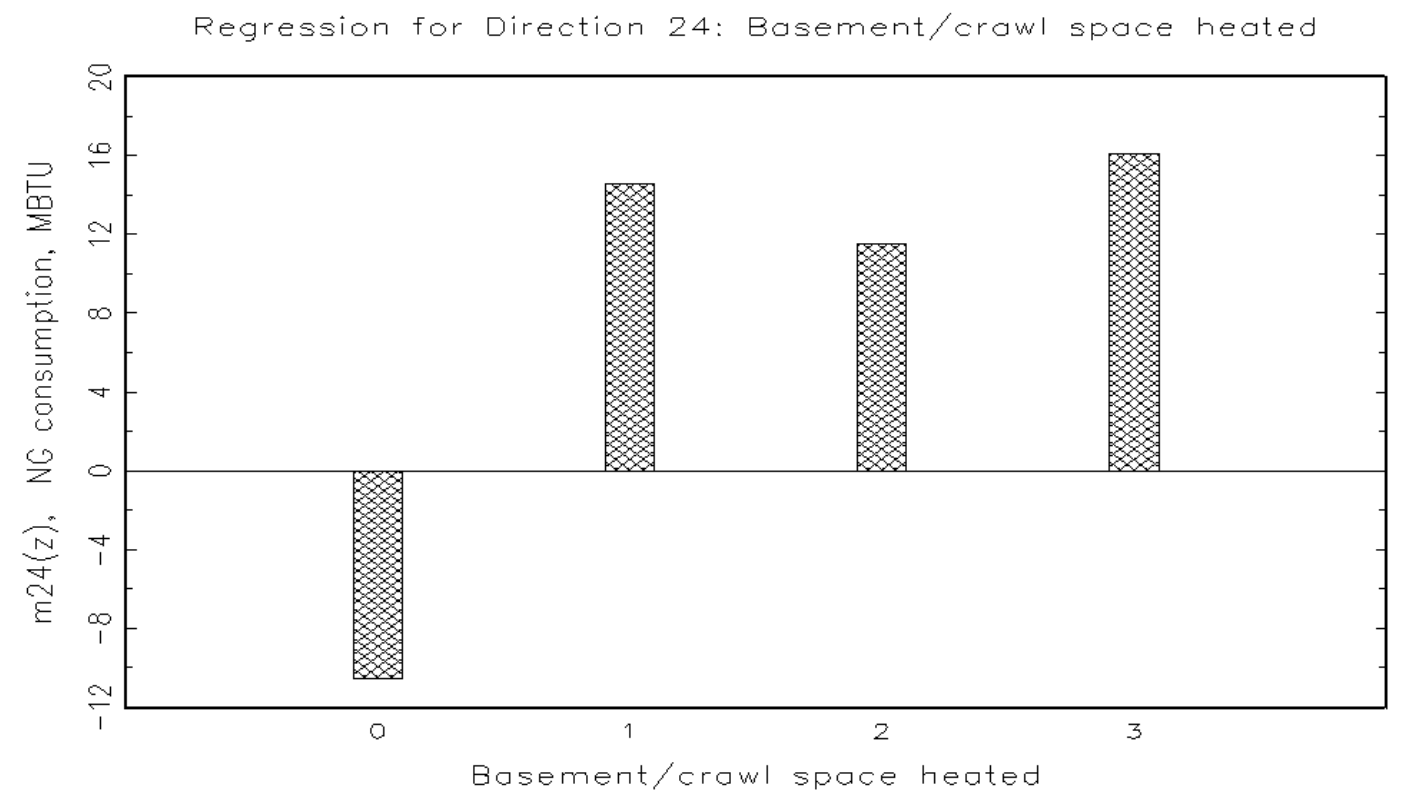

Figure B.24. Basement/Crawl Space Heated

$\begin{array}{ll}0 & \text { no basement } \\ 1 & \text { none } \\ 2 & \text { part } \\ 3 & \text { all }\end{array}$

Regression for Direction 25: Heated attic

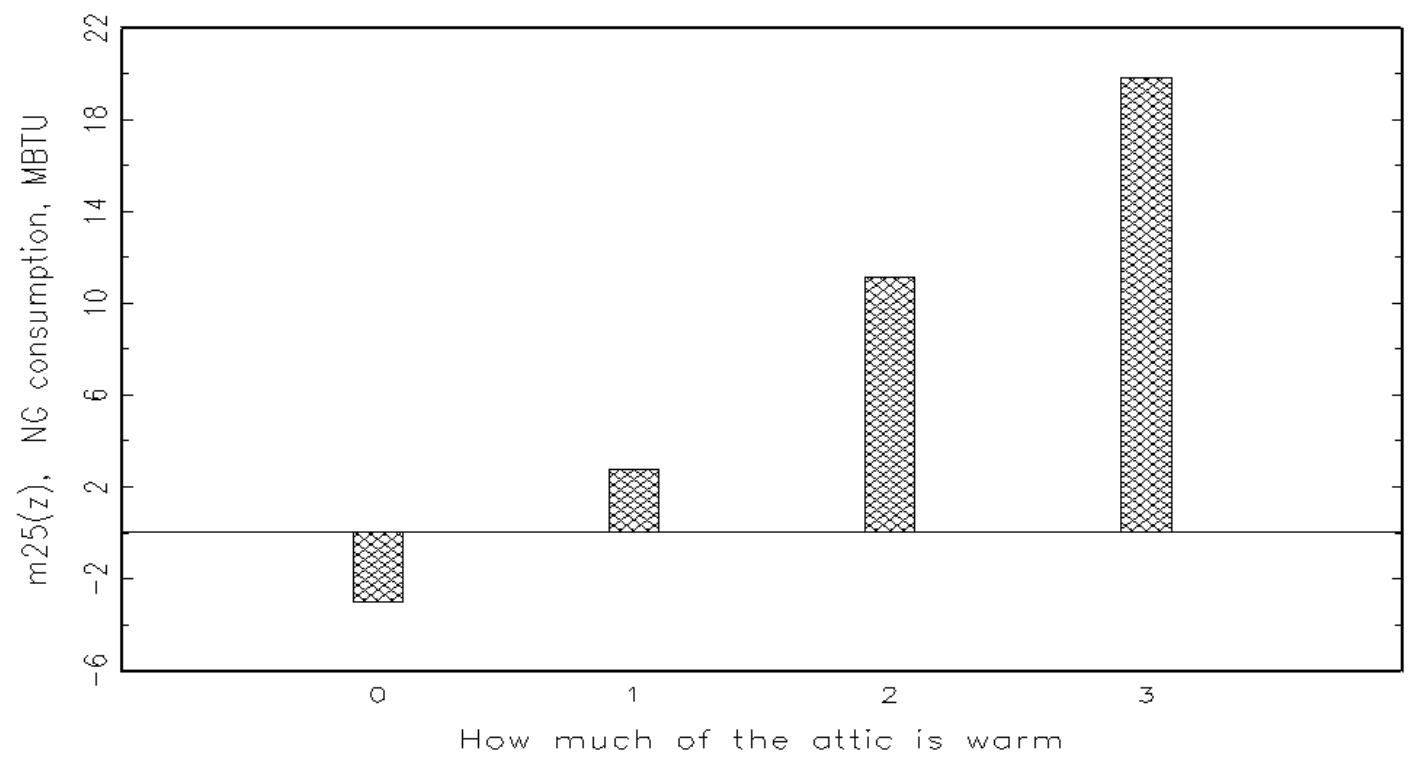

Figure B.25. How Much of the Attic is Warm

0 no attick

1 none

2 part

3 all 


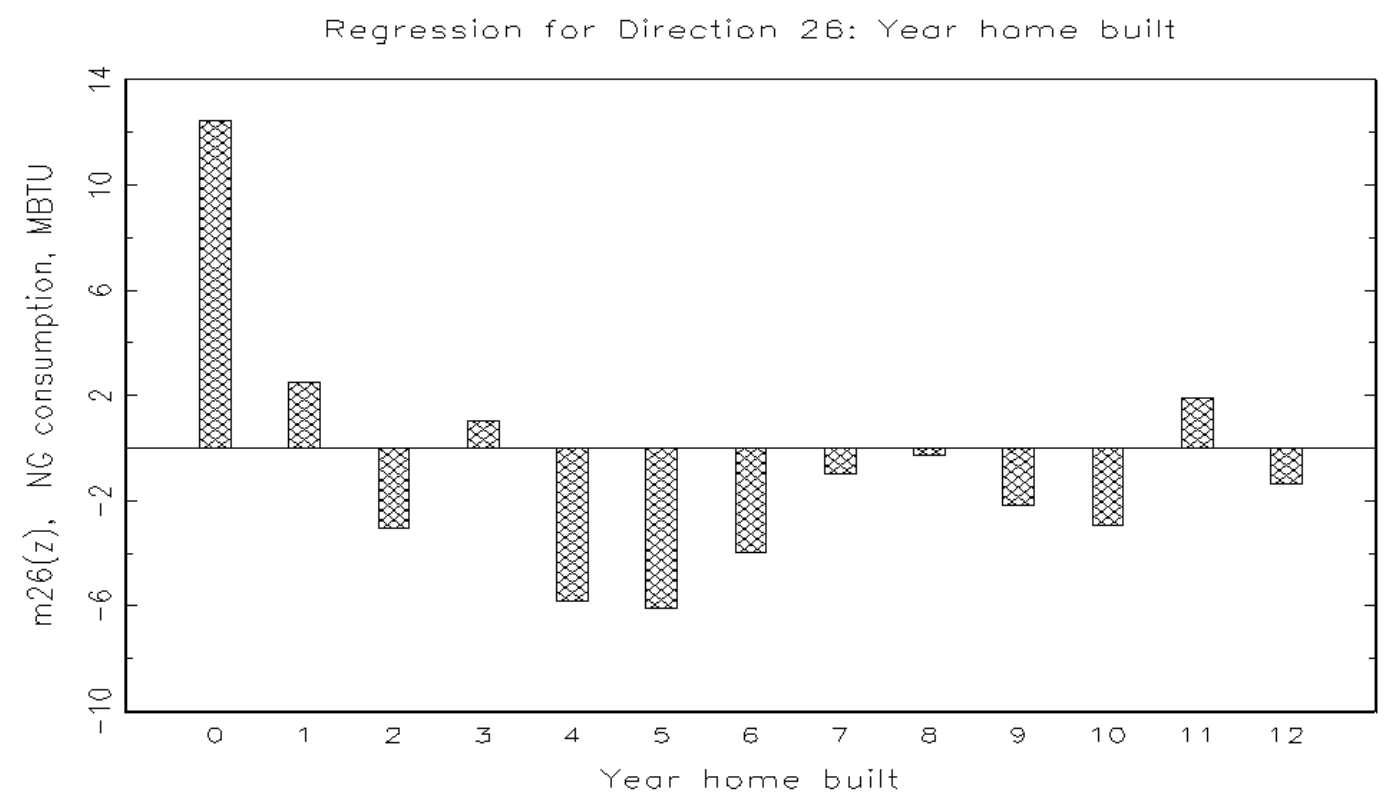

Figure B.26. Year Home Built

$\begin{array}{ll}0 & \text { before } 1940 \\ 1 & 1940-49 \\ 2 & 1950-59 \\ 3 & 1960-69 \\ 4 & 1970-79 \\ 5 & 1980-84 \\ 6 & 1985-89\end{array}$

$7 \quad 1990-94$

$8 \quad 1995-99$

$9 \quad 2000-02$

102003

112004

122005

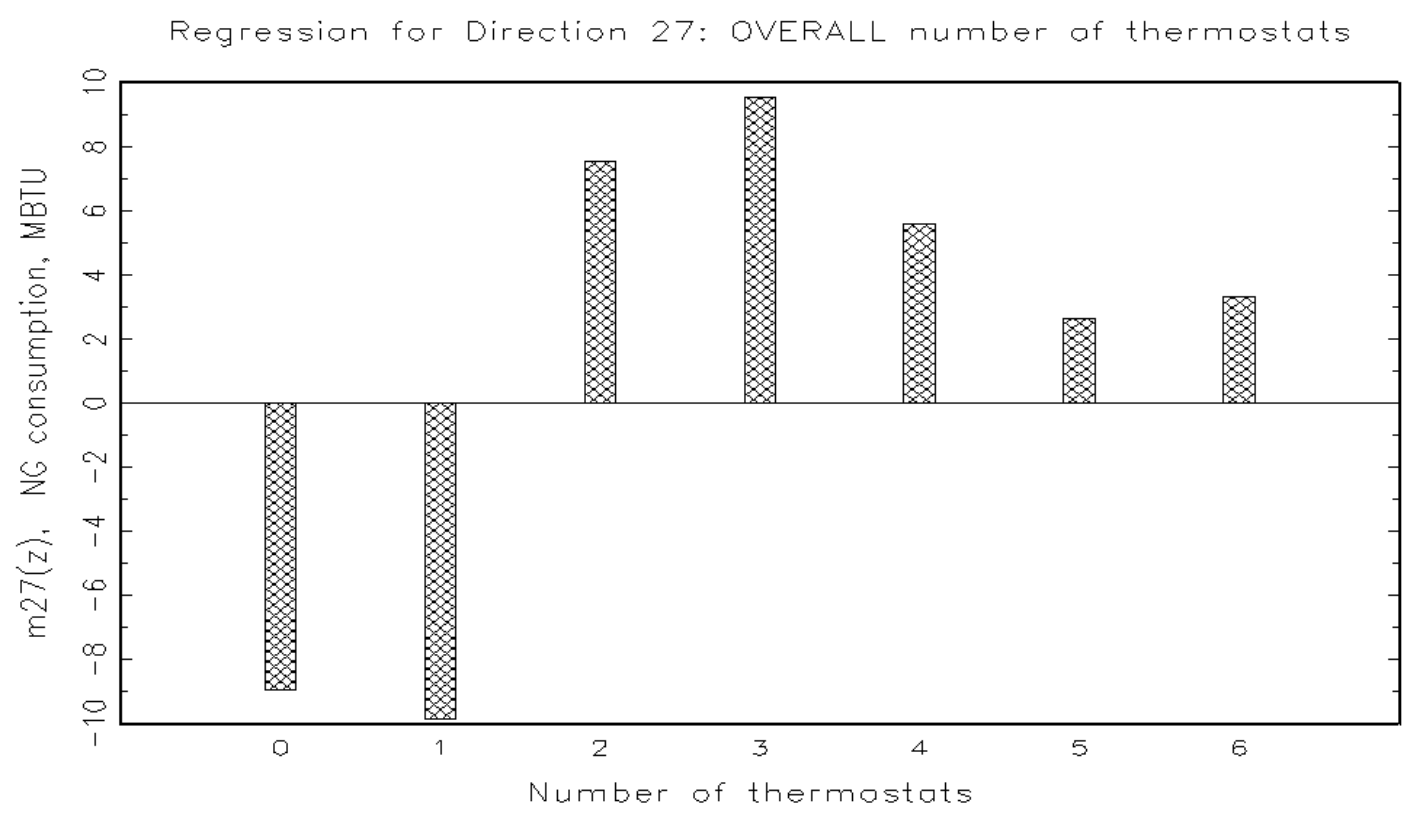

Figure B.27. How Many Thermostats Overall 


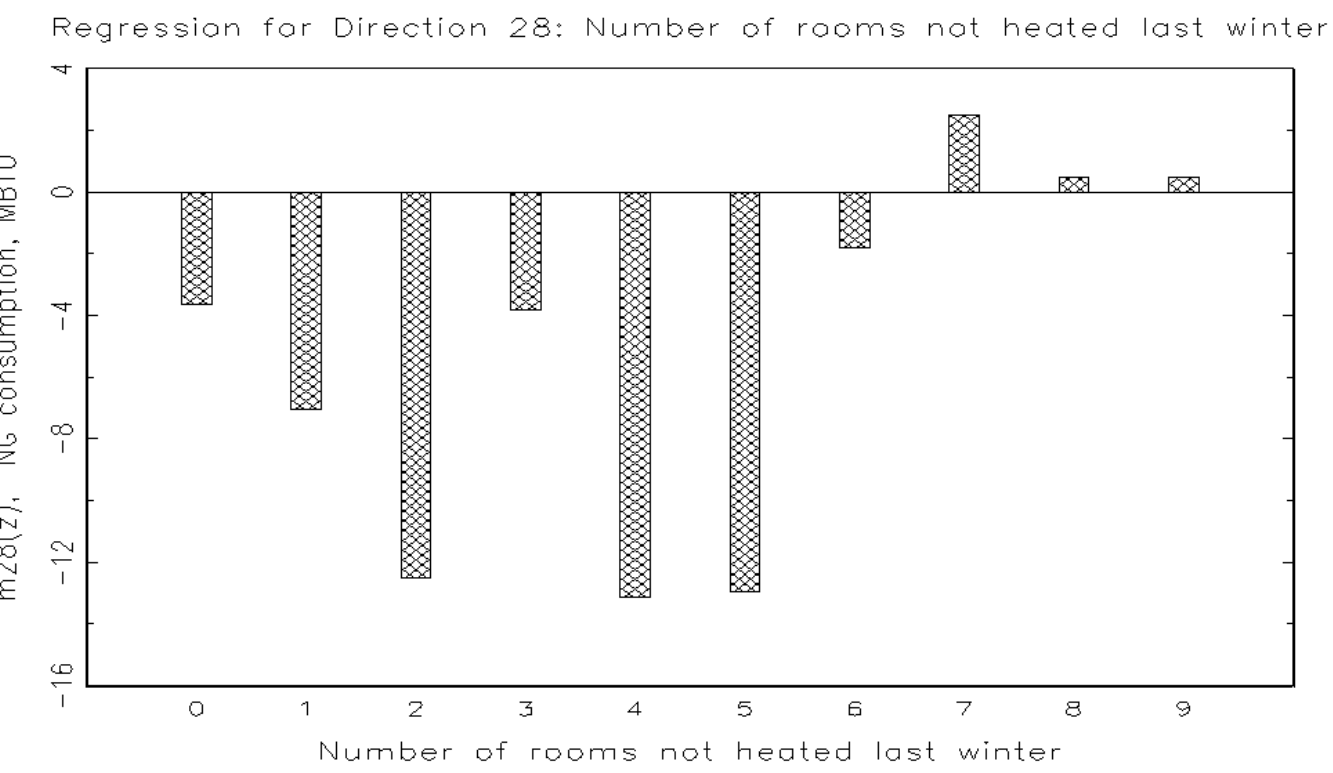

Figure B.28. Number of Rooms Not Heated Last Winter

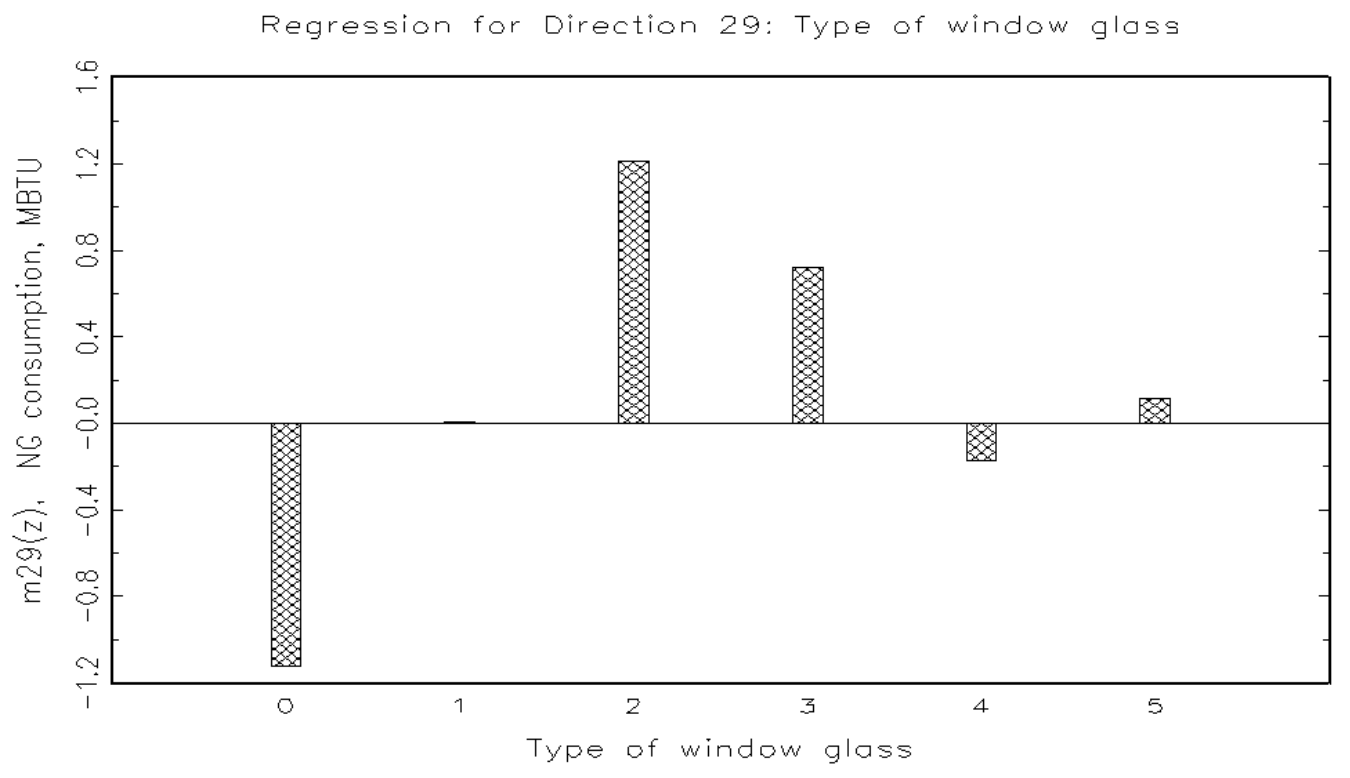

Figure B.29. Type of Window Glass

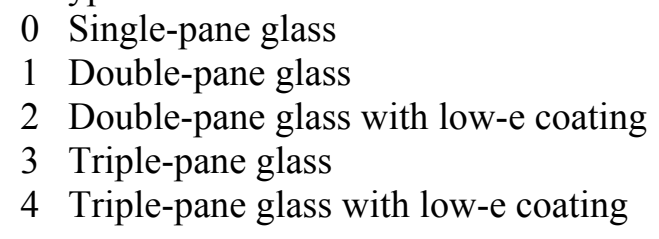


Regression for Direction 30: Number of occupants

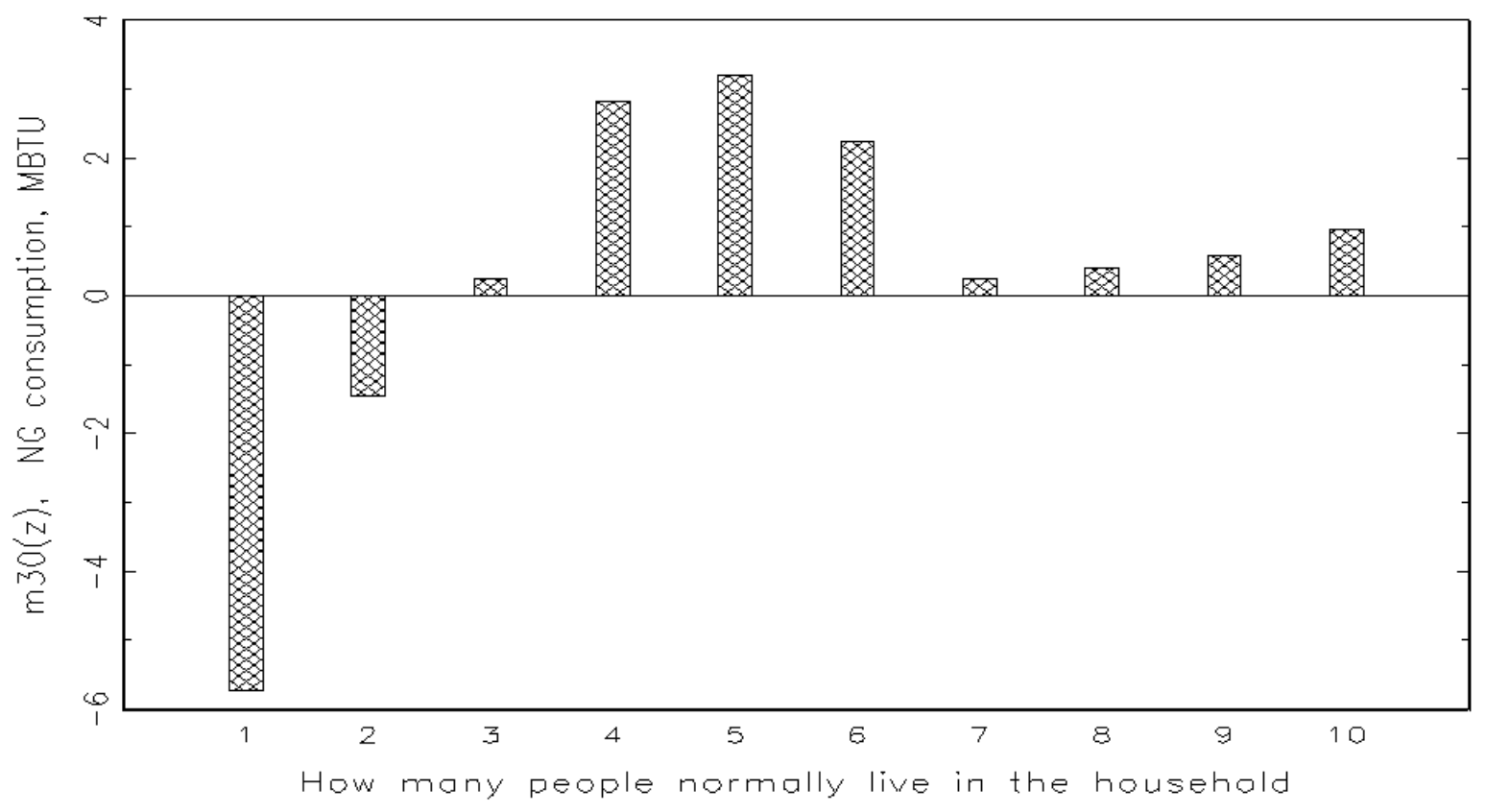

Figure B.30. How Many People Normally Live In This Household $0=$ none, up to 10 


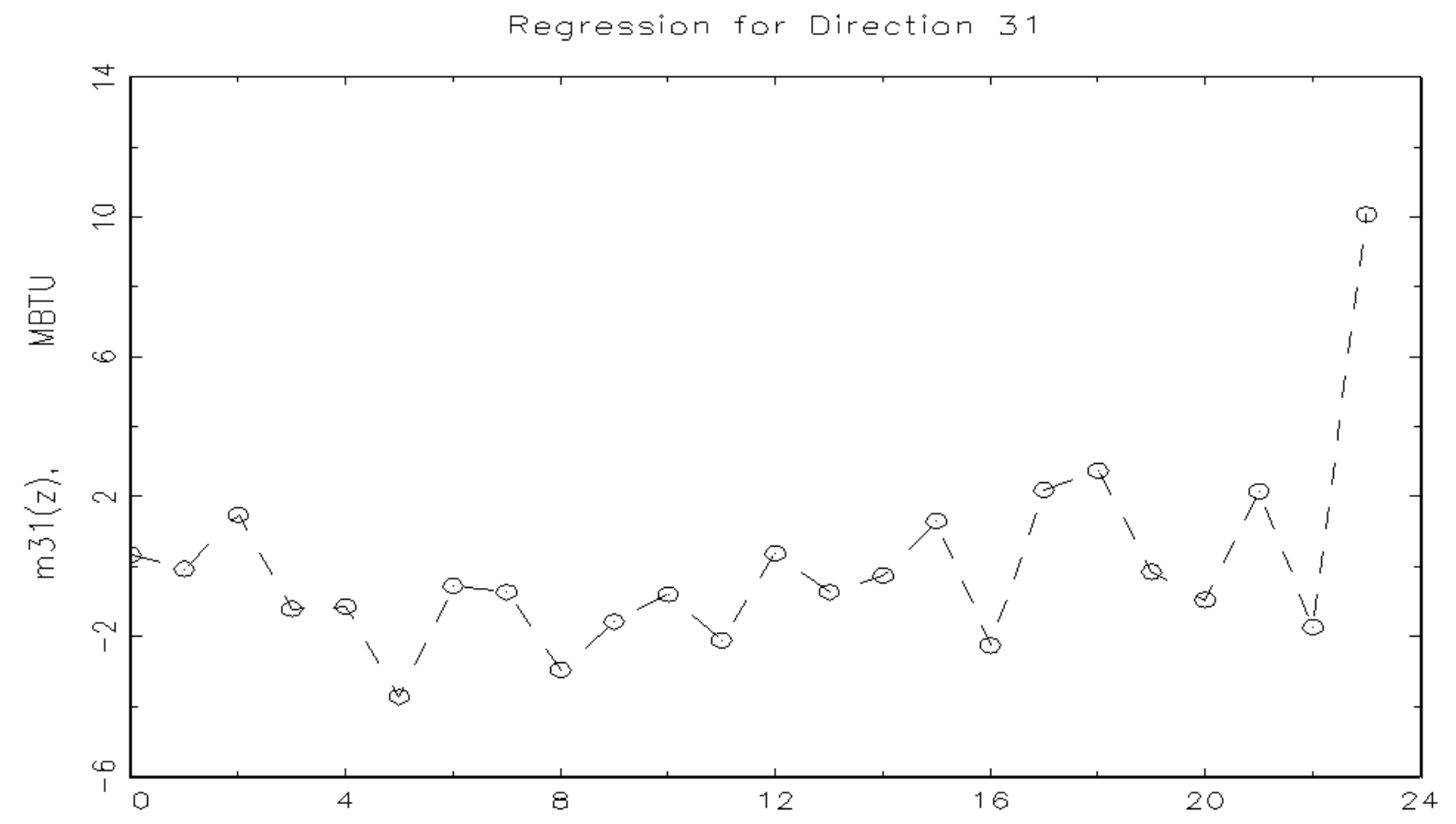

Figure B.31. Total Combined Income in the Past 12 Months

0 Less than $\$ 2,500$

$1 \$ 2,500$ to $\$ 4,999$

$2 \$ 5,000$ to $\$ 7,499$

$3 \$ 7,500$ to $\$ 9,999$

$4 \$ 10,000$ to $\$ 14,999$

$5 \$ 15,000$ to $\$ 19,999$

$6 \$ 20,000$ to $\$ 24,999$

$7 \$ 25,000$ to $\$ 29,999$

$8 \$ 30,000$ to $\$ 34,999$

$9 \$ 35,000$ to $\$ 39,999$

$10 \$ 40,000$ to $\$ 44,999$

$11 \$ 45,000$ to $\$ 49,999$

$12 \$ 50,000$ to $\$ 54,999$

$13 \$ 55,000$ to $\$ 59,999$

$14 \$ 60,000$ to $\$ 64,999$

$15 \$ 65,000$ to $\$ 69,999$

$16 \$ 70,000$ to $\$ 74,999$

$17 \$ 75,000$ to $\$ 79,999$

$18 \$ 80,000$ to $\$ 84,999$

$19 \$ 85,000$ to $\$ 89,999$

$20 \$ 90,000$ to $\$ 94,999$

$21 \$ 95,000$ to $\$ 99,999$

$22 \$ 100,000$ to $\$ 119,999$

$23 \$ 120,000$ or more 




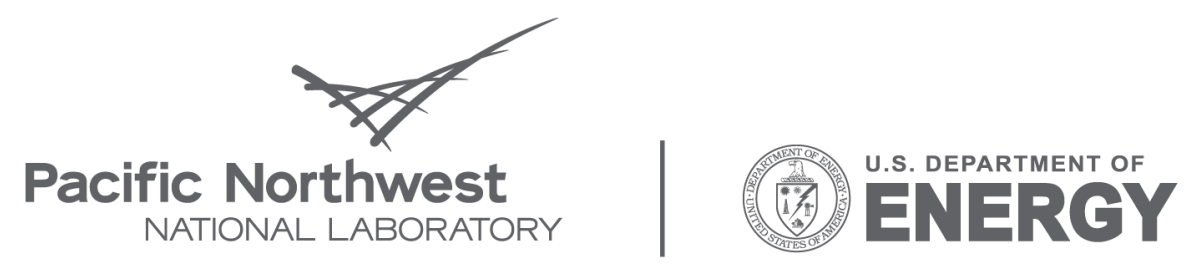

Proudly Operated by Battelle Since 1965

902 Battelle Boulevard

P.O. Box 999

Richland, WA 99352

1-888-375-PNNL (7665)

www.pnl.gov 